\title{
THE BIODYNAMICS OF AIRBLAST
}

\author{
Clayton S. White, Robert K. Jones, Edward G. Damon, \\ E. Royce Fletcher, and Donald R. Richmond
}

HEADQUARTERS

Defense Nuclear Agency

Washington, D.C. 20305

\author{
PREPARING AGENCY \\ Lovelace Foundation \\ for
}

Medical Education and Research

Albuquerque, New Mexico 87108

Contract No. DASA 01-70-C-0075

This work was sponsored by the Defense Nuclear Agency under NWER SUBTASK M A012-02.

\section{APPROVED FOR PUBLIC RELEASE \\ DISTRIBUTION UNLIMITED}




\section{DISCLAIMER}

This report was prepared as an account of work sponsored by an agency of the United States Government. Neither the United States Government nor any agency Thereof, nor any of their employees, makes any warranty, express or implied, or assumes any legal liability or responsibility for the accuracy, completeness, or usefulness of any information, apparatus, product, or process disclosed, or represents that its use would not infringe privately owned rights. Reference herein to any specific commercial product, process, or service by trade name, trademark, manufacturer, or otherwise does not necessarily constitute or imply its endorsement, recommendation, or favoring by the United States Government or any agency thereof. The views and opinions of authors expressed herein do not necessarily state or reflect those of the United States Government or any agency thereof. 


\section{DISCLAIMER}

Portions of this document may be illegible in electronic image products. Images are produced from the best available original document. 


\section{FOREWORD}

This report, prepared to delineate some of the fundamental accelerative and decelerative events associated with exposure to air-blast-induced winds and pressure variations and to elucidate the major biophysical parameters now known to influence dynamic load-response relationships among many mammals, is in essence a synthesizing summary of the more recent advances in blast and shock biology. The material was presented before the Symposium on Linear Acceleration of the Impact Type held June 23-26, 1971, in Porto, Portugal, under the sponsorship of the Aerospace Medical Panel, Advisory Group for Aeronautical Research and Development, North Atlantic Treaty Organization.

The important variables, the etiologic concepts, the early and delayed effects, the interspecies scaling, and the tentative biomedical criteria derived for the human case are among the significant understandings and accomplishments stemming from a research effort that has been under way continuously since 1951. Because there have been no systematic investigations of blast effects in the very young and very old, the information at hand may or may not apply to these groups. Also, the presentation does not cover experience with "small explosions" occurring near or against the body surface and causing only local damage, as might result from the detonation of land mines and hand-held dynamite caps.

The data, directly applicable mostly to "fast-rising" blast overpressures and to charges ranging in size from pounds to megatons of TNT-equivalent yield, have been and are broadly useful to organizations manufacturing, using, and controlling high-energy liquids, solid propellants, high-pressure gases, and explosives both nuclear and conventional in type. This includes military and civilian personnel including range and missile-base safety officers, service and industrial physicians, safety engineers, physicians who care for those injured by blast and other varieties of "high-energy" trauma; to firms engaged in sea, air, and ground transportation; and to management and operating employees responfor assessing hazards and preventing accidents through protective design of 
structures, vehicles, and equipment; and through the enforcement of operating procedures that enhance safety. 


\begin{abstract}
After pointing out that accelerative and decelerative events are associated with the direct (pressure) and indirect (translational events including penetrating and nonpenetrating debris and whole-body impact) effects of exposure to blastinduced winds and pressure variations, some of the relevant biophysical parameters' were selectively noted and discussed. These included the pressuretime relationship; species differences; ambient pressure effects; the significance of positional (orientational) and geometric (situational) factors as they influence the wave form, the pressure "dose," and the biologic response; and data bearing upon the etiology of blast injury. The consequences of pressure-induced, violent implosion of the body wall and the significance of the associated variations in the internal gas and fluid pressures were described and emphasized as were alternating phases of "forced" hemorrhage and arterial air embolization; fibrin thrombi; coagulation anomalies; and renal, cardiac, and pulmonary sequelae. Tentative biomedical criteria consistent with recent interspecies scaling and modeling studies for assessing primary-blast hazards were presented.
\end{abstract}




\section{ACKNOWLEDGMENTS}

The authors wish to acknowledge specifically the following: aid with illustrative material provided by Mr. Robert A. Smith, Mrs. Adele K. Sphar, Mr. Dale Calvert, and Mr. Joe E. Foster; and the effective efforts of Mrs. Ruth P. Lloyd, Mrs. Martha E. Mitchell, and Mrs. K. Maureen Gilmore, all of whom, with Miss Mildred E. Blake and Mr. Fred C. Rupprecht, contributed editorially and who, assisted by Mrs. Carol M. Riemen, processed the preliminary and final manuscripts.

More generally, gratitude is expressed to the Defense Nuclear Agency (formerly the Defense Atomic Support Agency of the Department of Defense) and the Division of Biology and Medicine of the U.S. Atomic Energy Commission for providing support making possible a continuous investigative program in nuclear effects at the Lovelace Foundation for amost 20 years; and to many members of the Lovelace staff for the use of their data, generously made available for this and many other publications. 

Foreword ................... iii

Abstract ..................... . .

Acknowledgments................... vi

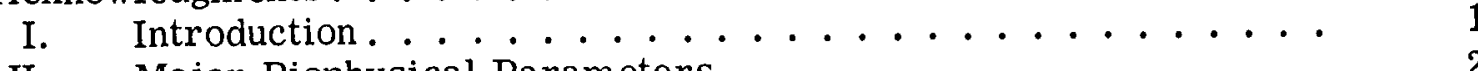

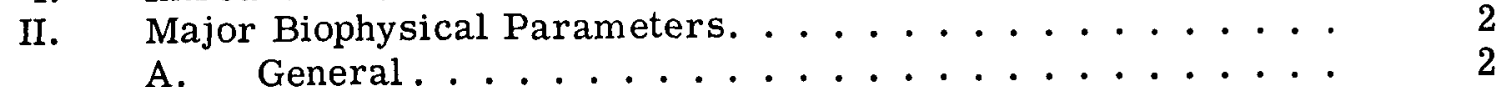

B. Pressure-Duration Relationship for "Classical"

Blast Waves ...................... 2

C. Species Differences ................ 3

1. "Small-" and "Large-Animal" Data . . . . . . . . 3

2. Lung-Volume and Density Data .......... 4

3. Relationship Between the Physical Dimensions of the Blast Wave and Animal Size ....... 4

D. Ambient Pressure ..................... 5

E. Positional or Orientational Factors . . . . . . . . . 6

F. Geometric or Situational Factors . . . . . . . . . . 8

1. Multiple Pressure Reflections. . . . . . . . . . 8

2. Stepwise Increases in Overpressures . . . . . . . 9 9

3. Smooth-Rising Wave Form s. . . . . . . . . . 12

G. Etiologic Mechanisms . . . . . . . . . . . . 12

1. General. . . . . . . . . . . . . . . 12

2. Thoraco-Abdominal Response to Blast Pressures ................... 14

3. Idealized-Response Curves to "Fast-Rising," "Long-Duration" Pressure Pulses . . . . . . . . 17

a. Alternating Phases of Acceleration and Deceleration. ............ 17

b. Alternating Phases of "Forced" Hemorrhage and "Forced" Air Embolization . . . . . . . 19

4. Arterial Air Emboli . . . . . . . . . . . . . 22

5. Fibrous Emboli ................ 23

6. Two-Step, "Fast-Pressure" Increases . . . . . . . 24

III. Tentative Primary-Blast Criteria . . . . . . . . . . 26

A. General. ................... 26

B. Interspecies Data. . . . . . . . . . . . 26

C. Tentative Criteria for "Fast-Rising" Blast . . . . . . . . 28

D. Nonclassical Wave Forms . . . . . . . . . . 28

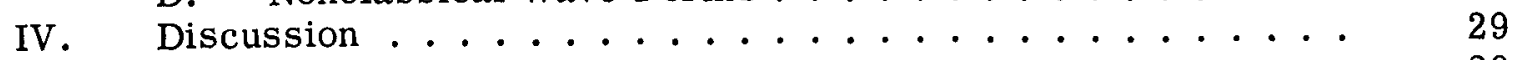

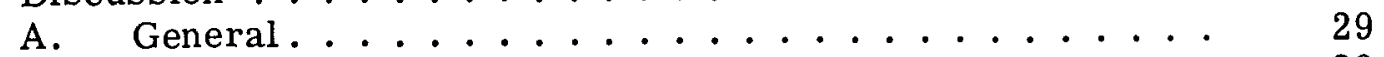

B. Interspecies Relationships. . . . . . . . . . . 29

1. Group Segregation . . . . . . . . . . . 29

2. Whole-Body Impact . . . . . . . . . . 30 
3. Lethality-Time Data ............. . 30

4. Interspecies Scaling ............. 31

C. Wave Form ................ 33

D. Etiologic Mechanisms ............. 34

1. Air Emboli ................. . . 34

2. Whole- and Partial-Body Implosion and Impact Trauma . . . . . . . . . . . 35

E. Additional "Dose-Response" Data .......... 36

1. Orbital Fractures into the Paranasal Sinuses. . . . 36

2. Renal Infarcts and Hypertension......... 37

F. Limitations .................. 38

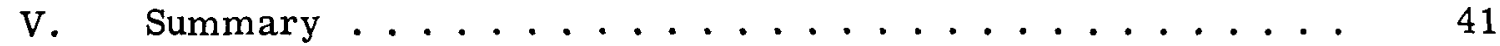

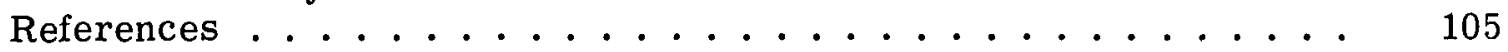

\section{LIST OF TABLES}

1. Overpressure of a "Long-Duration" Blast Wave Producing 50-Percent Mortality (1-Hour) in Exposed Mice Versus Experimental Ambient Pressure . . . . . . . . . .

2. Mortality Data for Guinea Pigs Exposed to "Fast-Rising," "Long-Duration," Shock-Tube-Produced Overpressures With the Incident and Reflected Overpressures Applied in Steps. . . . . . . . . . . . . . .

3. Intrathoracic Pressures in Animals Exposed to a "Long-Duration," "Square-Wave" Pressure Pulse in a Shock Tube ....................

4. Incidence of Renal and Myocardial Infarcts in Sheep Exposed to a "Long-Duration," "Square-Wave" Pressure Pulse in a Shock Tube ....................

\section{LIST OF FIGURES}

1. Fatal Overpressure-Time Conditions for Dogs Exposed to Blast Waves Produced by High Explosives. . . . . . . . .

2. Charge-Distance Diagram Showing Characteristic Lines of Destruction for Dogs, Guinen Pigs, Aircraft Surfaces, and Windowpanes . . . . . . . . . . . . 
TABLE OF CONTENTS (Continued)

$\underline{\text { Page }}$

3. Pressure-Duration Curves for 50-Percent, 24-Hour

Survival When Exposure Involves "Sharp-Rising"

Overpressure .................

4. The Geometry and Dimensions of One of the Shock

Tubes Used by Richmond and Colleagues. . . . . . . . . . .

5. The Pressure-Duration Relationship and Lethality at

24 Hours for Large and Small Animals (Mice, Rats,

Hamsters, Guinea Pigs, and Rabbits) . . . . . . . .

6. Average Lung Volume Per Body Mass and Average Lung

Density as Functions of Body Mass for 8 Species of

Mammals ....................

7. The Physical Dimensions of Blast-Pressure Pulses

Having Durations of 2,6 , and $18 \mathrm{Msec}$. in Relation to

Targets Assumed to be 1 and 6 Feet Long . . . . . . . . .

8. Fifty-Percent, Twenty-Four-Hour Survival Curves for

Larger and Smaller Animals . . . . . . . . . . . .

9. Relation of the 50-Percent, 1-Hour Survival Pressure to Experimental Ambient Pressure for 5 Species of

Mammals .....................

10. The Relations Between the Incident, Reflected, Dynamic, and Stagnation Pressures. ...............

11. L $D_{50}$ Conditions, Assessed at 24 Hours, for Guinea

Pigs in Various Orientations ..............

12. Maximal Incident and Reflected Overpressures Associated With 50-Percent Lethality Over 24 Hours in Guinea Pigs as a Function of Exposure Geometry. . . . . . . . . .

13. Pressure-Time Records Associated With the Deep

Chamber. .....................

14. Wave Forms Illustrating Almost Instantaneous and Stepwise Increases in Overpressure . . . . . . . . . . . . 


\section{TABLE OF CONTENTS (Continued)}

$$
1
$$

15. Mortality Variations for Animals Exposed Against or at the Indicated Distances From the End Plate Closing

a Shock Tube ....................

16. "Slow-Rising," Pressure-Time Patterns With Various Rates of Rise......................

17. Diagram of Model Response to "Very Slowly" Rising

Overpressures ...................

18. Diagram of Model Response to "Slowly" Rising

Overpressures to Which "Protective" Response is

Effective .....................

19. Diagram of Model Response to "Moderately Rapid-Rising" Overpressures to Which "Protective" Response is

Inadequate .....................

20. Diagram of Model Response to "Fast-Rising" Overpressures

of "Long" Duration. . . . . . . . . . . . . . .

21. Comparison of Computed and Recorded Internal Pressure-

Time Curves for a Rabbit Exposed in a Shock Tube to a 20-P.s.i., "Long-Duration" Pressure Pulse........

22. The Intrathoracic Pressure-Time Response Elicited in a

Rabbit by a "Short-Duration" Blast Wave ..........

23. Pressure-Time Relationships Between External Pressure

and the Internal Gas and Fluid Pressures. . . . . . . .

24. Blood-Velocity and Embolus-Detector Traces Before and

After Blast ....................

25. Infarction Sequelae in the Kidneys of a Sheep Sacrificed 30 Days After Exposure to an HE-Produced Overpressure of 166 P.s.i. and 3.0-Msec. Duration (near LD50). . . . .

26. Infarction Sequelae in the Heart of a Sheep Sacrificed 30 Days After Exposure to an HE-Produced Overpressure of 164 P.s.i. and 3.3-Msec. Duration (near $\mathrm{LD}_{50}$ ). . . . 
TABLE OF CONTENTS (Continued)

$\underline{\text { Page }}$

27. Scattered Small Scars in the Lung of a Dog Surviving Severe Blast Injury and Sacrificed 31 Days Post

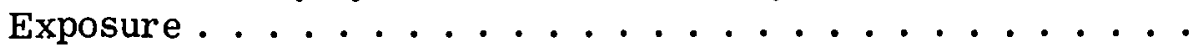

28. Computed Intrathoracic Overpressure Versus Time

for 1.7-Kg. Rabbits Exposed at Various Distances

From the End Plate of a Shock Tube. . . . . . . . . .

29. Incident and Reflected Blast-Pressure Pulses and Intrathoracic Pressure-Time Responses Recorded in Guinea Pigs With an Intraesophageal Transducer . . . . . .

30. A Test of Body-Mass Scaling for Similar Animals . . . . . .

31. Increase in Tolerance When the Time to Maximum Pressure is Delayed by Separating the Incident and Reflected Pressure Pulses for "Fast-Rising,"

"Long-Duration" Waves . . . . . . . . . . . . .

32. Survival Curves (24-Hour), Applicable to "Sharp-Rising" Blast Waves, Derived From the Analysis of Data for 12 Mammalian Species (excluding guinea pigs) . . . . . . . .

33. Scaled Peak Reflected Overpressures and Scaled Durations for "Sharp-Rising" Blast Waves Which Will Result in 50-Percent Mortality. .............

34. Survival Curves Predicted for $70-\mathrm{Kg}$. Man Applicable to Free-Stream Situations Where the Long Axis of the Body is Parallel to the Direction of Propagation of the Shocked Blast Wave . . . . . . . . . . . . . .

35. Survival Curves Predicted for $70-\mathrm{Kg}$. Man Applicable to Free-Stream Situations Where the Long Axis of the Body is Perpendicular to the Direction of Propagation of the Shocked Blast Wave ................

36. Survival Curves Predicted for $70-\mathrm{Kg}$. Man Applicable to Blast Situations Where the Thorax is Near a Surface Against Which a Shocked Blast Wave Reflects at Normal Incidence ..................... 
TABLE OF CONTENTS (Continued)

$\underline{\text { Page }}$

37. Animal Body Mass Versus the "Square-Wave" Overpressure for 50-Percent Survival at Sea Level, the Average Gaseous Lung Volume Divided by Body Mass, the Average Lung Density, and the 50-Percent Lethal Velocity for Perpendicular Impact With a Nonyielding Surface ......................

38. Impact Velocity Versus Mortality for Man . . . . . . . .

39. Accumulative Percent of Mortally Wounded Animals Dying Over the 2-Hour Period Following Exposure to "Sharp-Rising" Overpressures of 3- to 4-Msec.

Duration ...................

40. Accumulative Percent of Mortally Wounded Animals

Dying Over the 24-Hour Period Following Whole-Body

Impact .....................

41. Guinea-Pig Mortality Over the 30-Day Period Following Exposure to "Fast-Rising," "Long-Duration" Shock-

Tube-Produced Blast Waves. . . . . . . . . . . .

42. Lethality-Time Data for Guinea Pigs Exposed to

"Long-Duration," "Fast-Rising" Overpressures of the Indicated Magnitudes . . . . . . . . . . . . .

43. Lethality-Time Curves for Small Animals (Mice, Rats, Guinea Pigs, and Rabbits), Goats, and Dogs Exposed to "Fast-Rising" Overpressures of Various Durations . . . . .

44. The Relation Between Lung Weight, Mortality, and the Incidence of Coronary Air Embolism in Guinea Pigs Surviving and Fatally Injured by "Fast-Rising," Shock-Tube-Produced Overpressures of 6- to 8-Sec.

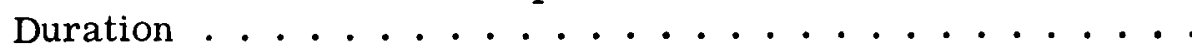

45. The Time Relation Between Lung Weight and the Incidence of Coronary Air Emboli in Surviving and Nonsurviving Guinea Pigs Exposed to "Fast-Rising," "Long-Duration" Blast Waves . . . . . . . . . . . 
TABLE OF CONTENTS (Continued)

$\underline{\text { Page }}$

46. Time of Death and the Incidence of Air Embolism in

56 Dogs Mortally Injured by Exposure to "Fast-Rising,"

"Long-" and "Short-Duration" Overpressures of the

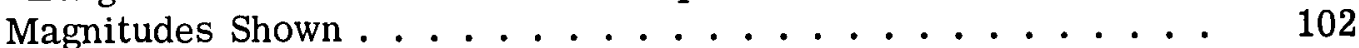

47. Plastic Injection Casts of the Renal Circulation in a

Control Sheep and in a Sheep Sacrificed 30 Days After

a Single Exposure to Blast Overpressure in a Shock

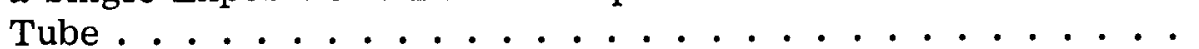




\section{THE BIODYNAMICS OF AIRBLAST}

Clayton S. White, Robert K. Jones, Edward G. Damon, E. Royce Fletcher, and Donald R. Richmond

\section{INTRODUCTION}

The fact that accelerative as well as decelerative events, along or in tandem, may follow exposure of biologic media near an explosive source has been appreciated for some time. For example, accelerative experiences can, depending upon circumstances, include those due to the direct effects of the sudden increase in overpressure and the after-coming winds that emanate radially from a detonation and two indirect effects, both involving translational events (References 1 through 6); namely, (a) the impact of penetrating and nonpenetrating, blastenergized debris (References 7 through 15) and (b) the initiation of whole- or partial-body displacement (References 16 through 19) that may involve significant gain in velocity particularly if the explosive source is large (Reference 4). Decelerative experiences can include not only the rather obvious occurrences of impact (Reference 20)--violent or not--following whole- or partial-body displacement induced by blast winds, debris, ground shock, and gravity, but loss of velocity by sliding friction and/or decelerative tumbling (Reference 18) and the less appreciated dissipation of kinetic energy imparted to the body wall by the implosive effects (References 21 through 23) of blast overpressure and wind.

Beyond these physical and biophysical events, there are biological ones which, through improvements in both technology and conceptual understanding combined with consistent support of research over the past 15 years, have become better understood. A few of these will be summarized in a selective way below; however, no mention will be made of the miscellaneous blast effects (References 1, 4, and 5) due to dust and to thermal effects involving flash. (References 24 through 26), non-line-of-site burns: (References 3, 4, 27, and 28), and blastinduced fires. Included will be data that have been useful in refining tentative biomedical criteria for "clean" wave forms formulated several years ago to help assess blast hazards (References 4, 5; and 29 through 31). Also, some 
information that bears upon potential delayed or chronic sequelae of significant blast injury will be included (References 32 and 33 ). However, the positive results of a blast therapy program (References 34 and 35 ) that has been under way for the past 2 years will only be noted here in passing even though the data bear much upon research trends that will be followed to further understanding the etiology of blast injuries. Thus, this report is a review of the recent progress regarded as significant in advancing the "state of the art" in blast and shock biology, and those who wish a more fundamental and detailed exposition of the subject are referred to a number of informative papers and excellent reviews (References 2, 3, 5, 29, 31 through 33, and 36 through 55) each of which should be read keeping in mind the time period in which the manuscript was prepared.

\section{MAJOR BIOPHYSICAL PARAMETERS}

\section{A. General}

Though Hooker (Reference 36) in the 1920 time period appreciated that there was a difference between animal responses following exposure to "long-" and "short-duration" blast overpressures and the British workers (References 2 , 56, and 57) in the 1940 's were correlating a relationship between body size and peak blast overpressure among animals lethally injured by exposure to blast from "small" HE charges, it remained for the German group (References 39 through 42 ) in about the same time period and Clemedson (Reference 58) and collaborators in Sweden later on to point out and establish that for "fast-rising" or classical wave forms primary-blast effects were sensitive to both overpressure and pulse duration except when the explosive yield was "large."

\section{B. Pressure-Duration Relationship for "Classical" Blast Waves}

For example, note Figure 1, prepared from the data of Desaga (Reference 39), showing the pressure-duration relationship for $\mathrm{dog} s$ exposed at appropriate ranges from detonations of six individual explosive charges, the weights of which are shown. It is evident that for the "shorter-duration" pulses-which were single, "fast-rising," "classical" blast waves--tolerance in terms of the maximal pressure was the highest; whereas, for the "longer-duration" overpressures, tolerance was down almost by a factor of three. 
Figure 2 (References 3 and 42), equally instructive, not only shows that the characteristic curves of destruction for physical objects and two animal species are similar in shape, but that at the greater ranges from the larger charges tolerance is a function of the maximal overpressures while, for small charges at close range, the effects curves approach parallelism with the iso-momentum lines (the area under the pressure-time curve usually expressed as p.s.i. -msec. or atmosphere-milliseconds).

By the end of the $1940^{\prime} \mathrm{s}$, Clemedson (Reference 58), in a most elegant and laborious study using rabbits, confirmed the pressure-duration relationship, and also presented charge-distance diagrams to illustrate his results. In addition, he pointed out that "the genesis of deadly injuries to rabbits is proportional neither to maximum pressure nor to impulse. Both of these factors may cooperate."

\section{Species Differences}

As a result of a program under way since the early 1950 's, a group working at the Lovelace Foundation in Albuquerque, New Mexico, has likewise confirmed the German, Swedish, and British findings and, in addition, pointed out certain interspecies differences among 15 mammals as tolerance varies for high-explosive-produced and shock-tube-generated, "fast-rising" overpressures over a spectrum of pulse durations. Details follow.

\section{1. "Small-" and "Large-Animal" Data}

The Lovelace Foundation data, mostly obtained by Richmond and colleagues and assembled by Fletcher (Reference 59) in a diagram to show the 50-percent survival curves as they vary with the magnitude and duration of the overpressures, are shown in Figure 3. Animals were exposed at an ambient pressure of 12 p.s.i. against a reflecting surface, either on a ground-level surface with the charge directly overhead or against a metal plate closing the end of a shock tube, one arrangement for which--published by Richmond et al. (References 60 through 62)--is illustrated in Figure 4 (Reference 60). Thus, the 
overpressure referred to in Figure 3 is the maximal overpressure measured on, or close to, the reflecting surface and near the exposure location. Survival, in all instances, was assessed at 24 hours after exposure.

That there is indeed a grouping of data according to whether animals are small or large is apparent and needs emphasis as given in Figure 5 (Reference 52). Note the iso-impulse lines dashed across the figure. Attention is called to the fact that other iso-pressure lines, parallel to that shown for 100-p.s.i. level of overpressure, might have been included to make clear that tolerance for the "longer-duration" pressure pulses is indeed a matter of the magnitude of the overpressure.

Attempts to explain the differences and similarities apparent in Figures 3 and 5 have hardly been completely successful. However, a few relevant matters are appreciated. Three of these will be noted briefly. Two are more biologically oriented, while the third if physical in nature.

\section{Lung-Volume and Density Data}

The biologically related factors referred to above also evidence an important difference between small and large animals. These concern information regarding lung volumes and lung densities published by Crosfill and Widdicombe (Reference 63). Bowen et al. (Reference 49) assembled the data as shown in Figure 6. Note that the lung densities of the larger species, including man as well as monkey, cat, and dog, are about one-half those of the smaller species; on the other hand, the lung volumes--normalized to body mass--of the larger species are approximately three times as large as those for the smaller animals. It is unlikely that these relationships are accidental and studies to obtain relevant data from additional species are obviously needed.

\section{Relationship Between the Physical Dimensions of the Blast} Wave and Animal Size

It is instructive to emphasize that as a consequence of the 'speed of sound in air, blast pressure waves of different durations actually have 
different physical dimensions; viz., pressure pulses of 2-, 6-, and 18-msec. duration emanating from a surface detonation, for example, roughly occupy 2 , 6, and 18 feet of ground measured parallel to the direction of travel of the blast wave. These conditions are diagrammatically presented in the upper portion of Figure 7. The lower portion of the figure shows two targets, assumed to be 1 and 6 feet long. Should any of the three blast waves shown move over the 1 -foot target, in each instance the target would suddenly be engulfed in a region of high pressure and "squeezed" from all sides. A similar situation would exist for the larger 6-foot target only for the $18-\mathrm{msec}$. pulse. In contrast, the situation would be different for the 2-msec. pulse; namely, a wave of overpressure 2 feet long would "squeeze" only a 2-foot portion as it moved progressively over the target. Thus, one can appreciate that the smaller target would "regard" all three of the pressure pulses shown in Figure 7 as long. To the contrary, the larger target would "consider" only the 18-msec. pulse as "long" and the 2msec. pulse as short.

No doubt the pressure-pulse, target-size relationship is a significant matter and is at least one reason why small and large animals react differently to "sharprising" overpressures of different durations as emphasized in Figure 8 reproduced here from Richmond et al. (Reference 60) in a study carried out at Albuquerque altitude (12 p.s.i.) and reported about 10 years ago.

\section{Ambient Pressure}

Though the ambient pressure at which exposure occurred was, in the mid $1950^{\prime} s$, predicted to be an important parameter influencing tolerance to air blast (Reference 3), it remained for Damon and colleagues (References 64 through 67 ) to work out the quantitative relationships. This was accomplished in Albuquerque, New Mexico, beginning in the mid 1960's using shock tubes of special design to produce "fast-rising" overpressures, the durations of which were long for each of the five species involved. Relevant data, available first for mice and tabulated in Table 1 (Reference 65), show that tolerance in terms of the 1-hour, 50-percent survival overpressure varied by over a factor of four-from 20.3 to 91.8 p.s.i. --when the exposure ambient pressure was changed by 
a factor of six--from 7 to 42 p.s.i. Similar data referable to the other mammals are illustrated graphically in Figure 9 (Reference 67).

It is important that some quantitative assessment of the ambient-pressure effect is at hand for several reasons. Three among them will be noted. First is the obvious significance of the information in helping assess tolerance to underwater blast. The second concerns the relevance of the data to elucidating the effects of exposure to two or more, near-simultaneous or somewhatsuperimposed pulses of overpressure. The third involves the work in modeling the blast response of the thoraco-abdominal system (References 49 and 59) wherein much attention of necessity is paid to the pressures inside and outside the animal as they change with time. Some of these matters will be discussed subsequently.

\section{E. Positional or Orientational Factors}

Specifying the "dose" in terms of overpressure to which an individual may be exposed is not always a straightforward matter (Reference 68). Consider for example Figure 10 which shows the relation between the incident $\left(\mathrm{P}_{\mathrm{i}}\right)$, reflected $\left(P_{r}\right)$, dynamic $(Q)$, and stagnation $\left(P_{S}\right)$ overpressures. The incident and stagnation pressures can be measured with gages located side-on and headon, respectively, to the advancing pressure pulse whereas the reflected pressure is the maximal pressure occurring on a flat surface placed at right angles to the direction of travel of the blast wave. Though strictly defined by the expression:

$$
\begin{aligned}
& \mathrm{Q}=\rho \mathrm{V}^{2} / 2 \\
& \rho: \text { air density } \\
& \mathrm{V}: \text { air velocity }
\end{aligned}
$$

the dynamic pressure, Q, can, for the lower overpressures, be approximately taken as the difference between the stagnation and incident overpressures and represents the pressure of the blast wind. 
To cite a specific arbitrary instance, note in Figure 10 that any target such as an animal or a man, exposed side-on at sea level to a 33 -p.s.i. incident blast wave, will on the upstream side experience a reflected pressure spike of 114 p.s.i. This will endure briefly and only for as long as it takes the high-pressure pulse to spill over and around the target and fall to a value that is equal to the pressure of the wind $(\mathrm{Q})$ plus the incident pressure $\left(\mathrm{P}_{\mathrm{i}}\right)$. Although determining the actual overpressures on the upstream and downstream sides of the target as they alter with time is very complex and will not be discussed further here, it must be obvious that care must be used in quantitative work aimed at developing "dose-response" relationships. Too, a little reflection will alert one to the fact that orientation of an animal--side-on or head-on, for example--to an advancing blast wave might be different quantitative experiences.

Fortunately, certain compromises that simplify the problem posed by animal orientation have been studied (Reference 68) and Figure 11 from Richmond et al. (References 52 and 69) shows shock-tube results for guinea pigs exposed in five orientations. Four of these are "free-stream" or "free-field" exposures and the other is against a reflecting surface. The figure refers to 50 -percent survival conditions for all the groups and the germane question is how does one specify the dose for each exposure circumstance?

Perusal of Figure 11 will convince the reader that for exposure against a reflecting surface the biologically-effective pressure was the reflected pressure. For "free-field" exposures, in contrast, the biologically-effective pressure was close to the incident pressure for tail-on or head-on orientations, and was the incident plus the dynamic pressures for vertical or prone positions when side-on to the advancing wave. Thus, though the biologically-effective pressures were approximately the same for all the exposure groups shown in Figure 11, the incident pressures--those existing "free-field" very near the exposure station-were quite different, viz., the values for the incident pressures were:

1. 17 to 18 p.s.i. for animals exposed prone (broadside) or suspended vertically; 
2. 25 to 26 p.s.i. for tail-on or head-on exposures; and

3. $\quad 10$ p.s.i. for animals against a reflecting surface.

The influence of orientational or positional factors will not be pursued further here, but will be referred to later in presenting tentative criteria formulated for a variety of exposure conditions.

\section{F. Geometric or Situational Factors}

That geometric or situational factors create difficulties in quantitating blast tolerance is illustrated by Figure 12 (References 4 and 70) which depicts diagrammatically three exposure conditions for guinea pigs in shallow, "deep," and "deep-with-offset" chambers bolted to the wall of a shock tube. The 50percent survival pressures for "fast-rising," "long-duration" overpressures were determined for the three exposure geometries. The results, in terms of the average incident pressure measured by a gage mounted in the wall of the shock tube opposite each chamber, are shown at the top of the figure to be 34.9 , 19.5 , and 26.8 p.s.i. At first surprising, the matter was somewhat clarified by measurements taken with gages placed in the walls of the chambers near the chests of the animals. That these were close to the biologically-effective pressures--or pressure "doses"--is indicated by the numbers 35.9 p.s.i. for the "deep-with-offset" chamber, 34.6 p.s.i. for the "deep" chamber compared with 34.9 p.s.i. as the "dose" for the shallow chamber.

\section{Multiple Pressure Reflections}

It is instructive to contemplate the wave forms measured in one experiment by four gages flush-mounted in the walls and located as illustrated in Figure 13. Gage a, situated just upstream of the chamber, recorded a "fastrising, "flat-topped wave. All other wave forms measured had a delay in development of the peak pressure and a series of fast and slow components during the rise to the maximal pressure. Of course, the question is which of the pressure records most closely specifies the pressure-time pattern to which the animal is 
sensitive and was responding. The course adopted to date is to consider the gage nearest the chest of the animal to be the most important one--gage $c$ in Figure 13--and to plan studies to determine which is the critical portion of the wave, such as the maximal pressure, the average rate of pressure rise, the early "fast-rising" series of stepwise increases in the pressure, the area under the pressure-time curve, etc. These matters will be noted again later on, but attention will now be directed to responses to single, "fast-rising" pulses compared with those that rise abruptly in two steps.

\section{Stepwise Increases in Overpressures}

Attention is directed to Figure 14 which shows the type of wave forms recorded in a shock tube by wall-mounted gages placed on and at various distances upstream from the metal plate closing the end of the tube. Note the sharp rise in the upper left wave form in the figure, a typical "square-wave" response recorded when an incident wave undergoes reflection at the end plate. In contrast, records from wall gages mounted at various distances upstream from the end plate show a two-step, almost instantaneous rise in pressure, first the incident and then the reflected pulse separated by a time that is, among other things, a function of the distance from gage to end plate. The idealized wave forms on the left side of Figure 14 illustrate the facts, as do the two actual recordings reproduced in the right portion of Figure 14.

That there are significant quantitative changes in response of animals as a consequence of exposure on and at various distances from the end plate of a shock tube will now be illustrated.

Consider Table 2 which includes data from a study in which the 50-percent mortality overpressures, $\mathrm{P}_{50}$ 's, were determined for guinea pigs cage-mounted on and at the indicated distances upstream from the end plate of a shock tube (References 4 and 72). Note that against the end plate, the $P_{50}$ was associated with an incident overpressure of 12 p.s.i. reflecting to 37 p.s.i. This load was imposed almost instantaneously on the downstream side of the guinea pig; however, 
the pressure increased in two steps over the upstream portions of the animal. When the entire guinea pig was subjected to stepwise increases of overpressure, arranged by moving the exposure station progressively upstream, the overpressures associated with the $P_{50}$ increased to reach a maximum at 6 inches and then appeared to level off. The gain in tolerance, from 37 to 57-59 p.s.i. in terms of the maximal reflected pressure, was associated with changes in four variables; namely, the magnitudes of the maximal reflected pressure $\left(P_{r}\right)$, the "sharp-rising" incident overpressure $\left(\mathrm{P}_{i}\right)$, the second abrupt stepwise increase in pressure $\left(P_{r}-P_{i}\right)$, and the time interval between the first and second pressure rise.

Which combination of these variables the animal regards as significant is not entirely clear. However, one way to view the matter is to assume that, given enough time to respond to an initial nonlethal pulse, some adaption or some change in the target occurs, such that resistance to the second pulse is enhanced. As a consequence, an animal might indeed survive a second pulse that given by itself would be lethal.

Experiments were designed by Richmond and colleagues (Reference 72) not only to test this assumption but to explore the significance of the time interval between the first and second stepwise increases in overpressure when the magnitudes of the first and second steps were kept constant. Specifically, an attempt was made, within the variation inherent in shock-tube operations, to produce for each exposure an incident shock of $17 \mathrm{p} . \mathrm{s}$. i. which would reflect to 52 to $53 \mathrm{p} . \mathrm{s} . \mathrm{i}$. The time between the pulses was altered by exposing the animal at different distances upstream of the end plate. The results, given in tabular and graphic form in Figure 15, show that all animals exposed against the end plate were lethally injured (Reference 72). As the distance from the end plate increased, animal survival progressively began to occur and reached 100 percent or near 100 percent for all four species studied when the animal stations were far enough from the end plate; e.g., mortality went from 100 percent down to 0 to 25 percent. 
An even more remarkable fact is that animals can, as was shown by this sharp difference in survivability, distinguish between environmental events separated by an incredibly short interval of time. By moving the mouse away from the end plate $1 / 2$ inch, and thus at the side of the animal nearest the end plate separating the incident and reflected pulses by approximately 50 micro$\underline{\text { seconds, }}$ survivability was raised from zero to 37 percent; at 1 inch (100 microseconds), survivability was 71 percent, and all animals survived at the 2 -inch station (200 microseconds).

Since all animals exhibited an impressive increase in tolerance, though the time required for the effect to become apparent was somewhat longer for the "larger" animals, it is important that the mechanisms at play be studied and elucidated. Because, as noted above, some adaptation or alteration in response to the first pulse seems to take place which gives the animal protection against the second, it is well to explore the matter a bit more here. In the experiments referred to in Figure 15, the first pressure rise averaged about 18 p.s.i., the second, 34 p.s.i. for a maximum of $52 \mathrm{p} . \mathrm{s} . \dot{\text { i. }}$ (see figure). It is significant that the 18-p.s.i. figure is below the level for lethality and that the $\mathrm{P}_{50}$ for mice at Albuquerque altitude for a single "sharp-rising" overpressure of "longduration" is about 26 p.s.i. (Reference 52), a figure well below the $34-$ p.s.i. magnitude of the second pressure pulse to which the mice were exposed. Indeed, a single $34-$ p.s.i. pulse can be expected to mortally injure over 90 percent of the mice. Thus, there must be events of critical biological significance--making the difference between life and death in fact--taking place very rapidly after the arrival of the first stepwise increase in pressure which serve to nullify the hazardous effect of the second pulse.

There is evidence that this concerns a change in the interval pressure of the animal which occurs very rapidly after the arrival of the first pressure rise. Indeed, if the internal pressure could reach a high enough figure--52 p.s.i. above ambient or higher to be exact--before the reflected pulse engulfed the animal, there would be little or no additional "load" imposed on the body wall and little effect due to the second pressure rise. In essence, the proposition is that the 
animal might have a "new" or imposed "internal-ambient" pressure effective at the time the second pulse arrived and, consistent with the work of Damon already described, tolerance to the second pulse would be enhanced by an amount dependent on the internal pressure rise due to the first step.

\section{Smooth-Rising Wave Forms'}

Since these matters concern the implosion process which will be discussed in the next section, the enigma of an animal's response to stepwise loading by overpressure will not be pursued further here. However, it is appropriate to point out that, except for the ears and sinuses, animals tolerate "slowrising" pressures very well providing the initial "fast" component of the wave is delayed enough and providing the maximum pressure develops in periods in excess of $20 \mathrm{msec}$. For example, Figure 16 (Reference 52), from a 1957 shocktube study by Richmond et al. (Reference 73) undertaken to help clarify responses to pressure-time records obtained inside protective structures in the course of full-scale field operations (Reference 5), shows wave forms which produced only minimal damage to the lungs of dogs, though eardrum rupture and sinus hemor rhage occurred in all cases--the latter, rather marked at pressures above 150 p.s.i. (Reference 73).

That small animals as well can resist such high, "smooth-rising" pressure was shown by the Albuquerque group at the time the dog studies referenced above (Reference 52) were accomplished and by Wünsche in Germany (Reference 75). Although in the experiments of Wünsche, rats survived 28 atmospheres of pressure inside a container when the rise times were on the order of 0.5 to 0.6 seconds, there was mortality noted among animals exposed to 33 to 46 atmospheres attributed to hold time at maximal pressure and time of decompression and not to the initial loading phase.

\section{G. Etiologic Mechanisms}

\section{General}


Though no one has yet envisioned and established a completely satisfactory explanation for the mechanisms producing primary-blast injury (References 2, 3, 21, 23, 39 through 44, 49, and 76 through 81), considerable progress has been made in gathering and synthesizing enough data to formulate a concept of some of the significant early and delayed events. Before describing these, some background information will be noted. It is well to keep in mind three points on which authorities agree in general: first, blast pathology is most marked in or near the air-containing organs of the body--the lungs, the gastrointestinal tract, the ears, and the paranasal sinuses--and is also seen in other locations where there are significant variations in tissue density.

Second, there may, in addition, be early effects in other organs due to vascular air emboli entering the circulation in the lungs (References 39 and 40), changes in the hematologic system (References 44 and 65), and cardiorespiratory malfunction (References 44 and 65). Too, it is now known that there can be delayed effects evident as chronic sequelae involving the lungs, kidneys, and heart (References 32 and 33).

Third, beyond the consensus that the impact of the blast wave with the body wall is the primary event (References 23 and 78) and that the mammal is extraordinarily sensitive to the rate, character, magnitude, and duration of the pressure rise and fall, there are at least four etiologic mechanisms of interest to blast biologists (References 21 and 23). These include: (1) inertia effects, (2) spalling effects, (3) implosion effects, all proposed by Schardin (Reference 42), and (4) a gross implosive effect of the blast overpressure on the body as a whole (References 21 and 22).

The last-mentioned mechanism, a consequence of which can be the violent, inward movement of the body wall (References 3,14, 21, 23, and 77 through 80), was made a major interest of the Lovelace group over the past 15 years for a number of reasons. Four among them will be mentioned:

One concerned the need to explain the important, puzzling, and at first not fully appreciated, evidence in data published in 1949 by Clemedson (Reference 58) 
that respiratory exhalation sometimes occurred immediately following blast exposure of rabbits. The finding, subsequently confirmed by Clemedson (Reference 81 ), of course meant that pressures inside the thoracic airways had to be higher than the external pressure during the period of exhalation.

Another reason concerned the high incidence of vascular air emboli in blasted animals, first described by the German workers (References 39 through 41) and subsequently confirmed in Sweden (Reference 44) and the USA (References 21 and 22). Such data indicated that at some time during the "blast experience," pressures in the thoracic airways had to be higher than those in the vascular (fluid) components of the lung although there was no direct evidence that such was the case.

A third reason encompassed the need to explain, etiologically speaking, why there were important similarities between lung hemorrhages seen in blastexposed animals and those suffering severe thoracic trauma from other causes, a matter appreciated and noted by Zuckerman in 1941 (Reference 2).

The fourth reason concerned a desire to expedite progress emerging from concurrent investigations of blast-induced pressure differentials (References 3 and 21) and mathematical studies of animal similarities by Bowen and colleagues (References 49, 77, and 82) which indicated a general model for scaling interspecies "dose-response" relationships might become refined enough to make fruitful the efforts to extrapolate animal data with confidence to the human case.

\section{Thoraco-Abdominal Response to Blast Pressures}

Attention is directed to Figure 17 in which a simple model of the thorax and abdomen is presented along with a pressure-time curve, the rate of rise of which is slow enough to allow air flow down the trachea to keep the air pressure throughout the gas component of the chest rising apace with that of the external pressure. In Figure 18, a more rapid rise in external pressure is shown. The pressure increase was assumed to be rapid enough to outstrip pressure compensation by air flow into the lungs, but slow enough to allow implosion 
of the thoracic and abdominal walls to help bring about pressure equalization by time, T; viz., this inward movement of the rib cage and the upward movement of the diaphragm sufficiently reduced the thoracic gas volume to bring the pressure inside the chest up to the level of the external pressure.

This mechanism--pressure equalization by body wall implosion--is important and offers the body a means of compensating for rises in environmental pressure providing the latter are within tolerable limits regarding magnitude and rate of increase. That this may not always be the case is shown diagrammatically for "moderate-" and "fast-rising" pulses in Figures 19 and 20.

In preparing Figure 19, a smooth-pressure increase was assumed that was sufficient in magnitude and rise-rate to bring about two potentially hazardous consequences; namely (a) a maximal implosion of the thoracic borders and an associated marked distortion of the thoracic organs including the delicate lung, and (b) abdominal-, other extra-thoracic-, and thoracic-fluid flow into the compressible gas phase of the lung, which even by time, $\mathrm{T}$, has a pressure well below that existing in the internal thoracic fluids and outside the body as well. That hemorrhage into the airways and shearing and telescoping of the lung along and around the relatively "stiff" major bronchi and accompanying pulmonary arteries could be severe, is not difficult to visualize.

The situation is even worse for the "fast-rising" pressure case depicted in Figure 20. The pressure magnitude, duration, and its near-instantaneous riserate were assumed to be sufficient to impart a high velocity and hence great energy of motion to the inward-moving body wall and the upward-moving abdominal contents. Because it was thought a sufficient rise in internal gas pressure was the most likely means of bringing the inward-moving body wall to rest and because of the work of Clemedson (noted above), who stated that "if the shock wave is of relatively 'long' duration there is a certain amount of air expelled from the lung," (Reference 81 ) the intra-thoracic, gas-pressure curve in Figure 20 was drawn to overshoot the external pressure and to approach the level of the latter by a series of decreasing oscillations. 
That under appropriate circumstances the intrathoracic pressure actually rises above the external blast pressure has been demonstrated in guinea pigs, rats, monkeys (Reference 59), rabbits (References 49, 59, 77, and 81 through 87), and dogs (References 49 and 59). An example is shown in Figure 21 for a rabbit exposed against the end plate of a shock tube (Reference 83). The incident shock, between 7 and 8 p.s.i., reflected against the end plate to a little over 20 p.s.i. The internal pressure-time tracing, recorded with a transducer placed in the mediastinal portion of the esophagus near the bifurcation of the trachea and posterior to the heart, showed a pressure rise peaking to almost 60 p.s.i. in about a millisecond.

Values for peak intrathoracic pressure recorded with intraesophageal transducers in 48 animals distributed among five species exposed in a shock tube to various levels of "fast-rising" overpressures of "long" duration were graphed by Fletcher in a recent study (Reference 59) from data made available by Richmond and colleagues (Reference 88). The results are included in Table 3. The data show that the magnitude of the rise in intrathoracic pressure is clearly a function of the magnitude of the maximal blast pressure. Also, though there are exceptions, the trend in the data shows that the time it takes for maximal internal pressure to develop is shorter the higher the maximal external pressure.*

Clemedson and colleagues have recorded similar results with transducers actually in the airways of the lungs of rabbits (References 86 and 87). In one such experiment known to the authors, a record furnished by Jönsson (Reference 84) showed a peak of 157 p.s.i. in the lung of a rabbit exposed near a partially reflecting surface to an $\mathrm{HE}$-produced incident pulse enduring for about $2 \mathrm{msec}$. with a maximal pressure of about 54 p.s.i. (Reference 87). It is, however, well to point out that Clemedson noted earlier that the expulsion of air from the chest following blast exposure was sensitive to the duration of the pulse (References 81 and 89) and it now seems clear that the character and magnitude of the intrathoracic pressure reached during blast exposure will also be sensitive not only to the duration of the incident pulse, but to its magnitude and rise characteristics as well. That such is the case can be appreciated by comparing the curves for a 
"long-duration" overpressure given in Figure 21 with those noted in Figure 22 showing data for a "short-duration" blast wave.

\section{Idealized-Response Curves to "Fast-Rising," \\ "Long-Duration" Pressure Pulses}

It is instructive to think further about the implication of the early response to "fast-rising" overpressure of "long" duration. Consider, for example, Figure 23 showing a "fast" square wave rise in external pressure of "long" duration intrathoracic pressure-time curves similar to those in Figure 21 assumed to occur in an exposed animal. A time, $\mathrm{T}_{\mathrm{O}}$, is noted and is taken to represent, as discussed by Bowen et al. (Reference 49), the time at which the thorax has undergone maximal compression (implosion).

\section{a. Alternating Phases of Acceleration and Deceleration}

In the upper, A, portion of Figure 23, alternating periods of acceleration followed by deceleration of the thoracic borders (the chest wall, abdominal contents, and diaphragm) are noted. For example, during the time the external pressure exceeds the internal thoracic pressure, the thoracic borders are accelerated and move inwards. Immediately after the internal thoracic pressure exceeds the external pressure, the thoracic borders undergo deceleration until such time $\left(\mathrm{T}_{\mathrm{O}}\right)$ as the "air spring" brings the inward-moving tissues to rest, noted as $R_{1}$ on the intrathoracic pressure curve. At this point, the compressed thoracic gases accelerate the chest wall again, until, by outward movement, the chest volume increases to such an extent that the internal gas pressure reaches the value of the external pressure. At this time, decelerative loading again ensues. The latter endures until the increasing excess of external over internal pressure brings the thoracic borders to rest a second time at $\mathbf{R}_{\mathbf{2}}$. Following this, until the pressure oscillations cease, the process of alternate acceleration and deceleration of the chest borders will repetitively occur. 
Of course, the greater the magnitude of the accelerative and decelerative loads and the shorter the time, $\mathrm{T}_{\mathrm{O}}$, the more significant are the alternating periods of inward and outward movements forced upon the chest borders and upon the contents of the thorax. In this regard, it is impressive to note some relevant quantitative data from three sources: viz., (a) Lord Penny and colleagues (References 79 and 80), after analyzing unpublished data furnished by Zuckerman, proposed that the lungs of man or animals would be severely damaged if the "chest walls were flung inwards with such acceleration that they acquire a velocity of 20 meters per sec (65.6 ft./sec.) in half a msec. or less;" (b) Clemedson and Jönsson (References 23 and 87) by direct measurements of rib movements in blast-exposed rabbits concluded that, depending upon the amount of displacement involved, relative velocities of the chest wall greater than 10 to 15 meters per sec. (32.8-49.2 ft./sec.) attained within 150 to 200 microseconds are very critical; and (c) Bowen and colleagues (Reference 49) noted that though the time to $\mathrm{T}_{\mathrm{O}}$ is a nonlinear function of the magnitude of the "fast-rising" overpressure and will therefore be "long" for lower pressures and very "short" for higher pressures, the value for $\mathrm{T}_{\mathrm{O}}$ applicable to "fast-rising" overpressures of "long" duration that are near the $\mathrm{P}_{50}$ for dogs is close to 1.25 msec. at Albuquerque altitude (12 p.s.i.). Also, the maximal intrathoracic pressure measured with an intraesophageal transducer in dogs exposed in a shock tube to a near-50-p.s.i., "long-duration, " reflected pressure was very close to 250 p.s.i. (Reference 49 ).

Thus, it is evident that very high pressure differentials are involved, $\mathrm{T}_{0}$ times are short, velocity changes are substantial, and G loads on the order of several thousands of $\mathrm{G}$ to the chest wall and contents are involved when blastpressure loading begins to reach damaging levels. When this occurs, quantitative assessment of the values of $\mathrm{T}_{\mathrm{O}}$ and the associated partial impulse, $\mathrm{I}_{O}$, computed by Bowen et al. (Reference 49) from animal effects data and from the associated early portion of the blast wave that represents the most challenge to the animal, is most important (Reference 49). The interested reader is referred to a paper by Bowen et al. (Reference 49 ) in which values, scaled to sea-level pressures 
and according to body mass, are reported for small (mouse, hamster, rat, guinea pig, and rabbit) and large (cat, monkey, dog, goat, sheep, cattle, and swine) mammalian species.

This is a most intriguing matter, for few believe that for a "fast-rising," "long-duration" overpressure of classical form the animal "cares" either about the last half of the falling phase of the pulse or the underpressure which follows. Neither, for a 400-msec. long wave, for example, does even a large animal "regard" the pressure change from the last half of the first 200-msec. portion of the wave as critical. However, by a process of continuing to ask about a decreasing segment of the "front" end of the wave, one arrives at a point where it is necessary to know the critical period of time involved. No doubt for very short blast waves of high enough pressure to be hazardous, the matter concerns mostly the energy delivered to the animal in a time which is "short" compared to the implosion time of the thorax. For a "long-duration" wave, the critical portion of the pulse is at least as long as the time it takes to reach maximum internal pressure (near the $\mathrm{T}_{\mathrm{O}}$ noted in Figure 23) and may extend as long as it takes the oscillating pressures in the thorax to damp out and reach a true equilibrium with the level of the external pressure. In any case, the time is probably less than $1 \mathrm{msec}$. for a small animal and may be as long as 2 to $5 \mathrm{msec}$. for an animal the size of man $(70 \mathrm{~kg}$. ).

\section{b. Alternating Phases of "Forced" Hemorrhage and "Forced" Air Embolization}

To aid further in exploring the pressure differentials at play during the blast-induced implosion process, attention is directed to Figure 23B showing idealized pressure-time curves assumed appropriate for intrathoracic fluids and gases when an animal is exposed to a "fast-rising," "squarewave," external pressure pulse. Since, as one extreme, the fluid pressures just beneath the skin and close to the surface of the body would remain reasonably "close" to the external pressure, and, as another extreme, the intrathoracic fluid pressures measured very near the air-fluid interface would have values 
near those existing in the gas in the lungs, the intrathoracic fluid pressure curve shown in Figure 23B was drawn to represent some "average" between the two extremes mentioned. For as long in the moving-inward process as it takes the "average" internal fluid pressure to increase and reach the level of the external pressure, pressure differentials exist which potentially can drive fluid (blood, lymph) into the gas-containing portions of the lung. This eventuality is noted in the figure and can be thought of as a period of "forced" hemorrhage, marked $A_{1}$, during which accelerative forces directed inward are acting on the tissues comprising the thoracic borders.

In contrast, during the time that the average intrathoracic pressures are above the external air pressure--the interval, $A_{O}$, in Figure 23B, over which the compressed gases in the lungs exert a large outward accelerative force on the imploding tissues and over which the internal gases reach maximal compression $\left(R_{1}\right)$ and not only arrest the inward-moving chest wall and upward-moving diaphragm, but hurl them subsequently and explosively outward--pressure differentials exist which will drive gas into the fluid portions of the lungs. It seems, therefore, appropriate to think of the period marked " $\mathrm{A}_{\mathrm{O}}$ " in Figure 23 as one of "forced" air embolization. That these periods of forced hemorrhage and forced air embolization are repetitive until the pressure oscillations damp out is noted in Figure $23 \mathrm{~B}$.

To reiterate somewhat, it is helpful to note that the pressure differentials at play and depicted in Figure 23 have two important, early effects. Initially, they do work upon the moveable mass of tissue contiguous with and comprising the perimeters of the thorax. This results in a gain of velocity and a transfer of considerable energy to the imploding mass. Secondly, the pressure differentials again do work upon the moving tissues to the end that the energy of inward motion is, in part, dissipated; the inward velocity is arrested; an outward velocity is imposed rapidly on the tissues (including the thoracic wall and abdominal contents) separating the thoracic gases from the exterior environment; and energy of motion requiring subsequent dissipation is for a second time imparted 
to the system. As has already been noted, the process is repetitive, particularly so if the pressure differentials are high.

Also, it is well to pause and point out that the effects of the implosion process, and the oscillations that follow, on the air-fluid interface in the lungs can hardly involve a uniform process. For example, during the initial moving-in of the thoracic borders and the subsequent opposition to continued decrease in lung volume by compression of the thoracic gases, different stresses and strains are sure to occur over the large area confining the lung gases. Contributing to these will be variations in the density, elasticity, and resistance to distortion of the moving tissues and hence a development of differential velocities and damage because contiguous internal structures have either (a) been moved too far or (b) been moved too fast. Certainly, the magnitude of the movements involved, and the speeds with which they are known to occur, may result in unequal flow of fluid into soft tissues and between soft and denser tissues, dissecting and telescoping effects, and rupture and tearing of the lungs, the outer portions of which are driven inward against and over the relatively firm structures comprising the roots of the lungs. Thus, the entire moving-in process, enduring until time to $\mathrm{T}_{\mathrm{O}}$ in Figure 23, and not just the initial portion marked " $\mathrm{A}_{i}$ " in Figure 23B, may be the interval over which the most structural damage to the thoracic organs occurs. This is not at all meant to imply that the oscillating phases described and the important events which follow are not hazardous, only that one must consider all portions of the implosive process and the subsequent consequences, be these physical or biological in nature.

Finally, one last point regarding hemorrhage and blast-induced pressure differentials: It is known from the work of Chiffelle (References 33 and 90) that bleeding into the airways occurs at two sites; namely, through alveolar-venous fistulae and through breaks in the surface continuity of the membranes and underlying structures lining the bronchial airways. Though it is easily possible for alveolar-venous fistulae to appear either during the moving-in or moving-out phase of the implosion process (up to $R_{1}$ or from $R_{1}$ to $R_{2}$ in Figure 23B), it is 
likely that the ruptures in the walls of the upper airways through which hemorrhage ensues are the result only of fluid flow towards and into the pulmonary airways; i.e., they probably occur during the moving-in portion of the implosion process.

\section{Arterial Air Emboli}

Concerning air embolization, there is now direct evidence, obtained by Nevison, Mason, and colleagues in Albuquerque (References 91 and 92) with an ultrasonic Doppler blood-flow detector implanted across the carotid artery of a dog subsequently subjected to blast in a shock tube, that large number of emboli, most probably gaseous in nature, pass the detector at times over the first half hour after exposure. Sample records are shown in Figure 24. At the top of the figure, results of record analysis are given on a minute-by-minute basis. Immediately below is a record labeled " $a$ " taken before the blast. The record labeled " $\mathrm{b}$ " shows the time periods 0 to 2 seconds, and between 5 to 6 seconds and 9 to 10 seconds following exposure. Responses on the embolus detector occurred in a matter of seconds. Multiple responses were noted over the first 10 seconds after the blast and then ceased for a time. They were noted again about 2 minutes after the blast beginning a few seconds after the animal exhibited convulsions presumably of anoxic origin following a period of apnea. Record "c," taken 12 minutes after the blast, shows somewhat rhythmic shower: of responses that were correlated in time with the breathing cycle of the animal, thus confirming predictions made by German workers over 20 years ago (References 39 and 40). Note also that at 5 and 7 seconds on the "c" record there is a definite tendency for the blood-flow velocity to fall towards zero after each burs of activity on the embolus-detector trace. That this occurred at other times after blast exposure can be seen at several points on the gross trace of maxima. and minimal blood velocity appearing, at the top of Figure 24, at times when there is the highest amount of activity on the embolus trace.

No doubt it is as obvious to the reader as it is to the authors that the interpretation of the early portion of the record obtained and shown in Figure 24 is 
difficult. However, the technique is promising and it may yet be possible by direct measurement to obtain firm, unequivocal evidence that air emboli indeed appear early enough to be consistent with the phases of air embolization defined and discussed in connection with Figure $23 \mathrm{~B}$.

\section{Fibrous Emboli}

Following a finding of multiple myocardial and renal infarcts in sheep sacrificed at 30 days after blast--examples of which are shown in Figure 25 for the kidney and in Figure 26 for the heart (Reference 93), a 60-day survivor study was undertaken. The results, tabulated in Table 4, not only show myocardial infarcts in 4 of 21 and renal infarcts in 18 of 21 of the 60-day survivors, but renal infarcts in 10 of 18 animals dying early (Reference 93). Such lesions have also been seen in cattle, swine, goats, and dogs (References 32 and 35). Also noted were multiple areas of fibrosis seen in the lungs of dogs (see Figure 27) and sheep (References 32, 33, and 90).

Careful study of microscopic sections from the sheep succumbing in a matter of hours revealed intravascular fibrin thrombi in small vessels of the kidneys, adrenal glands, and heart. These thrombi apparently form quite early and have been seen in renal arteries of animals dying within 5 minutes after blast exposure (Reference 93); cardiac myocytolysis has been observed within the same time period. Coagulation disorders, perhaps similar to those in disseminated intravascular coagulation, have been reported (References 34 and 35) and it is now known that significant changes occur in fibrinogen and platelet levels within a few minutes after blast exposure (Reference 93).

Currently, the relative contribution of fibrin thrombi and air emboli as etiologic agents and precursors of the ischaemia subsequently evidenced as frank infarction is not known. No doubt further careful and extensive studies will have to be carried out before the matter is completely understood. 


\section{6. $\quad$ Two-Step, "Fast-Pressure" Increases}

Now that the implosion process along with the related internal pressure-time responses have been discussed, it is well to return to the matter of stepwise increases in overpressure and the data given in Figure 15 showing the decrease in lethality for rabbits as a function of distance from the end plate of the shock tube. Bowen et al. (Reference 77) further analyzed the rabbit data using a mathematical model devised to compute pressure-time responses inside the thorax. The results are shown in Figure 28. Note that the highest intrathoracic pressure occurred for the 100-percent lethality case. The steploads used for the animal mounted against the end plate were taken to be that stepwise rise in blast pressure occurring at the midline of the animal. Note further that the peak intrathoracic pressures computed were inversely related to the minimum internal pressures occurring after arrival of the reflected shock; viz., when the intrathoracic pressure, noted at the time of the arrival of the reflected shock, was 4, 9, 32, and 44 p.s.i., the peak intrathoracic pressure computed was $333,218,84$, and $58 \mathrm{p.s.i.,} \mathrm{respectively.} \mathrm{Thus,} \mathrm{it} \mathrm{appears} \mathrm{that} \mathrm{the} \mathrm{internal}$ pressure resulting from the incident wave "inhibits" the effect of the reflected wave.

Two reasons for this effect and the associated decrease in lethality as the animal is moved from the end plate seem rational; namely, (a) the "driving" pressure of the reflected wave, taken as the difference between the external and internal pressure, is reduced because of the increased pressure in the lungs, and (b) the increased internal pressure also results in a stronger "air spring' $\mathrm{s}^{\prime}$ being active at the time of arrival of the second pulse and tends to inhibit further the inward motion of the chest wall. No doubt such an effect would be maximized--the animal would be a "stiffer" target and thus most "protected"--if the reflected shock arrives at a time when the lung pressure has reached a peak value in response to the incident wave. Also, effects noted in the animal will be very sensitive to the timing involved, and though extensive experiments have not yet been done, one can anticipate that there might be cyclic changes in lethality 
noted which would be related to the magnitude of the internal pressure at the arrival of the second pulse; i.e., the effect (lethality) would be minimal when the lung pressure was highest and maximal when the lung pressure was lowest.

Since the computation of internal pressure-time responses was accomplished as noted in Figure 28, studies using guinea pigs have been carried out in Albuquerque employing the shock-tube geometry shown in the left side of Figure 29, along with internal and external blast pressure recordings presented in the right portion of the illustration. The upper trace in each pair of records, from a wallmounted gage located at + as noted in Figure 29, shows the "sharp-rising" incident and subsequent reflected pressure pulses. The lower trace, from a small transducer located in the esophagus just posterior to the heart, gives the pressure-time response recorded inside the thoracic mediastinum. It is now possible to say that the empirical results of the study, carried out by Kabby Mitchell, Jr. and Charles S. Gaylord under the direction of Richmond and Jones (Reference 93), confirm the prior predictions of Bowen in that there was close agreement between experimental and model calculations using parameters appropriate for the guinea pig.

It is helpful to note Figure 30, also from Bowen et al. (Reference 77), showing that similar mammals have similar sensitivity to the time separation between an incident and reflected shock associated with 50-percent lethality, in that the time separation of the two pressure pulses is approximately proportional to the cube root of the body mass.

Such a relationship has also been helpful in attempts to integrate data among dissimilar animals ("small" and "large" mammals) obtained in shock-tube exposures against and at various distances from the end plate to determine criteria for pressures that increase in two "fast" steps. Figure 31, in which the time between steps has been normalized using the cube root of body mass, is reproduced from a recent study by Fletcher (Reference 59) to which the reader is referred for the most recent discussion of progress in modeling and interspecies scaling procedures important in predicting blast tolerance for man. 


\section{TENTATIVE PRIMARY-BLAST CRITERIA}

\section{A. General}

There have been two recent studies by Bowen, Fletcher, and Richmond (Reference 94), and Fletcher (Reference 59) in which available animal data have been employed to improve and update estimates of human tolerance to "fastrising" blast waves over a range of pulse durations. Selected information from these reports along with relevant data from earlier work will now be presented. However, those who would follow the emergence of empirical and theoretical progress starting with the understandings in 1959 (Reference 21) are referred to the publications of Richmond et al. (References 52, 60, and 69 through 73), Richmond and White (Reference 95), White (References 6 and 29 through 31), White and Richmond (References 21, 22, and 68), White et al. (References 4 and 5), Bowen et al. (References 49 and 77), Holladay and Bowen (Reference 82), and Damon et al. (References 64 through 67).

\section{B. Interspecies Data}

Employing data obtained from experiments involving 2, 097 animals carried out by the Lovelace Foundation group, completely tabulated for each of 13 species by Bowen et al. (Reference 94), an analytical framework was developed relating survival response in 24 hours to "fast-rising" blast waves specified in terms of maximal overpressure, duration of the pressure pulse, and body mass of the several species. Interspecies scaling procedures, described by Bowen and collaborators in detail, embodied two key concepts. The first concerned the demonstration that the significance of a blast wave's duration could be related to the ambient pressure, $\mathrm{P}_{\mathrm{O}}$, and to the mass, $\mathrm{m}$, of the animal (in kg.). Specifically, the experimental duration of the blast wave, $t_{+}$, was scaled to the equivalent duration, $\mathrm{T}$, applicable to a $70-\mathrm{kg}$. mammal and to sea-level ambient pressure (14.7 p.s.i.); the equation used was:

$$
\mathrm{T}=\mathrm{t}_{+}(70 / \mathrm{m} .)^{1 / 3}\left(\mathrm{P}_{\mathrm{O}} / 14.7\right)^{1 / 2}
$$

all pressures being expressed in p.s.i. 
The second procedure used in scaling the data among species was to relate the maximum pressure associated with the 50-percent survival response in 24 hours for each species when exposed at sea level to "fast-rising, " "long-duration" "square waves, " $\mathrm{P}_{\mathrm{Sw}}$, to the geometric mean of the values obtained for the large species (61.5 p.s.i.) in such a way that the maximal experimental overpressures, $P_{r}$, applicable to an ambient pressure, $P_{0}$, could be expressed as an equivalent overpressure, $P$, applicable to a mammal with a $P_{S W}$ of 61.5 p.s.i. and to sealevel ambient pressure. The relationship used for the scaled peak reflected overpressure was:

$$
\mathrm{P}=\mathrm{P}_{\mathrm{r}}\left(61.5 / \mathrm{P}_{\mathrm{SW}}\right)\left(14.7 / \mathrm{P}_{\mathrm{o}}\right)
$$

with all pressures noted in p.s.i.

Figure 32 shows the tabulated data for the large and small species and the synthesis of the results among the species graphically. The "square-wave" overpressures resulting in 50-percent survival at sea level, $\mathrm{P}_{\mathrm{Sw}}$ 's, obtained by probit analysis of the data for each species and regarded as the indices of blast tolerance among the species, are shown along with the geometric mean figures for large and small animals. These pressures, scaled as described above to have a sea level equivalence with the average of the large species tested, are shown in Figure 32 to scatter randomly about the 50-percent probability curve. Though there was statistical difficulty with one species, the guinea pig, which was excluded from the parallel probit analysis used to help derive the overall probability figures shown, the points for guinea pigs fall very close to the curve and satisfyingly well within the range of all the other data obtained.

A more recent paper by Fletcher (Reference 59) included results for the large and small animals scaled separately, not normalized to the geometric mean for the large species, as shown in Figure 33. Though there were results for 83 more large animals and additional primates included (see tables in Figures 32 and 33) the 50-percent survival overpressures were essentially similar. As a consequence, there was no need to update the tentative biomedical 
criteria derived from the data by Bowen et al. in 1968 (Reference 94). However, those interested in interspecies scaling and advances in modeling are referred to the Fletcher study (Reference 59) for details.

\section{Tentative Criteria for "Fast-Rising" Blast Waves of Various Durations}

Based on the assumptions that a $70-\mathrm{kg}$. adult human is a member of the large-mammal group and that his tolerance could be tentatively approximated by using as an index the geometric-mean figure of $61.5 \mathrm{p} . \mathrm{s.i}$. noted in Figure 32 , Bowen et al. (Reference 94) prepared tolerance curves, applicable to a sea-level ambient pressure of 14.7 p.s.i., predicted for a 70-kg. man exposed under three conditions. Figures 34,35 , and 36 show the data in terms of the maximum incident overpressure for those situations when the biological-equivalent "dose" (see Figure 11) was taken to be (a) the incident pressure for an orientation with the long axis of the body parallel to the direction of the advancing blast wave, (b) the incident pressure plus the dynamic pressure when the long axis of the body is perpendicular to the direction of travel of the blast wave, and (c) the reflected pressure when exposure occurs against a reflecting surface.

All three charts, though applicable to a 14.7-p.s.i. ambient pressure and to a $70-\mathrm{kg}$. mammal whose $\mathrm{P}_{\mathrm{Sw}}$ blast tolerance is $61.5 \mathrm{p.s.i.} \mathrm{(assumed} \mathrm{to} \mathrm{be}$ man), can be scaled to other eventualities involving different ambient pressures, body masses, or blast tolerances by using the relationships noted in Figure 32 .

The curves for threshold lung damage (Reference 5), also shown in Figures 33, 34, and 35, were prepared consistent with data obtained by Richmond et al. (References 52 and 69) in which lung-injury threshold studies were reported for dogs and sheep. The generalized criterion, considered conservative, used was that lung damage begins to occur at one-fifth the 50-percent survival overpressure.

\section{Nonclassical Wave Forms}


No attempt will be made here to develop criteria for pressure pulses increasing in a stepwise or smooth manner, except to point out, first, that the data in Figure 31 indicate tolerance increases in some cases by as much as a factor of two when there is sufficient time delay between two "fast-rising" shock pressures and, secondly, for "smooth-rising" wave forms, such as shown in Figure 16, in which the development of maximal pressure occurs over periods like a few tens of msec. or more, survival tolerance in terms of the maximal pressure may be greater by as much as a factor of five compared to what it is for "fast-rising" blast waves. Those readers who wish to review information available for assessing hazards from exposure to disturbed wave forms are referred to other sources (References 4 through 6, 30, 52, 95, and 96), though they will find the data meager indeed.

\section{DISCUSSION}

\section{A. General}

Throughout the text are several $s u b j e c t$ areas worthy of further elaboration and discussion. These, which will be noted in turn below along with a number of limitations that should be kept in mind, include matters relevant to interspecies relationships, whole-body impact, waveform, etiologic mechanisms, and additional "dose-response" data.

\section{B. Interspecies Relationships}

\section{Group Segregation}

By way of emphasizing a point made earlier (see Figure 6) that data are accumulating indicating that man may indeed be a member of the large mammal group, attention is called to Figure 37, reproduced from a recent study (Reference 59). Beyond the overall fact that the parameters noted, while varying between the two animal groups, are on the average independent of body mass within a group, the relationships noted in the chart at the bottom of the figure are of particular interest to the authors because of their bearing upon criteria development for whole-body impact, an indirect blast effect. 


\section{Whole-Body Impact}

Following the emergence of the large - and small-animal differences in tolerance to blast overpressure, it was obvious that the earlier estimate of the 50-percent lethal velocity for whole-body impact derived from rodent data by Richmond et al. (Reference 20) would need updating. The situation was recently reappraised by Jones et al. (Reference 97 ) who reported data for the dog and man. In preparing Figure 38, data from Lewis et al. (Reference 98) were used to compute the probit curve relating lethality to impact velocity to obtain a $\mathrm{V}_{50}$ estimate of about $54 \mathrm{ft}$./sec. for man, a value appearing in the lower portion of Figure 37.

The $\mathrm{V}_{50}$ value of $64 \mathrm{ft} . / \mathrm{sec}$. for dogs, based upon the survival of 24 of 29 animals in experiments currently under way (Reference 93), is very tentative, but may not change by more than a few $\mathrm{ft}$./sec. as data accumulation continues.

\section{Lethality-Time Data}

An additional interspecies relationship of considerable interest is the similarity between the characteristic development of early lethality in animals severely injured by either blast overpressure or whole-body impact. Figure 39 illustrates the situation for primary blast and Figure 40 for whole-body impact. However obvious this similarity may be, considerable caution in interpreting such data is indicated for at least two reasons:

First, survival times are very strongly dependent upon the overpressure to which the animals were exposed, a fact which is not obvious from a single accumulative lethality curve such as that shown in Figure 41 based on data collected during the 30-day period following the exposure of 132 guinea pigs to "fast-rising" overpressures in a shock tube. However, this fact may be noted in Figure 42, based on the same guinea-pig data, which has a separate lethality-time curve for each of the four exposure overpressures used. Thus, in comparing survivaltime data among animal species, one must be aware of the possible variations due to the exposure pressures used. 
Second, for primary blast at least, there appears to be a species difference in survival time. Available information is shown graphically in Figure 43 for small animals (mice, rats, guinea pigs, and rabbits) and for goats and dogs. Thus, both intra- and inter-species comparisons of survival-time data must recognize that there is a species factor to be considered. Why this is so is not now known. Neither is it clear that what is true for primary blast will also be true for whole-body impact.

In any case, the differences in survival-time data are so great as to suggest that there may be different mechanisms accounting for lethality occurring "early," over "intermediate" time periods, and "late" as would result from exposure to high, intermediate, and low overpressures, respectively. Certainly those interested in etiology and therapy must be alert to the possibilities suggested if experimental design is to be accomplished with care and perceptiveness to the end that the interspecies data may be used with confidence in estimating man's response to pressure and impact loads.

\section{Interspecies Scaling}

It will be instructive here to elaborate further on the complex matter of interspecies scaling. Consider first the raw data in Figure 3 giving the individual pressure-duration relationships for each species. Initially by using dimensional analysis, the question of whether or not there was "similarity" among the mammalian species was explored by scaling the pressure-duration data for each species to account for the effects of body mass and ambient pressure in such a way that they would apply to a 70-kg. mammal exposed at sea level. That all animals were not "similar," as would have been indicated if all of the scaled datum points had fallen approximately along a single curve, was revealed graphically when Figure 33 was prepared. It was apparent that the mammalian species tested fell into two approximately "similar" groups, characterized as large and small mammals. It was significant that the curves for the several species had about the same shape and that a curve for any one species could be obtained by simply translating the curve for any other species along the 
pressure axis. In addition, it was found that (a) for each species and each overpressure duration, a linear relationship existed between mortality, in probit units, and the logarithm of peak overpressure and (b) the probit lines "statistically" all had a common slope except for the guinea pig.

One is led to feel that there was indeed a considerable similarity among all mammals tested, both large and small, a conclusion stemming from the essential parallelism of the probit lines, the guinea pig excepted, and the fact that the only noteworthy difference in the tolerance curves of the various species was in the value of the overpressure, $P_{\mathrm{Sw}}$, associated with 50-percent survival for "longduration," "fast-rising" shock waves at sea level.

Because dimensional analysis of the raw blast data revealed, but did not explain, the group difference between large and small animals, it was necessary to assume that man was either a member of the small or large species or that he could best be regarded as lying somewhere between the two. Since the lungdensity and lung-volume data along with the impact-tolerance information suggested, but did not conclusively indicate, that man should be taken to be among the large mammals, an arbitrary assumption was made; namely, that man could tentatively be assumed to have a $P_{s w}$ of $61.5 \mathrm{p.s.i.,} \mathrm{the} \mathrm{geometric} \mathrm{mean} \mathrm{of} \mathrm{all}$ the $\mathrm{P}_{\mathrm{SW}}$ values for the large mammals. By further assuming that the pressureduration curve for man had the common shape characteristic of all other mammals studied and that man's probit curves had the slope common to the other species, except for the guinea pig, it was possible to derive pressure-duration curves corresponding to different levels of survival, as shown in Figure 32, for men exposed against a reflecting surface to "fast-rising" overpressures. It is particularly gratifying that the individual interspecies datum points for 50 -percent survival fell, when scaled to apply to man, as close to the $\mathrm{P}_{50}$ curve in Figure 32 as they did, even including the four points for the guinea pigs, and that the scatter about the $\mathrm{P}_{50}$ curve appeared to be random, though less apparent for the "long" durations than for the "short," a result to be expected in view of the proportional influence of the uncertainties in the duration data. 
C. Wave Form

That mammals are most sensitive to the shape, character, rate, and magnitude of the pressure rise and fall and the duration of the overall blast wave, as well as its components, has been noted in the text and deserves considerable emphasis, particularly since the "free-field" overpressures and those occurring inside a variety of structures and other exposure locations can be remarkably different in wave form. Further, the advent of large yields may add new dimensions to the biological significance of the duration and of the falling phase of the blast wave, including the underpressure, and thereby greatly increase the overall significance of airblast across the whole gamut of "nonfree-field" exposures. One reason for this involves the fill phase of a structure having an entryway or other openings, which for a "short-duration" pulse might not allow time for significant pressure to develop inside the structure, but which for a "long-duration" pulse might be extremely hazardous because of the greater increase in internal pressure and the extended duration of the internal winds which occur as a consequence of the prolonged time during which the decreasing external pressure exceeds the rising internal pressure, an interval that is critically related to the pulse length and the geometry involved.

Another case in point may be illustrated by citing the rather puzzling data of Brown and Lee (Reference 100). These authors slowly pressurized mice to 80 p.s.i., held them at that pressure for 1 minute, 1 second, and $100 \mathrm{msec}$, and then "dumped" the pressure back to the previous ambient (near sea level) in $30 \mathrm{msec}$. The mortality observed proved to be a function of the hold time; viz., 80 percent when the hold time was 1 minute, 20 percent for 1 second, and 0 percent for hold times of $100 \mathrm{msec}$. Since it is unlikely that the findings noted were due entirely to lung damage from a rapid decompression, it is prudent to think about the physiology of rapid gas exchange and to be alert to the falling phase of the blast-produced overpressure, particularly when of "long" duration, and to the total hold time at overpressure, as was mentioned previously to be significant in some of the work done by Wünsche (Reference 75). 
Finally, regarding waveform, understanding underwater-blast exposures necessitates that careful consideration be given to the shape of the initial incident pulse as it is altered by the negative cut-off wave from the surface and by positive reflections from the bottom or other nearby objects. Thus, quantitative work in water, as well as in air, requires that the target site be adequately instrumented and that precise attention be paid to pulse definition and to all of the positional and situational factors that may significantly alter the apparent pressure dose.

\section{Etiologic Mechanisms}

\section{Air Emboli}

Any adequate concept of the etiology of primary-blast effects must be consistent with experimental findings as they accumulate over the years. It was in this spirit that emphasis was placed in this study on the phases of the implosion process that might bear upon the development of arterial air emboli and pulmonary hemorrhage. Consider, for example, the data in Figure 44, obtained from 556 caged guinea pigs subjected to overpressures, of 6 - to 8-sec. duration developing in single or double "fast-rising" steps; these data show the relationship between percent mortality, the incidence of air emboli seen post mortem in the coronary arteries, and lung weight expressed as a percent of body weight, an indirect index of the degree of pulmonary hemorrhage, both for the animals that did and those that did not survive for one hour following blast exposure. The vertical lines were arbitrarily drawn to delineate six groups in terms of lung weight. Taken together, the overall progressive increase in mortality as the lung weight increased, the progressive increase in the incidence of air emboli among the animals fatally injured, and the failure to find air emboli in any of the surviving animals lend credence to the significance of air emboli and lung hemorrhage as major factors in primary-blast injury. That air emboli were not seen in the superficial coronary vessels in all fatally injured animals was not surprising since the surface vessels represent only a small portion of the total coronary vascular system. However, the findings certainly did not rule out emboli in the unseen vessels. Also instructive is the fact that guinea pigs 
may die from blast with a normal lung weight but do not invariably die unless the lung weight has been increased by almost a factor of four, with the fates of individual animals having lung weights within the range mentioned depending upon some unknown factors. Whatever the reason for mortality in the above studies, the perceptive reader cannot help wanting to know the time sequence of emboli formation. This has been investigated in guinea pigs and dogs, and the results are given in Figures 45 and 46, respectively. That no coronary air emboli were seen in mortally injured guinea pigs that died at or after 10 minutes confirmed earlier German data (References 39 and 40) and was therefore expected. In contrast, air emboli were seen in the coronary vessels of 32 of 34 dogs when death occurred within 20 minutes, in 7 of 11 animals dying between 20 and 40 minutes, and in 4 of 11 animals that died between 40 and 120 minutes, the times to death being 76, 75, 60, and 55 minutes for the latter four dogs with air emboli. This was an unanticipated and novel finding.

Perhaps there is no point in speculating here about possible explanations for the above findings, since the writers know of none made exceptionally defensible by available data. Let it suffice to point out that additional experiments with emboli detectors, such as the one used to obtain the data noted in Figure 24, and many more similar studies will be required to unravel the etiologic facts and to learn how more rationally to guide those working in blast therapy. Also, one of the problems is to learn more about the proportions of "late" emboli that endure in the vascular bed as compared with those that arise anew to pose another threat to the animal at times considerably after the exposure to the blastwave.

\section{Whole- and Partial-Body Implosion and \\ Impact Trauma}

Though emphasis was placed on whole-body implosion as an experience "forced" on the animal by "long-duration," "fast-rising" blast waves, let it be clear that partial-body implosion also occurs, particularly if the duration of : the overpressure is "short" for the species concerned. Response by partial-body implosion might be viewed as perhaps even more effective as a means of pressure 
compensation than is the gross implosion process itself. Even if such is not entirely true, it is clear that, when whole-body implosion is the response to a "fast-rising," "long-duration" blast wave, minimal overpressures are lethal. In contrast, when the animal can respond by distortion to "fast-rising" overpressures "short" enough to avoid whole-body implosion, tolerance rises remarkably. This is of course only an expression of the pressure-duration relationship, but it is mentioned here in relation to the etiology of blast effects because an important question for the future is whether the etiologic mechanisms involved are identical, similar, or substantially different for whole-body as compared with partial-body implosion.

To be sure, one might think of a "long-duration" wave as loading all the thorax almost at once and, in contrast, of a very "short-duration" wave as loading half or less of the chest wall as the wave moves by. Such thoughts, concerning a lethal deposition of energy either over the entire thorax for a "longduration" pulse or over a portion of the thorax for a "short-duration" wave, inevitably lead one to consider the use of controlled local trauma, produced by nonpenetrating missiles of various weights and impact areas, as a means of studying the energy-response relationship common to both direct- and indirectblast effects. Such an approach was explored years ago in Albuquerque and found to be feasible and interesting (References 3 and 49). Experiments that were postponed because of higher priority work have been resumed and are currently in progress (Reference 93). No doubt there will eventually be interesting results forthcoming, not only in regard to the chest but to other areas of the body as well; viz., the body wall over the liver, spleen, and kidneys, for which criteria are sorely lacking at the present time.

\section{E. Additional "Dose-Response" Data}

1. Orbital Fractures into the Paranasal Sinuses

Another intriguing similarity between direct-blast effects and local trauma concerns "blow-out" fractures of the orbit. This lesion, seen clinically after blows to the eye from a fist, and less commonly, a baseball, or 
after impacts with a dashboard or a seat back in automobile accidents, was discovered in dogs subjected to "slow-rising" (though often irregular) blast overpressures of "long" duration by Richmond et al. (Reference 74). In a study involving 115 dogs, eleven "blow-out" fractures were seen in nine animals exposed in a shock tube to blast waves with rise times of 12 to $155 \mathrm{msec}$, , peak overpressures of 52 to 231 p.s.i., and durations of 0.4 to 20 seconds. Two parameters of the blastwave proved to be critical for orbital fracture into the nearby paranasal sinuses; namely, the time to and the magnitude of the maximal overpressure. The lesions were noted with pressures over 140 p.s.i., provided the time to maximal pressure was $30 \mathrm{msec}$. or less.

Orbital fractures and related eye signs have been noted by Levy and Richmond (Reference 101) in the Rhesus monkey exposed to a high-explosive-produced, "fast-rising" overpressure of $325 \mathrm{p} . \mathrm{s}$.i. enduring for $3.5 \mathrm{msec}$. and in man by Campbell (Reference 102). There are no quantitative data that allow one either to assess blast conditions that can be expected to produce the lesion in the human orbit or to know whether the pathology is likely to be seen in survivors exposed to "long-duration" overpressures. Apparently the lesion was rare in World War II experience, and the reader is referred to the study of Richmond et al (Reference 74) for references and a discussion of additional details.

\section{Renal Infarcts and Hypertension}

That data presented in the present study, namely the renal infarctions noted in Figure 25 and Table 4, may offer a rational explanation for the hypertension noted in survivors of the Texas City explosions by Blocker et al. (References 15 and 103) and Ruskin et al. (Reference 104), deserves emphasis here. Although hypertension was noted acutely and in the ten-year, follow-up study, there was difficulty attributing the effect only to blast exposure as one among other possible causes. However, if renal and myocardial infarcts occur in man, the phase-in of renin production from the damaged portions of the kidneys and the consequent elevation of blood pressure, in view of the findings reported here, are likely to pose a problem to therapists who may have to combat 
acute hypotension followed later by chronic hypertension which could only pose an additional hazard for a heart already embarassed by infarctions (see Figure 26 and Table 4).

In order to study the kidney lesions produced by blast in sheep, injection casts of the renal vascular tree were obtained. Casts from a control animal and from an animal subjected to shock-tube-produced overpressure and sacrificed 30 days later, shown in Figure 47, emphasize the type and severity of the blast damage that occurs. Attempts to produce the lesion by injecting air into the renal artery with a catheter failed, though blanching of the kidney was seen at the time the experiment was performed (Reference 93). However, in blasted animals surfactant material from the lungs may coat and stabilize blast-induced air emboli. Until further work is done, it will not be possible to say whether such emboli contribute to the renal lesions or whether the persisting fibrin emboli, known to occur early, are responsible for the occlusions in the renal vasculature.

\section{F. Limitations}

That the primary-blast criteria presented in this study apply only to young adult mammals, and not to the very young or the old, should be emphasized. Though data are scanty on the influence of age on primary-blast tolerance, some work done by Clemedson and Jönsson (Reference 84) has suggested that young rabbits are more vulnerable to airblast than are adult rabbits, a suggestion which is in accord with the results obtained in 1963 by Richmond and colleagues (Reference 106) using two groups of Sprague-Dawley, albino female rats, averaging 38 and 59 days of age, exposed to an 8-pound $\mathrm{HE}$ charge detonated overhead (ambient pressure: 12.0 p.s.i.). The 24-hour-survival pressures, $\mathrm{P}_{50}$ 's, applicable to the smaller (younger) and larger (older) rats were as follows: 


\begin{tabular}{lcccc}
$\begin{array}{c}\text { Number of } \\
\text { Animals }\end{array}$ & $\begin{array}{c}\text { Mean Body } \\
\text { Weight, } \\
\text { grams }\end{array}$ & $\begin{array}{c}\text { P50, } \\
\text { p.s.i. }\end{array}$ & $\begin{array}{c}\text { Confidence } \\
\text { Limits of } \\
\text { P50, p.s.i. }_{50}\end{array}$ & $\begin{array}{c}\text { Pulse } \\
\text { Duration, } \\
\text { msec. }\end{array}$ \\
\hline 50 (younger) & 121 & 31.2 & $27.6,35.1$ & 3.2 \\
40 (older) & 204 & 41.2 & $38.0,44.7$ & 2.9 \\
\hline
\end{tabular}

The difference in the tolerances of the two groups was significant at better than the 99-percent confidence level. It should be mentioned that the data of Lewis et al. (Reference 98), used to compute the probit curve relating impact velocity to human mortality as shown in Figure 38, also showed age differences in the lethality observed as being $88,25,54$, and 89 percent for the age groups 1.5 to 5,6 to 21,22 to 40 , and 41 to 66 years, respectively.

Though the data among the several mammalian species reviewed for this study seem to interrelate fairly well, nevertheless, there remain a number of bothersome problems, the solution of which should occupy interested investigators for some time. For example, there is the anomalous behavior of the guinea pigs mentioned in connection with Figure 32 ; the difficulty was that this species accounted for unacceptable statistical variability in the combined analysis, which variability became acceptable when the guinea-pig data were excluded. Also, there is some inconsistency in the results in Table 3 and in the unexplained matter (apparent in Figure 33) of the tolerance of the squirrel monkey; namely, that the creature responds more like a large animal when exposed to "longduration" overpressures and more like a small animal when subjected to "shortduration" overpressures. Too, there are the not-understood disturbances in blood coagulability and the yet-to-be-fully assessed intermediate- and long-term sequelae. In addition, no full explanation or corrections have yet been made for what seems to be an unduly large scatter in the data shown in Figure 31 . It is thought, however, that future studies will clarify these and the other remaining problems for a number of reasons, four of which will now be mentioned. 
First, the 1959 data shown in Figure 31 were obtained with animals exposed in metal cages, which partly protected them, while the more recent results were obtained with very wide-mesh cages offering little or no shielding from the pressure pulse. Further, as data accumulate, this figure may eventually have two curves, one for the small and one for the large animal species.

Second, sooner or later, means will be found for making models of the thoraco-abdominal implosion process more realistic and refined enough to minimize some of the difficulties now appreciated. For example, in the implosion process, the nonlinear "air-spring," active inside the body, involves air both below and above the diaphragm and not just that in the chest. Experiments so arranged as to minimize the amount of air in the abdomen should lessen the scatter in the results and much of the variation in the slopes of the probit response curves. Also, sophisticated experiments eventually will be done in which the volume of gas in the gastrointestinal tract as well as that in the lung will be determined and the values used as input for theoretical studies.

Third, beyond the difficulty in knowing the ratio of gas volumes above and below the diaphragm, is the fact that the implosion event strictly speaking involves the moving in of a mass subjected to forces acting over an area, all of which change in a complex way with time. Since the magnitude of the moving mass is changing in some relation to the distance moved and to the area responding to the pressure load, the numerical values of the significant parameters may always have to be best approximations. In any case, terms like effective area, effective mass, and effective volume are currently used by those studying modeling. However, there has been recent promising progress in evaluating model parameters and, in particular, their interrelations (References 49 , 59 , and 77).

Fourth, and finally, in due course more will be learned about how to evaluate the "dose" to an animal when the waveforms are complex and rise in a series of steps or smoothly at various rates to maxima, sometimes repetitive in certain geometries. In any case, astute experimentation and the concurrent application 
of theoretical modeling using available mathematical tools and computer technology to help guide subsequent empirical work are bound to pay high dividends in the years ahead, not only in advancing primary-blast studies, but those involving nonpenetrating trauma and whole-body impact as well.

V. SUMMARY

1. Initially, it was pointed out that exposure to blast overpressures and winds results in a variety of both accelerative and decelerative events of consequence.

2. That the accelerative events encompassed those due to both the direct and indirect effects of the blast wave was noted. The accelerative indirect effects included the initiation of whole-body displacement and the impact of blast-energized debris that might or might not penetrate the body surface. The accelerative direct effects involved a sudden inward and subsequent outward movement of the body wall, which might be oscillatory if the blast pulse were of sufficient magnitude and duration to implode the body wall violently and thus sharply increase the internal pressure over the external pressure as a consequence of the energetic decrease in the volume of the air-containing cavities of the body.

3. Decelerative events, characterized as occurring during the dissipation of the kinetic energy imparted to various parts of the body, included whole-body deceleration by means of tumbling and sliding or impact with a har d surface, and deceleration of the inward-moving body wall by means of the build-up of internal pressure in the air cavities made smaller as a consequence of the implosive effects of the blast overpressures and winds.

4. Because it was appreciated that mammals are extraordinarily sensitive to the duration; magnitude, rate, and character of the rise and fall of the blast-pressure pulse, a number of major 
biophysical parameters quantitatively influencing blast effects were noted and discussed. These, emcompassing the pressureduration relationship, species differences, ambient pressure effects, positional or orientational factors, geometric or situational factors, and etiologic mechanisms, were each dealt with and will be summarized here before turning to the section covering tentative tolerance criteria for primary blast.

5. The pressure-duration relationship, applicable to "fast-rising," classical blast waves and now established for 13 different mammalian species, states that, all other factors being constant, biological tolerance curves, like those for physical objects, are parallel with iso-pressure lines for "long-duration" blast waves and approach parallelism with iso-momentum lines for "shortduration" pressure pulses; i.e., there is a critical pulse duration, characteristic for each species, "longer" than which tolerance is a function only of overpressure and "shorter" than which the survival pressure rises. Thus, tolerance to overpressure progressively increases as the pulse duration decreases. Quantitatively, the pressure-duration relationship is impressive. For example, in dogs, lengthening the pulse duration from 2 to $12 \mathrm{msec} .--\mathrm{a}$ factor of six--decreased the lethal overpressure from near 220 to 75 p.s.i.--approximately a factor of three.

6. Species differences were noted wherein the characteristic pressure-duration curves for the tested species applicable to some significant effect, such as to high or low survival or to threshold lung damage, quantitatively fell into two groups; namely, a less tolerant small-animal group (mouse, rat, hamster, guinea pig, rabbit) and a more tolerant large-animal group (cat, dog, swine, sheep, goat, burro, steer, monkey). Similar segregation into large and small animals was cited from the literature for lungvolume and lung-density data, which information included man as 
among the large-animal group. A fourth matter, noted as bearing upon blast effects in different species, was the relation between animal size and the physical dimension of the blast wave; i.e., a blast wave of $2-\mathrm{msec}$. duration traveling over a ground surface and having a length of approximately 2 feet would be "sensed" as a "long-duration" wave by a mouse, but as a "short-duration" wave by an animal as large as a steer. One consequence of this relationship, apparent from dimensional analysis, is that the duration of the blast wave for a given effect in different animals should scale as the cube root of the mass of the animal.

7. The ambient-pressure effect, now empirically established for five mammals (mouse, rat, guinea pig, dog, and goat), was noted to be significant; i.e., when the ambient pressure at which mice were exposed was increased by a factor of six (from 7 to 42 p.s.i.), the 50-percent survival pressure increased by more than a factor of four (from 20.3 p.s.i. to 91.8 p.s.i.). Such data bear upon underwater blast tolerance, upon scaling blast effects to different above-sea-level locations, and upon how one views and interprets data involving exposures to two or more pressure pulses or to sudden stepwise increases in overpressure.

8. The effects of positional or orientational factors, including quantitative assessments of the 50-percent survival overpressures for exposures side-on and head-on under "free-field" conditions and also against a reflecting surface, were cited along with the definitions of the relationships between the incident $\left(P_{i}\right)$, dynamic $(Q)$, stagnation $\left(P_{S}\right)$, and reflected $\left(P_{r}\right)$ pressures to help elucidate how it is now thought best to specify the effective pressure "dose" appropriate to each orientation of the animal. For guinea pigs in the several orientations, there was a difference in terms of the $\mathrm{P}_{50}$ incident survival pressure of from 10 to 25 p.s.i., a factor of 2.5 ; 
i. e., the $P_{50}$ values were $P_{i}=10$ p.s.i. reflecting to 25 p.s.i. for exposure against a reflecting surface, $P_{i}=25$ to 26 p.s.i. for tail-on or head-on exposures, " $P_{i}=17$ to $18 \mathrm{p}$.s. $\mathrm{i}$. with an associated $Q$ of 8 p.s.i., and $P_{S}$ of 25 to 26 p.s.i. for the animals either prone and side-on to the blast wave or suspended vertically (head-up). From Figure 11, it can be seen that the maximal effective pressure for each exposure was approximately 25 to 26 p.s.i.

9. Geometric or situational factors were also noted to influence the effective pressure dose significantly. For example, beyond there being different incident overpressures of $34.9,19.5$, and 26.8 p.s.i. associated with the 50-percent survival conditions for guinea pigs depending upon their exposures respectively in chambers 1-body diameter deep, 3-body diameters deep, and 3-body diameters deep with a bottom offset (see Figure 12), there were complications of multiple pressure reflections; shape and character variations in the rising portion of the wave, and an overall delay in the development of the maximal overpressure revealed by pressure measurements from gages located close to the chests of the animals. Even so, the effective maximal $P_{50}$ pressures, revealed by gages placed close to the three animal locations, proved to be $34.9,34.6$, and 35.9 p.s.i., respectively.

10. Cited as germane to the situational factors were data for exposures either against or at some distance in front of a plate closing the end of a shock tube, whereby the animals received the incident and reflected waves either almost simultaneously or in two "fastrising" steps, the time between which varied as a function of the distance from the end plate. As a case in point, the 50-percent survival pressure for guinea pigs, being about 37 p.s.i. for caged animals against a reflecting surface, progressively increased when the exposure station was moved away from the reflecting surface to reach 57 to 59 p.s.i. at the 6 - to 12 -inch locations; 
i. e., tolerance in terms of the maximal overpressure increased by a factor of over 1.5 as a consequence of the locational change.

11. It was pointed out that otherwise fatal conditions reported for each of four species of animals, involving the exposure of the animals against the end plate of a shock tube to almost simultaneously applied incident and reflected overpressures of about 17 and 52 p.s.i., respectively, could be changed to allow survival to reach 100 percent in mice, rats, and rabbits and 75 percent in guinea pigs by the simple expedient of moving the exposure station 2 to 12 inches away from the end plate, at which locations the incident and reflected overpressures were unchanged. These remarkable results were associated with surprisingly short time delays between the incident and reflected shock pressures; i.e., about 100 microseconds for the mice, 300 microseconds for the rats, and 1,200 microseconds for the guinea pigs and rabbits. One possible explanation of the events responsible for converting an always fatal to an always or nearly always survivable condition was noted and discussed. It was suggested that the result was probably due to the imploding effect of the first stepwise increase in overpressure, the incident shock, resulting in an increase of internal pressure, perhaps to values near or equal to the second pressure increase. Thus, the effective load on the animal from the reflected shock would be reduced by the incident shock, and perhaps this load would be almost mitigated in instances where the internal pressure, was greater than, or approximately equal to, the reflected pressure at the time of its arrival.

12. A third situational factor noted involved the occurrence of "smooth-rising" overpressures of the type often measured in structures of "large" volume filling through "small" entryways. Instances of such curves with maximum pressure developing in approximately $30,60,90$, and $150 \mathrm{msec}$, all of which were 
nonlethal to dogs even though the pulse durations were 5 to 10 seconds and the overpressures in some instances were well over 150 p.s.i., were illustrated. In such exposures there was, however, damage to the eardrums, sinuses, and larynx, with mild, small hemorrhagic lesions in the lungs.

13. Concerning the etiology of primary-blast injury in which damage characteristically involves the interface of tissues of different density and, in particular, the lung and other air-containing organs, the fact that there was no completely satisfactory explanation of all the mechanisms responsible for the pathology observed, including the physical and biological events occurring during and after the primary impact of the shock wave with the body wall, was noted. However, inertia effects, spalling effects, and implosion effects were mentioned as was the gross implosive effect of the blast overpressure on the body as a whole. In emphasizing the latter, results obtained from simple models of the thoracoabdominal system as well as intrathoracic pressure-time measurements were presented to elucidate the fact that, given a "fast-rising" overpressure of sufficient magnitude and duration, the body wall can be violently hurled inwards far enough and with such high velocity that the internal fluid and gas pressures will eventually exceed the external pressure by a considerable amount. Such an occurrence not only brings the inward-moving body mass to rest, but subsequently hurls it explosively outwards. Recorded internal pressure-time curves show that the initial energy imparted to the body is eventually expended by a series of highly damped oscillations, the frequency of which is, for "fast-rising" waves, a function of the magnitude of the overpressure and the size of the animal involved. 
14. That much of the injury to the lung, regarded as the critical organ, occurs during and after the initial implosive response as a consequence of structures moving both too far and too fast was suggested. Also, hazardous shearing and telescoping effects were thought to occur as the soft peripheral tissues of the lungs were forced inward over the relatively stiff structures of the airways and accompanying branches of the pulmonary arterial tree.

15. Alternating phases of acceleration and deceleration of the chest wall and abdominal cavities were described as were alternating phases of "forced" hemorrhage and "forced" air embolism. The compatible relation of these concepts to the two known sites of pulmonary hemorrhage, alveolar venous fistulae and breaks in the continuity of the membranes and underlying structures lining the bronchial airways, and to the well-documented occurrence of arterial air emboli was pointed out.

16. Recordings were presented which were obtained, before and after the exposure of dogs to blast, with a Doppler-type instrument implanted around the common carotid artery of each animal. These showed, on a second-by-second and minute-by-minute basis, velocity variations of blood and intermittent occurrence of emboli which were probably air, but perhaps fibrin and/or aggregated blood elements.

17. Findings of multiple infarctions of the heart and kidney, noted in animals sacrificed 30 and 60 days after blast exposure, were also reported, as was the post-exposure occurrence of intravascular fibrin thrombi in the small vessels of the adrenals, kidneys, and hearts of lethally injured animals. It is significant that some of these have been seen in animals succumbing within 5 minutes after blast exposure. This fact, along with recently observed coagulation disorders suggesting a syndrome similar to disseminated 
intravascular coagulation, opens up a new avenue of investigation to those interested both in the pathophysiology and therapy of severely injured animals and in the infarction sequelae involving two such vital organs as the kidney and heart. Similarly, there remains much to be done in evaluating the lung sequelae, such as emphysematous areas and patchy fibrosis visible, even at lowpower, in microscopic sections of the lung.

18. The results of prior theoretical studies using a mathematical model to help explain the effects of "fast" stepwise increases in overpressure, mentioned above in terms of predicted internal pressure-time changes, were compared with recent concurrent internal and external pressure-time recordings. Their compatibility was noted and emphasis given to the useful interplay between theory and experiment now being brought to bear upon the etiologic aspects of primary-blast injury and upon the very important matter of interspecies scaling. Such work is needed to help improve conceptual understandings and to extend the information base essential in making extrapolation of animal data to man a more rational procedure rather than a vacuous exercise as is so often the case.

19. Tentative primary-blast criteria for man were summarized from prior analytical studies of data on over 2,000 mammals encompassing 13 species. The procedures for estimating man's tolerance from the data on pressure and duration versus survival for mammals exposed to "sharp-rising" overpressures against a reflecting surface were explained.

20. By using dimensional analysis and by assuming that the various mammalian species were "similar," the pressure and duration data for each species, shown in Figure 3, were scaled to account for the effects of body mass and ambient pressure in such a way 
that they would apply directly to a 70-kg. "similar" species exposed at sea level. Thus, the scaled data for all species should have fallen approximately a long a single curve, provided the species were indeed approximately "similar."

21. When the scaled data were plotted, it was apparent (see Figure 33 ) that the mammalian species tested fell into two approximately similar groups characterized as large and small mammals, with the curves for all of the species having approximately the same shape and differing only in the value of the overpressure, $\mathrm{P}_{\mathrm{Sw}}$, that each approached for a "long-duration" wave. It was further determined that, for each species and duration, a linear relationship existed between the probit of mortality and the logarithm of peak overpressure, and that all of these lines had a common slope except in the case of the guinea-pig data. Obviously there was a considerable degree of similarity among all the mammals tested, both large and small.

22. Evidence at hand and presented, suggesting, but not establishing conclusively, that man is a member of the large-animal group, prompted an arbitrary decision tentatively to take his tolerance to be 61.5 p.s.i., the geometric mean of the $P_{S W}$ values for this group. Pressure-duration curves (see Figure 32) corresponding to various levels of survival were then prepared for man, exposed against a reflecting surface, by using the value of 61.5 p.s.i., the common shape of the pressure-duration curves for all species, and the common (except for the guinea pig) probit slope.

23. The 50-percent survival data (shown in Figure 3) for the various species were scaled to account for variations in body mass, $P_{S W}$, and ambient pressure so that they should, if the results were appropriate and consistent, apply to a 70-kg. man exposed at sea 
level; these scaled data fell with minimal scatter along the 50percent survival curve in Figure 32, where they were plotted in order that the similarities in the responses of the various mammals and the manner in which the data for all species tested were used in establishing predictions for man might be more fully appreciated.

24. Since orientational and situational factors complicate the expression of dose-response relationships, probability-of-survival curves estimated for man under sea-level conditions for "fast-rising" blast waves were computed and plotted in terms of the maximum incident overpressure and duration for three conditions; namely, (1) long axis of the body parallel to the blast winds, (2) long axis of the body perpendicular to the blast winds, and (3) thorax of the body against or very near a reflecting surface perpendicular to the blast winds. Also included in the illustrations, Figures 34, 35 , and 36 , were curves representing the threshold for lung damage which, from the data obtained by exposing animals to "fast-rising" blast waves, was conservatively estimated to occur at pressure levels of approximately one-fifth of the 50-percent survival pressure.

25. That no satisfactory criteria were available for disturbed wave forms was noted. However, it was pointed out, first, that tolerance expressed in terms of the maximal overpressure might be increased by a factor of 1.5 to 2.0 for "fast-rising" overpressures rising in two steps, depending upon the time between the steps and, second, that tolerance $\mathrm{might}$ increase by a factor of five for "slowly" rising overpressures compared with the classical "fast-rising" variety.

26. In discussing the results, an earlier estimate, scaled from smallanimal data to man, of the whole-body impact velocity associated 
with 50-percent survival was updated using human data from the literature; i.e., the new figure of about $54 \mathrm{ft} . / \mathrm{sec}$. was thought to be more realistic than the prior figure of $26 \mathrm{ft} . / \mathrm{sec}$, extrapolated from data for mice, rats, guinea pigs, and rabbits, particularly in view of the differences in small and large mammals noted in the primary-blast studies.

27. In the discussion attention was called to previous, but incomplete, lethality-time studies also indicating interspecies differences for the small compared with the large mammals exposed to blast overpressures.

28. Additionally in discussing the results, mention was made of the critical significance of the wave duration and form at the target site, which might or might not be those for the "free-field" case. That the fill time for structures is much a matter of pulse length and that very "long-duration" overpressures, attainable with the large-yield explosives available today, offer the opportunity for supersaturation of blood and thoracic fluids with $\mathrm{CO}_{2}$ and other lung gases were noted and emphasized.

29. Data relevant to lung weight, mortality, and the incidence of air emboli were discussed in relation to etiologic concepts.

30. Whole - and partial-body implosions as responses to "long-" and "short-duration" overpressures, respectively, were mentioned and attention was called to similarities in the distortions accompanying partial-body implosion and the thoracic deformations following the impact of nonpenetrating missiles with the chest wall. Studies currently under way to further understanding of the energy--"deposition" process were noted and viewed favorably.

31. Blast-induced orbital fractures and the possible relation between renal infarction and blast hypertension were mentioned as 
additional areas where dose-response relationships should be pursued.

32. By way of limitations, the applicability of the primary-blast data presented to young adults but not to the very young or the old was noted and emphasized. Also, that many practical constraints made certain compromises necessary in model studies was noted. Attention was called to the progress being made by concurrently moving ahead with both theoretical and empirical approaches, not only in primary blast but in the areas of nonpenetrating trauma and whole-body impact as well. 
TABLE 1

OVERPRESSURE OF A "LONG-DURATION" BLAST WAVE PRODUCING 50-PERCENT MORTALITY (1-HOUR) IN EXPOSED MICE VERSUS EXPERIMENTAL AMBIENT PRESSURE

\begin{tabular}{ccc}
\hline $\begin{array}{c}\text { Experimental } \\
\text { Ambient } \\
\begin{array}{c}\text { Pressure, } \\
\text { p.s.i. }\end{array}\end{array}$ & \multicolumn{2}{c}{$\mathrm{LD}_{50}-1$-Hour Overpressure } \\
\cline { 2 - 3 } & p.s.i. & atm* \\
\hline 7 & 20.3 & 2.90 \\
12 & 31.2 & 2.60 \\
24 & 44.5 & 2.47 \\
42 & 55.3 & 2.30 \\
& 91.8 & 2.19 \\
\hline
\end{tabular}

*Atmospheres in terms of the experimental ambient pressure. After Damon et al. (Reference 65). 
TABLE 2

MORTALITY DATA FOR GUINEA PIGS EXPOSED TO

"FAST-RISING," "LONG-DURATION, " SHOCK-TUBE-PRODUCED OVERPRESSURES WITH THE INCIDENT AND REFLECTED OVERPRESSURES APPLIED IN STEPS

\begin{tabular}{|c|c|c|c|c|c|}
\hline \multirow{2}{*}{$\begin{array}{l}\text { Distance* } \\
\text { From } \\
\text { Cage to } \\
\text { End Plate, } \\
\quad \text { in. }\end{array}$} & \multirow{2}{*}{$\begin{array}{l}\text { Number } \\
\text { of } \\
\text { Animals }\end{array}$} & \multicolumn{3}{|c|}{$\begin{array}{c}\text { Overpressures Producing } \\
\text { 50-Percent Mortality, } \\
\text { p.s.i. }\end{array}$} & \multirow{2}{*}{$\begin{array}{c}\text { Computed Time Between } \\
\text { Arrivals of Incident and } \\
\text { Reflected Pressures at } \\
\text { Midline of Animal, } \\
\text { msec. }\end{array}$} \\
\hline & & $P_{i}$ & $\mathbf{P}_{\mathbf{r}}^{* *}$ & $P_{r}-P_{i}$ & \\
\hline 0 & 140 & 12.1 & $36.7 \pm 0.7$ & 24.6 & 0.20 \\
\hline 1 & 75 & 13.4 & $40.8 \pm 2.1$ & 27.4 & 0.33 \\
\hline 2 & 78 & 15.6 & $48.3 \pm 1.3$ & 32.7 & 0.45 \\
\hline 3 & 87 & 16.9 & $52.8 \pm 1.9$ & 35.9 & 0.57 \\
\hline 6 & 99 & 18.7 & $58.6 \pm 1.6$ & 39.9 & 0.95 \\
\hline 12 & 109 & 18.2 & $57.1 \pm 1.1$ & 38.9 & 1.71 \\
\hline
\end{tabular}

$\mathrm{P}_{\mathbf{i}} \quad$ : Incident overpressure

$\mathrm{P}_{\mathrm{r}} \quad$ : Reflected overpressure

$P_{r}-P_{i}$ : Second stepwise increase in overpressure

*Distance from midline of animal to end plate was approximately 1.5 inches greater than distance from cage to end plate.

**Plus-or-minus figure refers to the standard error of the mean.

Modified from Richmond et al. (Reference 72). After White et al. (Reference 4). 
TABLE 3

INTRATHORACIC PRESSURES IN ANIMALS EXPOSED TO A

"LONG-DURATION," "SQUARE-WAVE" PRESSURE PULSE

IN A SHOCK TUBE

(Ambient Pressure: 12.0 p.s.i.)

\begin{tabular}{|c|c|c|c|c|c|}
\hline $\begin{array}{c}\text { Species } \\
\text { and } \\
\text { Mean Body } \\
\text { Mass } \\
\end{array}$ & $\begin{array}{c}\text { Number } \\
\text { of } \\
\text { Animals } \\
\text { Tested } \\
\end{array}$ & $\begin{array}{c}\text { External } \\
\text { Overpressure, } \\
\text { psi }\end{array}$ & $\begin{array}{c}\text { Peak } \\
\text { Internal } \\
\text { Overpressure, } \\
\text { psi } \\
\end{array}$ & $\begin{array}{c}\text { Timex } \\
\text { to Peak } \\
\text { Internal } \\
\text { Pressure, } \\
\text { msec }\end{array}$ & $\begin{array}{l}\text { Experimental } \\
\text { Arrangement }\end{array}$ \\
\hline $\begin{array}{c}\text { Rat } \\
0.24 \mathrm{~kg} .\end{array}$ & $\begin{array}{l}4 \\
1 \\
1 \\
2 \\
3\end{array}$ & $\begin{array}{r}7.6 \\
9.4 \\
13.8 \\
18.1 \\
36.9\end{array}$ & $\begin{array}{r}12.5 \\
19.5 \\
29.5 \\
38.4 \\
119.0\end{array}$ & $\begin{array}{l}0.70 \\
0.68 \\
0.58 \\
0.56 \\
0.30\end{array}$ & $\begin{array}{l}\text { A } \\
\text { A } \\
\text { A } \\
\text { A } \\
\text { A }\end{array}$ \\
\hline $\begin{array}{l}\text { Guinea } \\
\text { Pig } \\
0.45 \mathrm{~kg} .\end{array}$ & $\begin{array}{r}1 \\
1 \\
1 \\
1 \\
1 \\
5 \\
5 \\
10 \\
1 \\
1\end{array}$ & $\begin{array}{r}7.0 \\
8.0 \\
9.0 \\
10.0 \\
16.5 \\
18.4 \\
18.5 \\
18.5 \\
27.7 \\
33.7\end{array}$ & $\begin{array}{l}13.0 \\
14.5 \\
16.5 \\
20.5 \\
37.3 \\
36.0 \\
43.0 \\
46.3 \\
70.0 \\
86.5\end{array}$ & $\begin{array}{l}1.60 \\
1.50 \\
1.40 \\
1.30 \\
0.90 \\
0.85 \\
0.97 \\
0.75 \\
1.10 \\
0.65\end{array}$ & $\begin{array}{l}E \\
E \\
E \\
E \\
E \\
C \\
A \\
D \\
E \\
E\end{array}$ \\
\hline $\begin{array}{l}\text { Rabbit } \\
1.8 \mathrm{~kg} .\end{array}$ & 2 & 20.0 & 57.0 & 1.04 & A \\
\hline $\begin{array}{l}\text { Rhesus } \\
\text { Monkey } \\
3.9 \mathrm{~kg} .\end{array}$ & 2 & 58.0 & 156.0 & 0.90 & $B$ \\
\hline $\begin{array}{l}\text { Dog } \\
12.8 \mathrm{~kg} .\end{array}$ & $\begin{array}{l}2 \\
2 \\
2\end{array}$ & $\begin{array}{l}47.6 \\
48.6 \\
57.0\end{array}$ & $\begin{array}{l}140.0 \\
224.0 \\
258.0\end{array}$ & $\begin{array}{l}1.25 \\
1.38 \\
i .02\end{array}$ & $\begin{array}{l}\text { A } \\
\text { A } \\
\text { A }\end{array}$ \\
\hline
\end{tabular}

* That is, the reflected overpressure for Arrangements $A, B$, and $C$, and the incident overpressure for Arrangements $D$ and $E$.

* Time was measured from the point where the recorded intrathoracic pressure first began to rise.

NOTE: Average figures reported when more than one animal involved.

EXPERIMEN'TAL ARRANGEMENTS

A

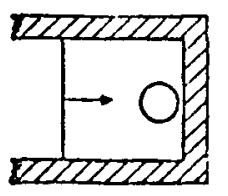

B

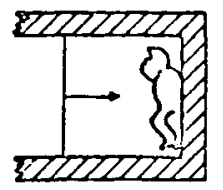

$\mathrm{C}$

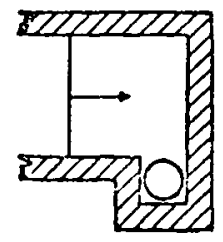

D

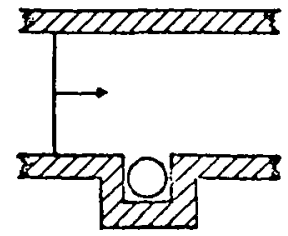

$E$

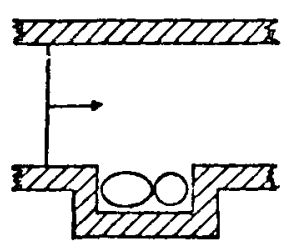

Data from Richmond and colleagues (Reference 88 ) as used by Fletcher (Reference 59). 
TABLE 4

INCIDENCE OF RENAL AND MYOCARDIAL INFARCTS IN SHEEP

EXPOSED TO A "LONG-DURATION, " "SQUARE-WAVE" PRESSURE

PULSE IN A SHOCK TUBE

\begin{tabular}{|c|c|c|c|c|c|c|}
\hline \multirow{2}{*}{$\begin{array}{l}\text { Over- } \\
\text { pressure, } \\
\text { p.s.i. }\end{array}$} & \multirow{2}{*}{$\begin{array}{l}\text { Number } \\
\text { of } \\
\text { Animals } \\
\text { Exposed }\end{array}$} & \multirow{2}{*}{$\begin{array}{l}\text { Percent } \\
\text { Mortality }\end{array}$} & \multicolumn{2}{|c|}{ Myocardial Infarcts } & \multicolumn{2}{|c|}{ Renal Infarcts } \\
\hline & & & $\begin{array}{l}\text { Early } \\
\text { Deaths }\end{array}$ & $\begin{array}{c}\text { 60-Day } \\
\text { Survivors }\end{array}$ & $\begin{array}{l}\text { Early } \\
\text { Deaths }\end{array}$ & $\begin{array}{l}\text { 60-Day } \\
\text { Survivors }\end{array}$ \\
\hline 47.2 & 5 & 20 & $0 / 1$ & $0 / 4$ & $0 / 1$ & $4 / 4$ \\
\hline 49.6 & 10 & 20 & $0 / 2$ & $0 / 8$ & $1 / 2$ & $7 / 8$ \\
\hline 52 & 10 & 50 & $0 / 5$ & $2 / 5$ & $3 / 5$ & $4 / 5$ \\
\hline 54 & 10 & 70 & $0 / 7$ & $1 / 3$ & $4 / 7$ & $2 / 3$ \\
\hline 57 & 4 & 75 & $0 / 3$ & $1 / 1$ & $2 / 3$ & $1 / 1$ \\
\hline Totals & 39 & & $0 / 18$ & $4 / 21$ & $10 / 18$ & $18 / 21$ \\
\hline
\end{tabular}

Data, courtesy of Jones and Richmond (Reference 93), obtained at ambient pressure of 12.0 p.s.i. (Albuquerque, New Mexico). 


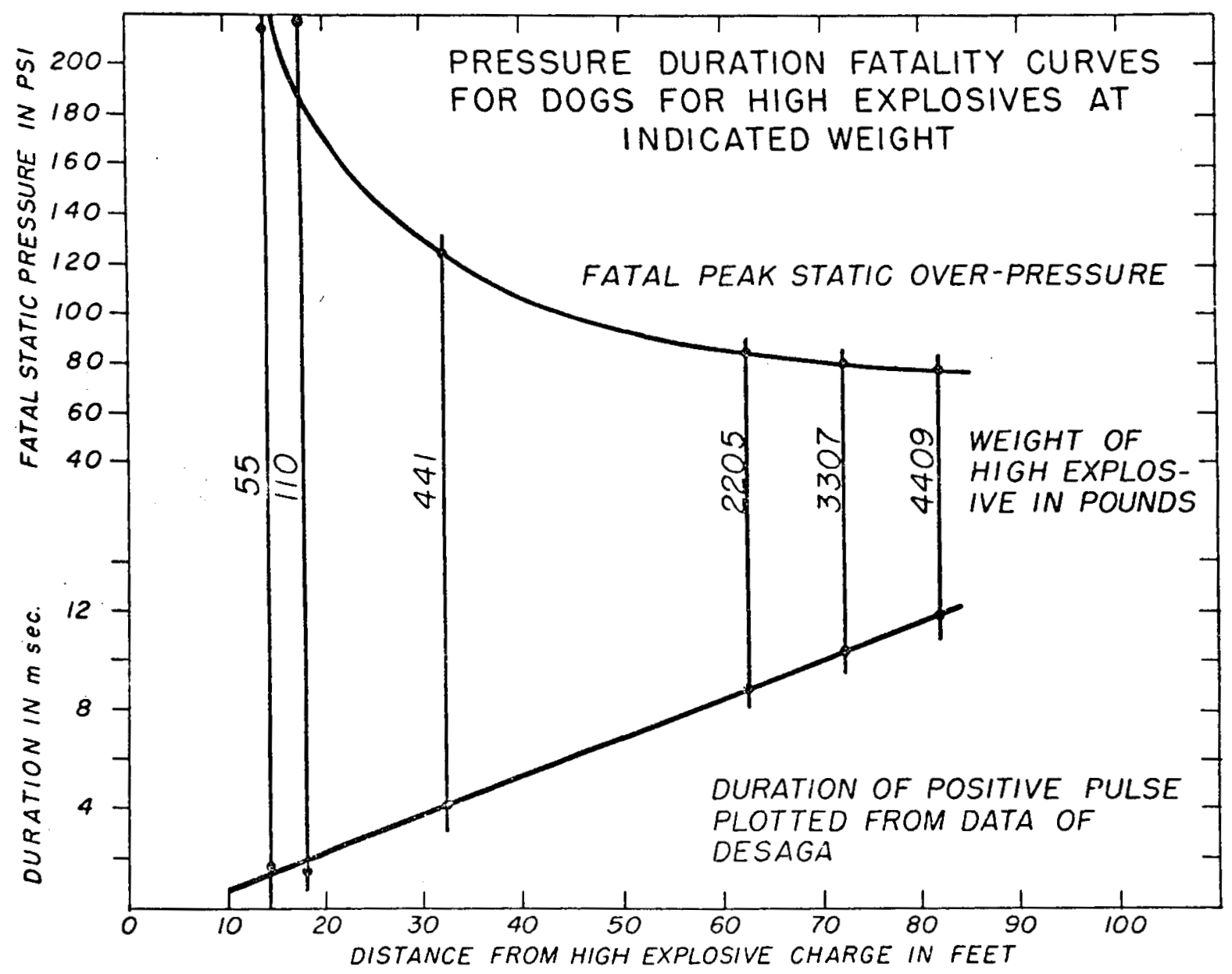

Figure 1.--Fatal overpressure-time conditions for dogs exposed to blast waves produced by high explosives. Plotted from the data of Desaga (Reference 39). 


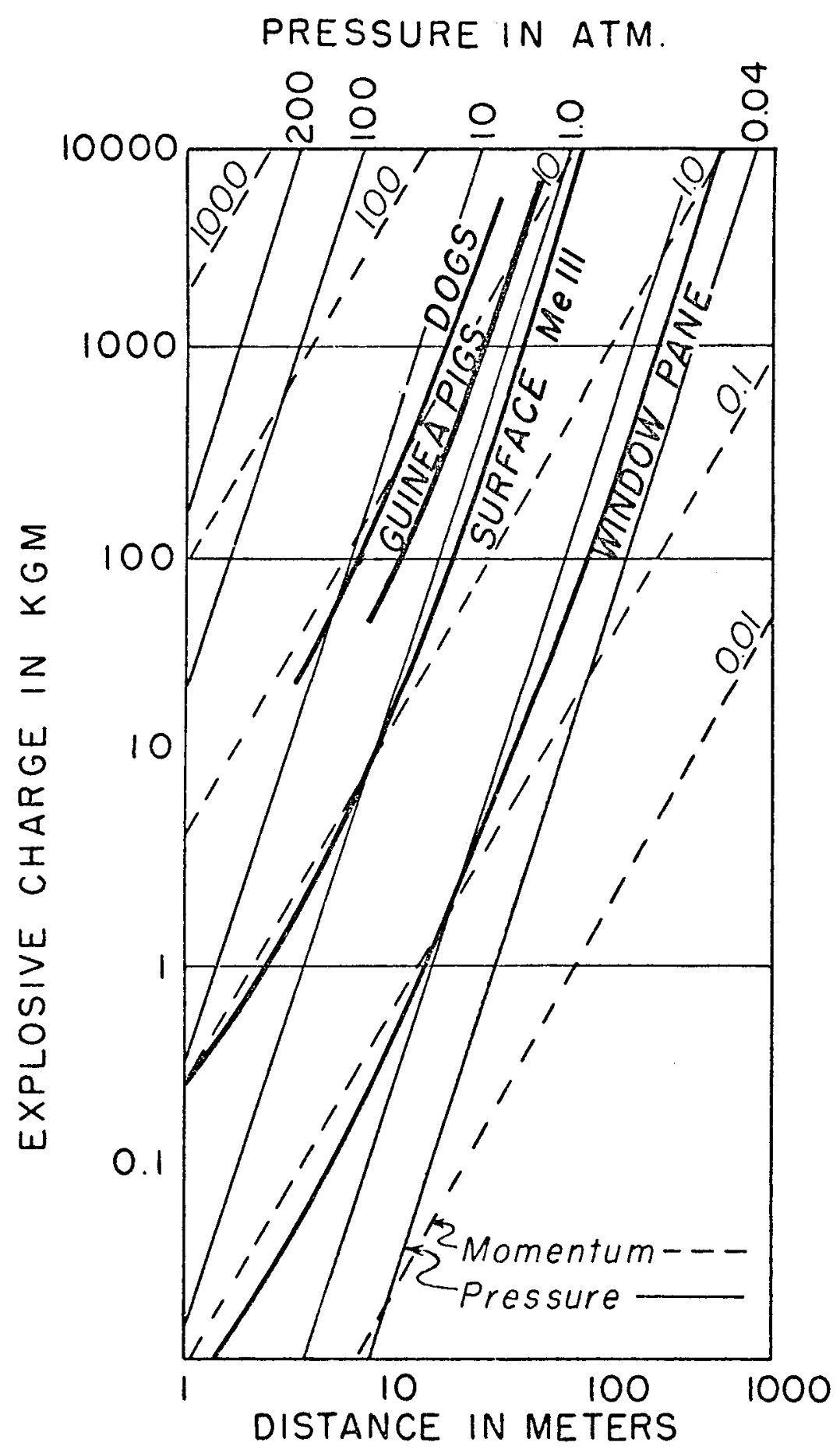

Figure 2. --Charge-distance diagram showing characteristic lines of destruction for dogs, guinea pigs, aircraft surfaces, and windowpanes. Solid and broken lines show pressure in atmospheres and momentum in atmosphere-milliseconds, respectively. Modified from Schardin (Reference 42). 


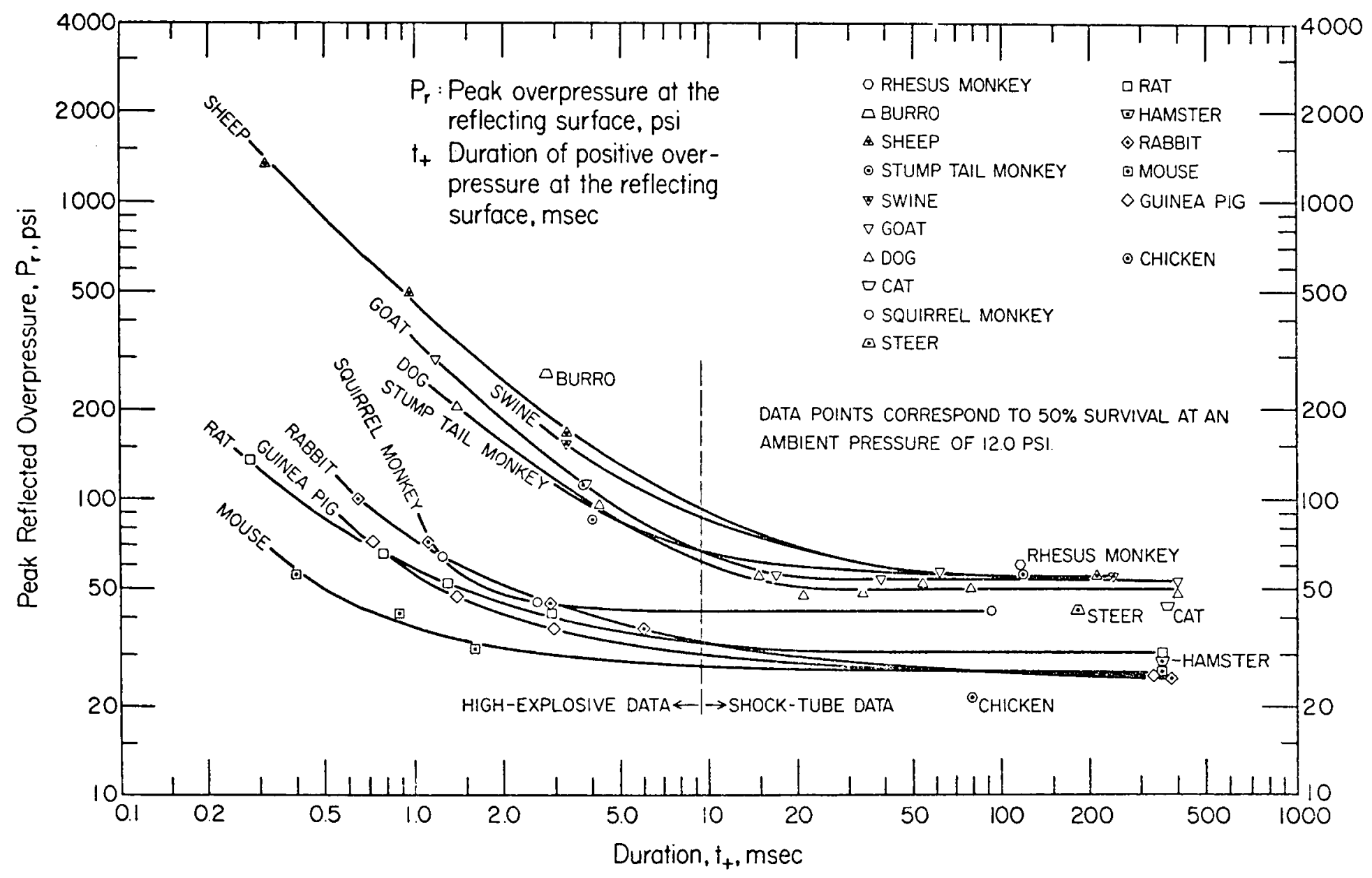

Figure 3.--Pressure-duration curves for 50-percent, 24-hour survival when exposure involves "sharp-rising" overpressure. From Fletcher (Reference 59). 


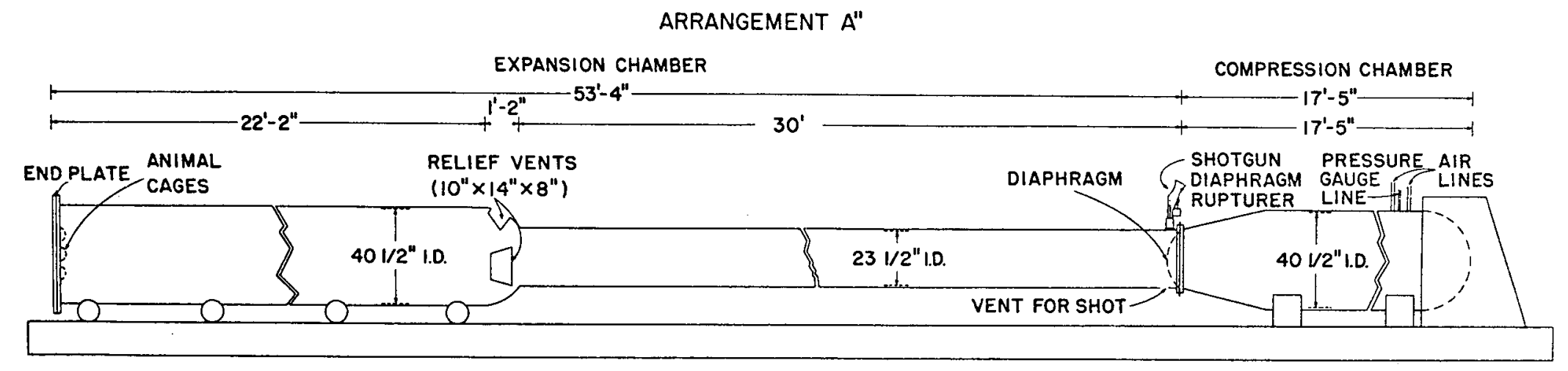

Figure 4. --The geometry and dimensions of one of the shock tubes used by Richmond and colleagues (Reference 60). 


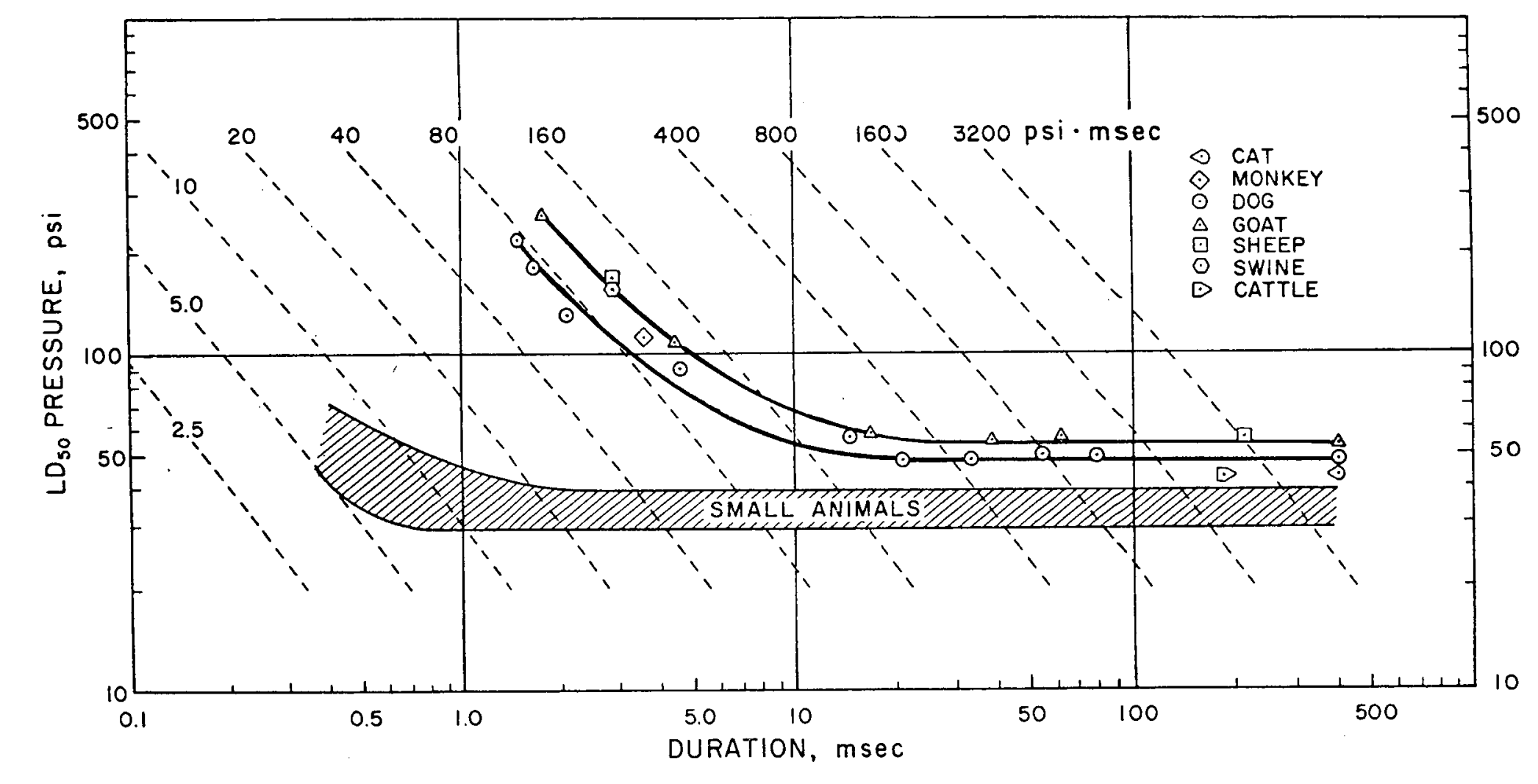

Figure 5. --The pressure-duration relationship and lethality at 24 hours for large and small animals (mice, rats, hamsters, guinea pigs, and rabbits). All measurements were made at an ambient pressure of 12 p.s.i. After Richmond et al. (Reference 52). 

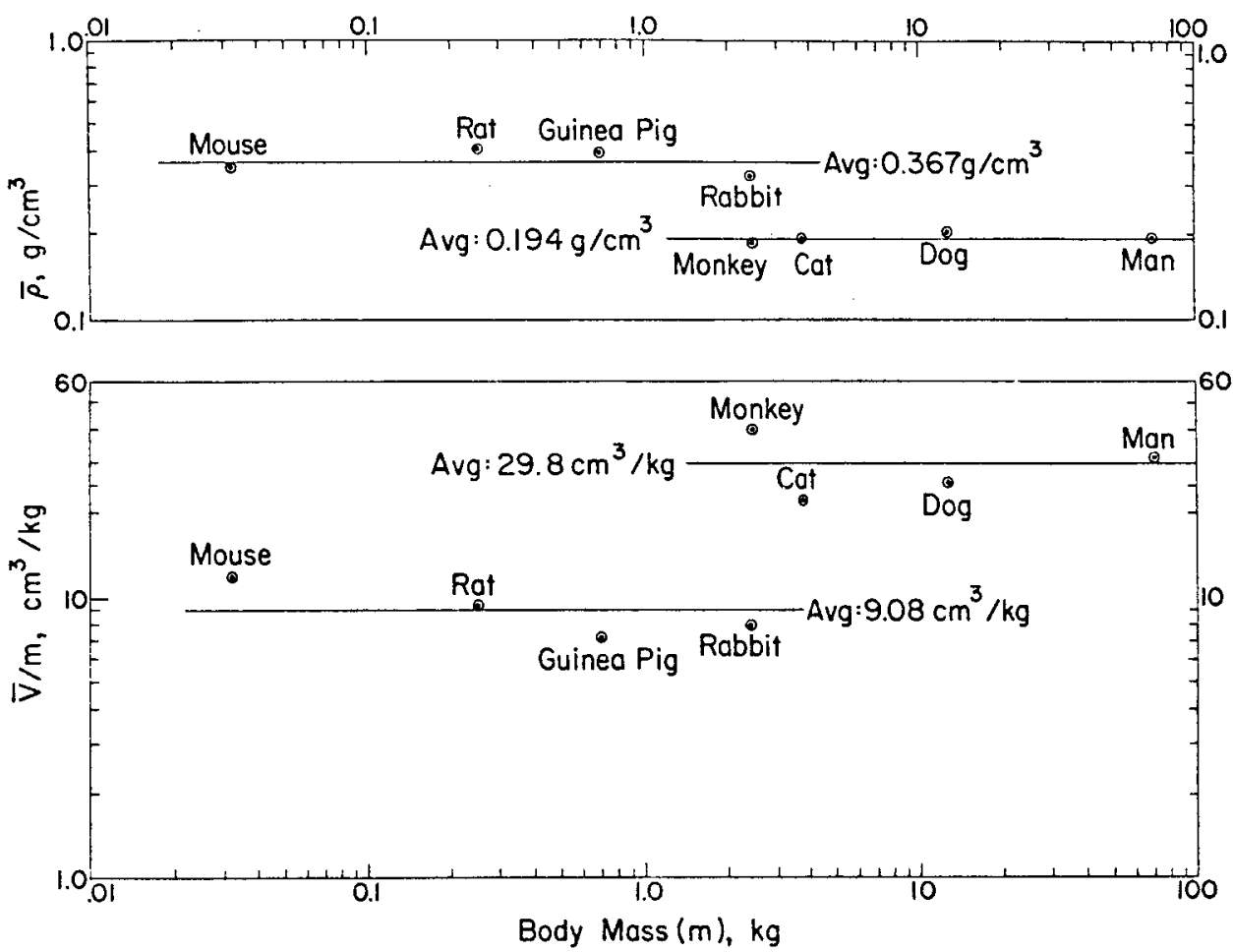

$$
\begin{array}{lll}
\bar{V} / m=(F R C+1 / 2 T V) / m & \bar{\rho}=M /(\bar{V}+v) \\
\bar{V}: \text { Avg gaseous volume of lungs } & \bar{\rho}: \text { Avg density of lungs } \\
m: \text { Body mass } & v: \text { Volume of lung tissue } \\
\text { FRC : Functional residual capacity } & \text { * Density of lung tissue assumed to } \\
T V: \text { Tidal volume } & \text { be } 1.0 \mathrm{~g} / \mathrm{cm}^{3} \\
M: \text { Mass of lungs } &
\end{array}
$$

Figure 6. --Average lung volume per body mass and average lung density as functions of body mass for 8 species of mammals. Data from Crosfill and Widdicombe (Reference 63). After Bowen et al. (Reference 49). 


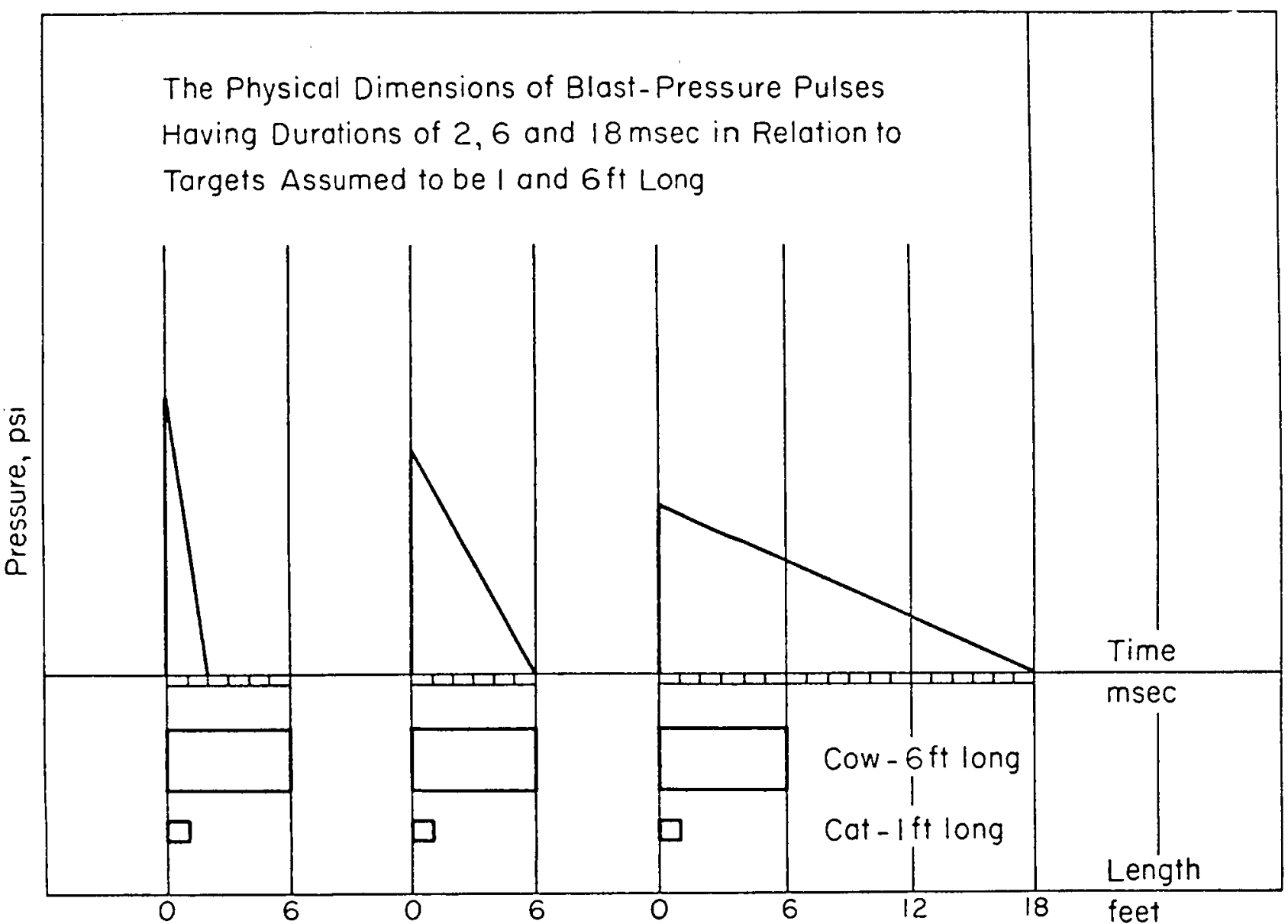


Lethality Curves for "Larger" and "Smaller" Animals

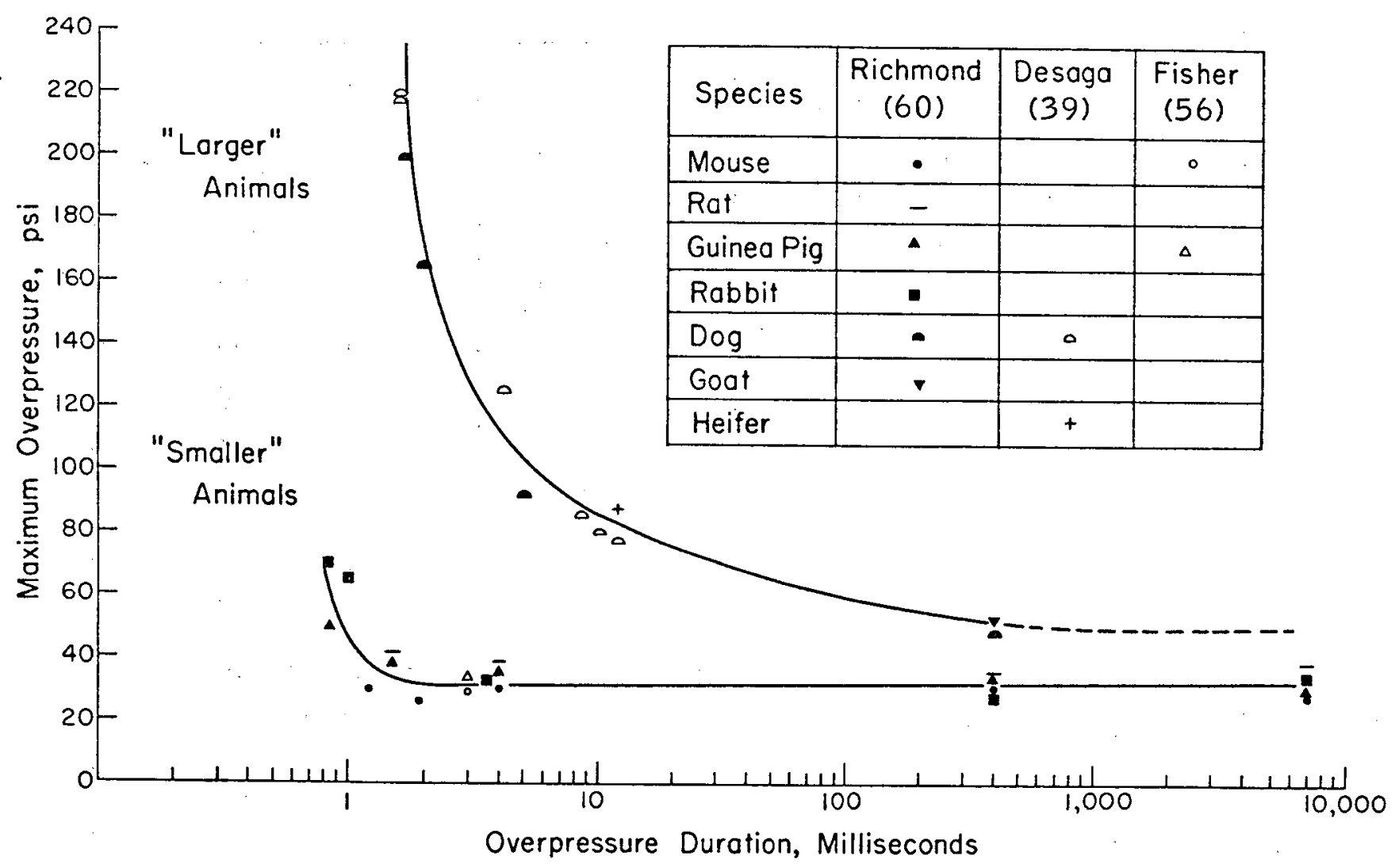

Figure 8. --Fifty-percent, twenty-four-hour survival curves for larger and smaller animals. Modified from Richmond et al. (Reference 60). 


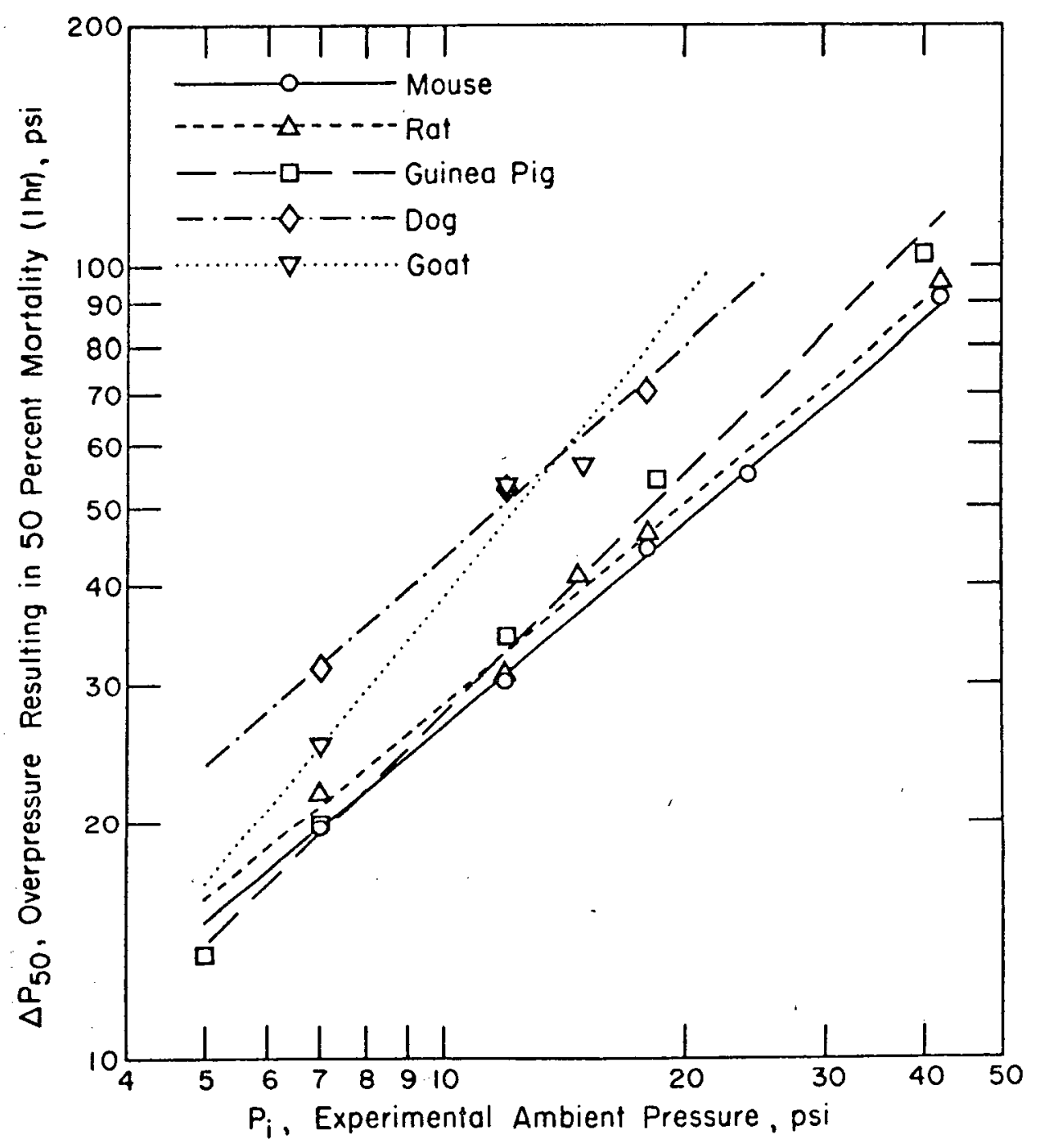

Figure 9.--Relation of the 50-percent, 1-hour survival pressure to experimental ambient pressure for 5 species of mammals. After Damon et al. (Reference 67). 


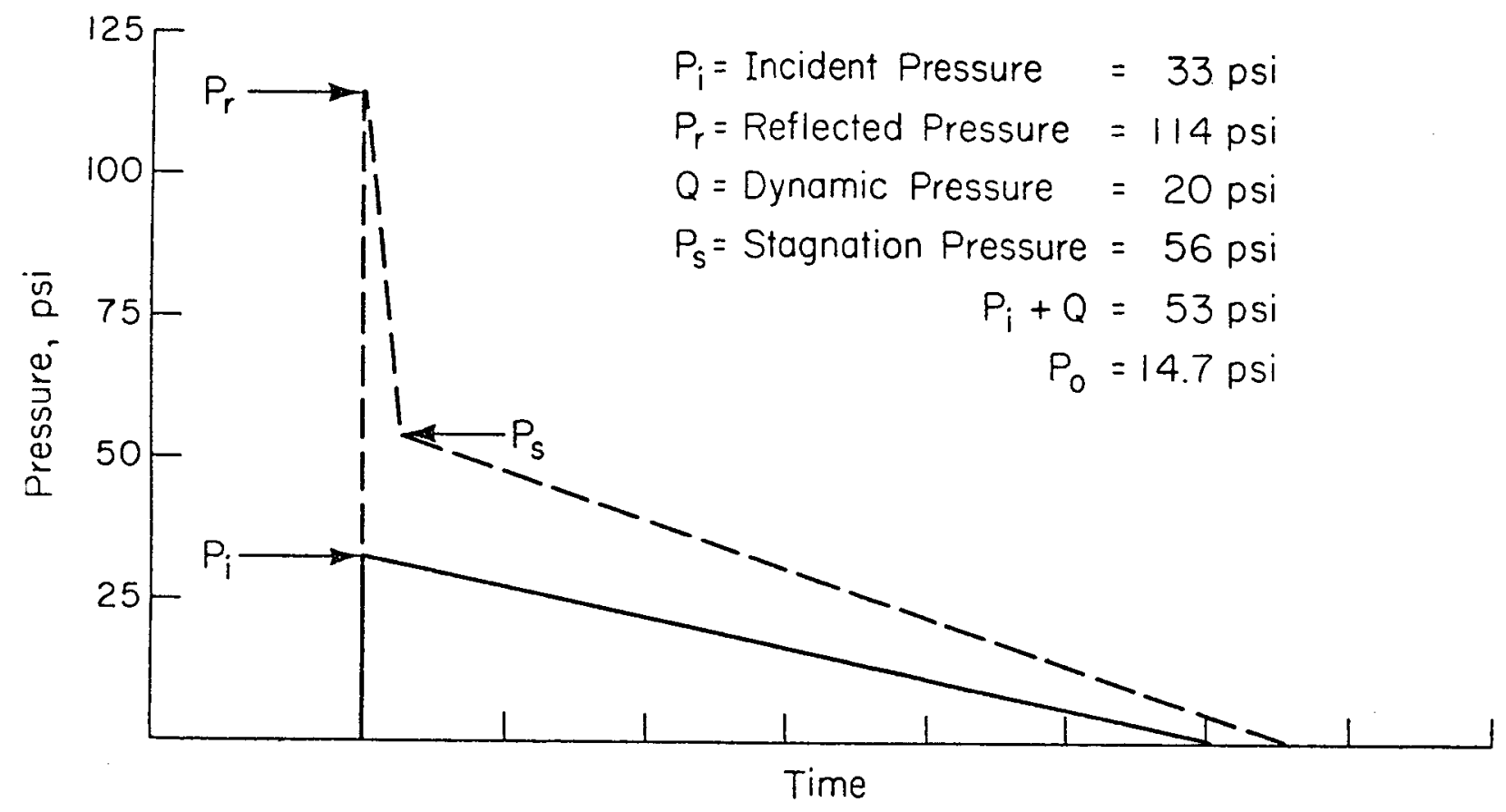

Figure 10.--The relations between the incident, reflected, dynamic, and stagnation pressures. Modified from White and Richmond (Reference 68). 


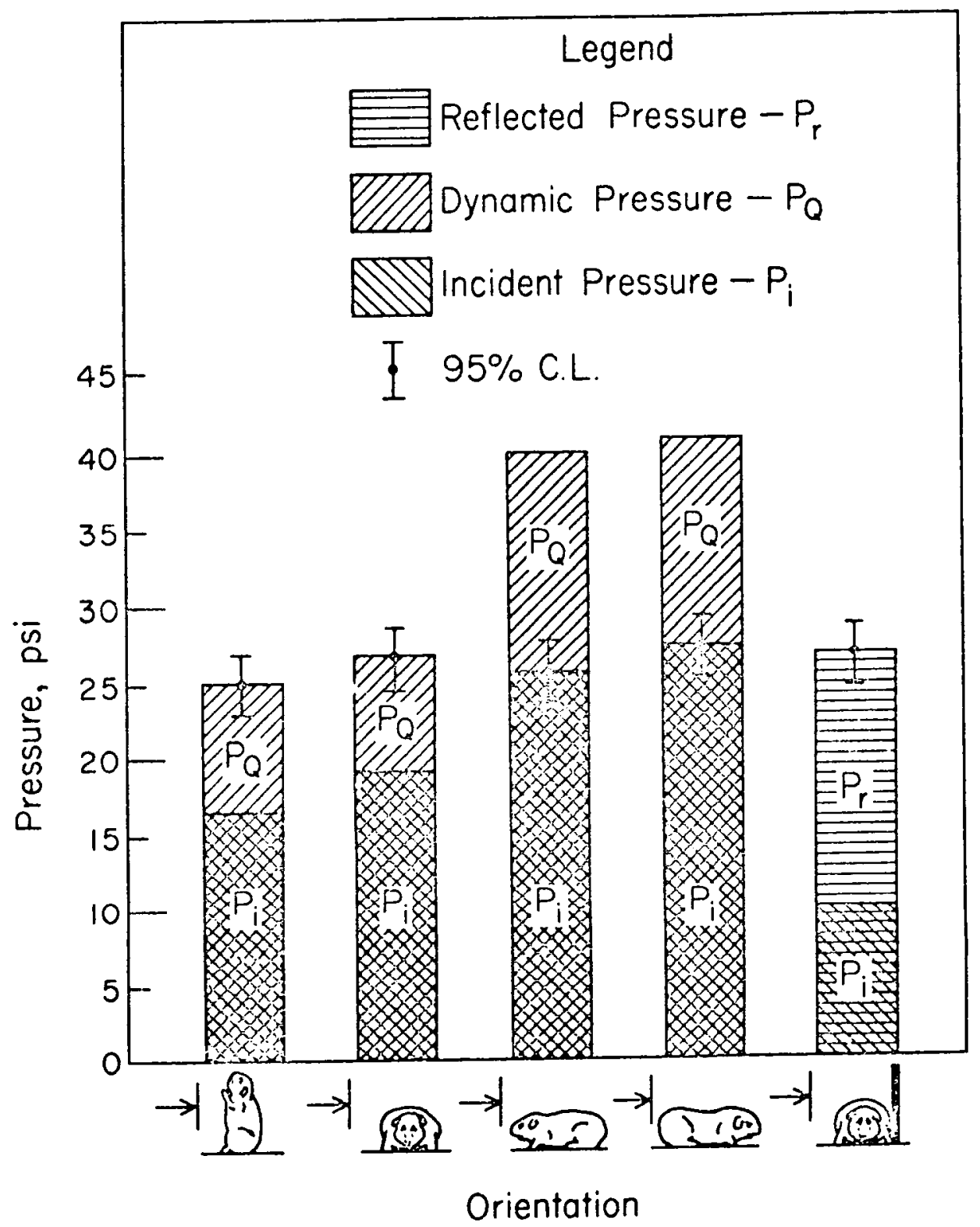

Figure 11. --LD50 conditions, assessed at 24 hours, for guinea pigs in various orientations. All measurements were made at an ambient pressure of 12 p.s.i. Modified from Richmond et al. (References 52 and 69). 


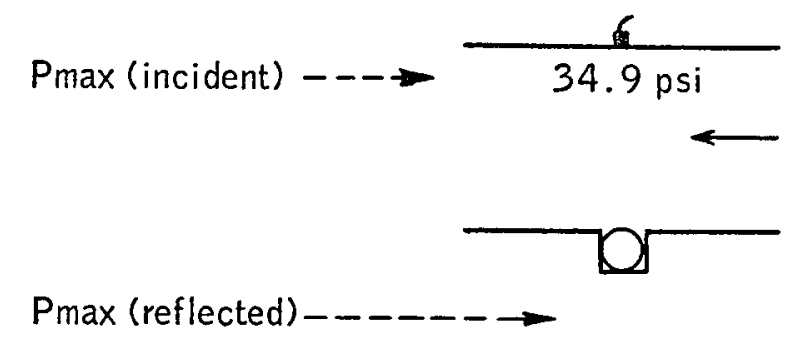

$P \max ($ reflected) $-\ldots$
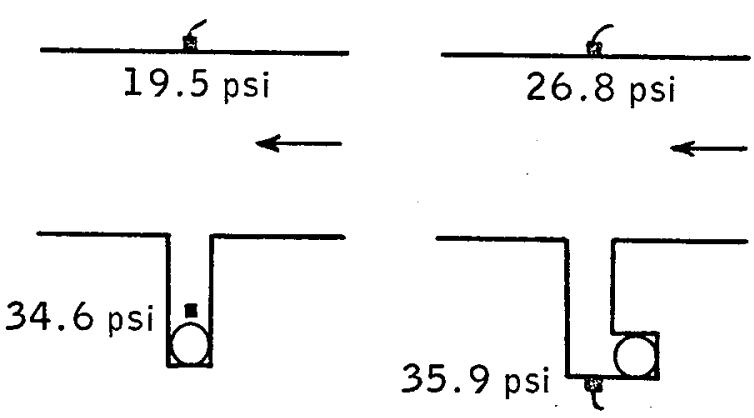

1 Pressure transducers

—_ Direction of travel of incident shock pressure

Location of guinea pigs

Figure 12. --Maximal incident and reflected overpressures associated with 50 -percent lethality over 24 hours in guinea pigs as a function of exposure geometry. From Richmond et al.

(Reference 70) and White et al. (Reference 4). 

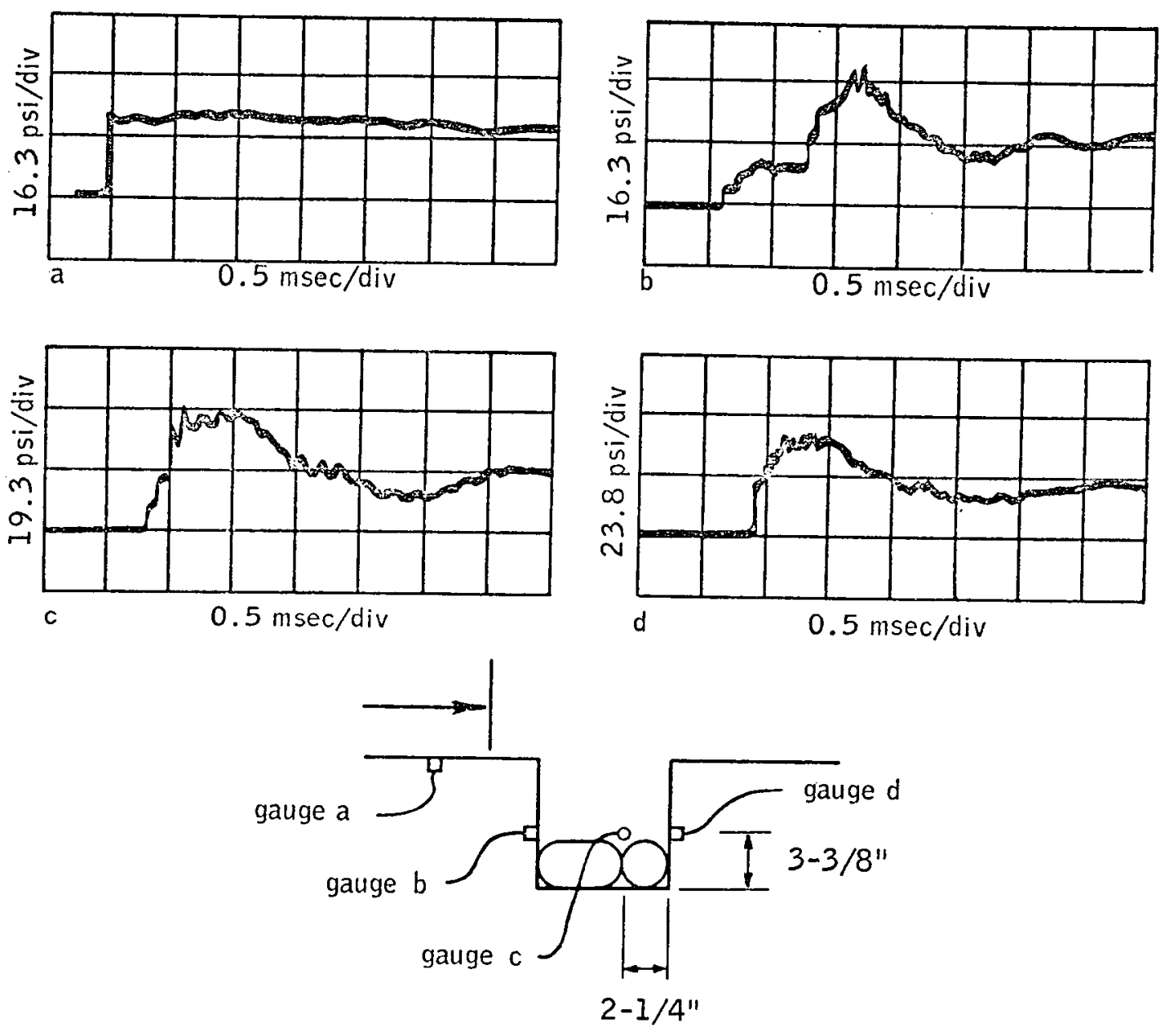

Figure 13. --Pressure-time records associated with the deep chamber. From Richmond et al. (Reference 70). 

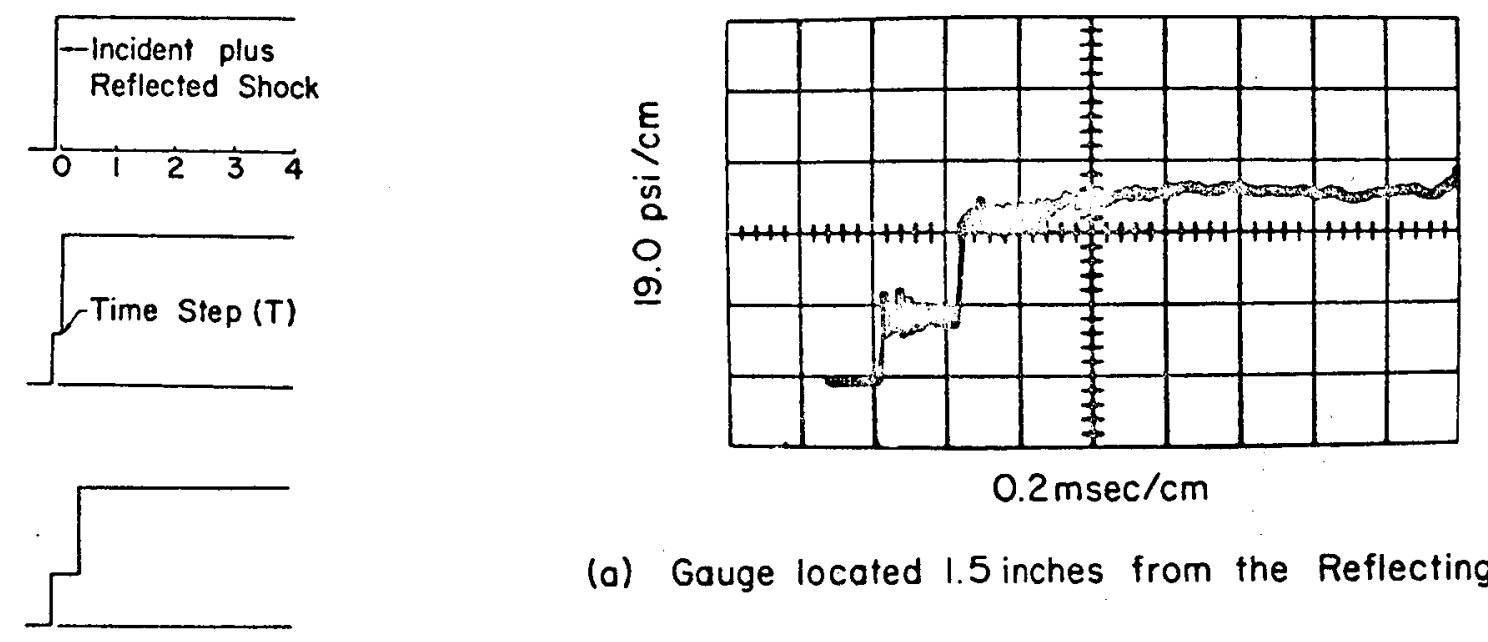

(a) Gauge located 1.5 inches from the Reflecting Plate
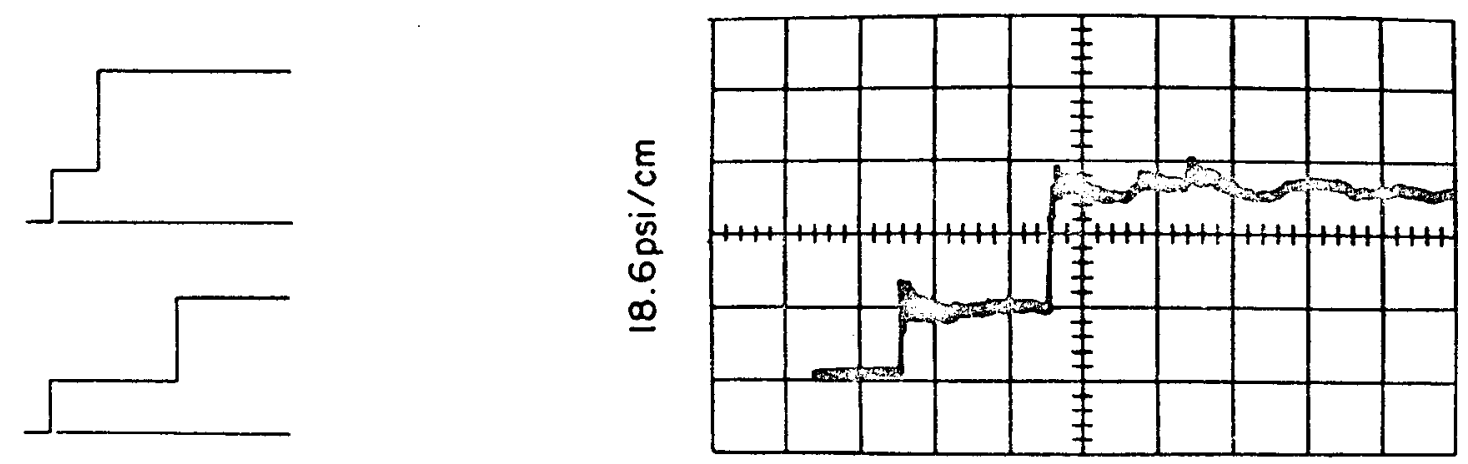

Time, msec

(b) Gauge located 7.5 inches from the Reflecting Plate

Figure 14. --Wave forms illustrating almost instantaneous and stepwise increases in overpressure. Modified from Clare et al. (Reference 71). After White et al. (Reference 4). 


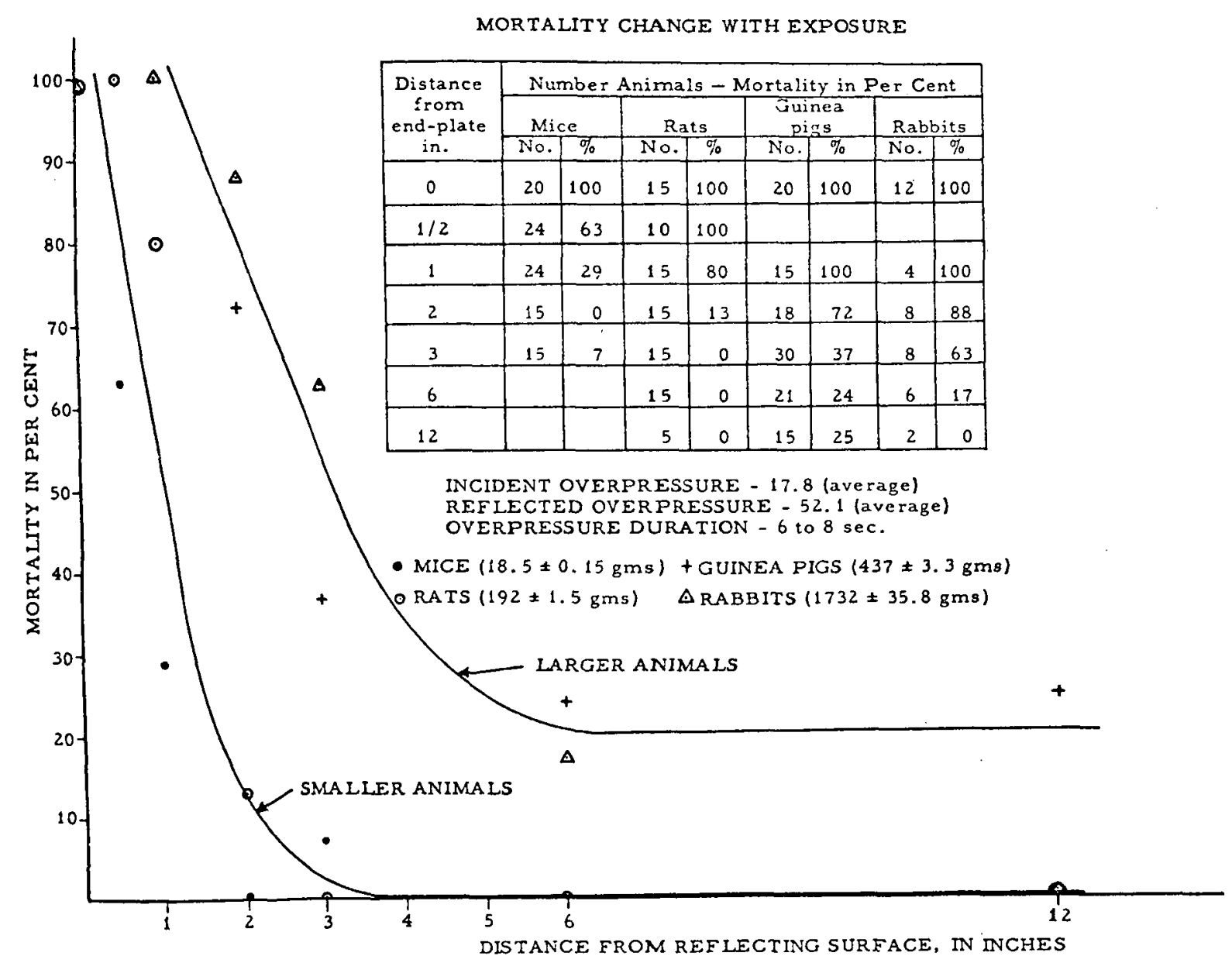

Figure 15. --Mortality variations for animals exposed against or at the indicated distances from the end plate closing a shock tube. Incident and reflected overpressures varied from 16.6 to 18.7 and 48 to 55 p.s.i., respectively, and endured for 6 to 8 seconds. Data from Richmond et al. (Reference 72). After White et al. (Reference 4). 

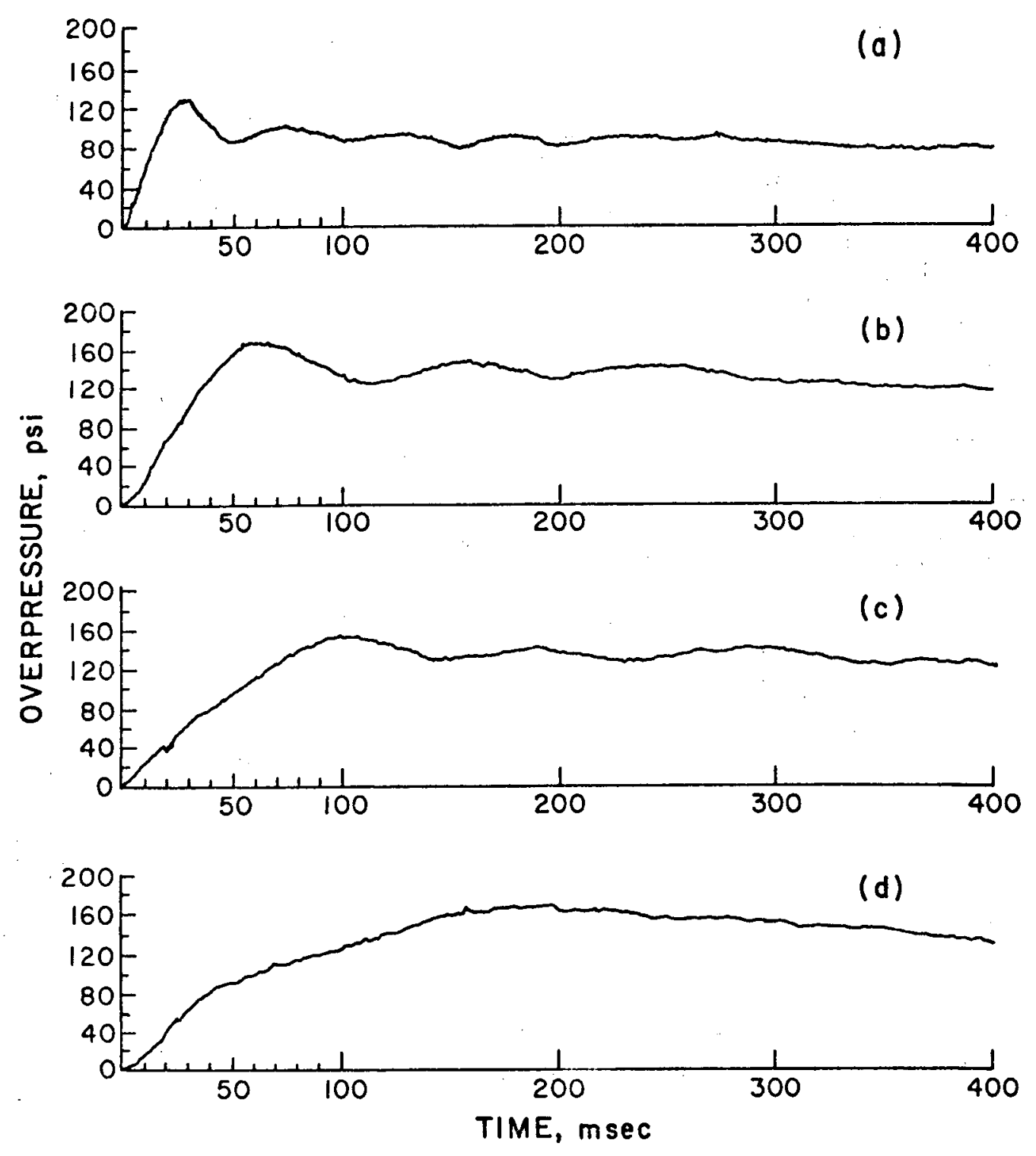

Figure 16. --"Slow-rising, " pressure-time patterns with various rates of rise. Recordings made at an ambient pressure of 12 p.s.i. After Richmond et al. (Reference 73). 


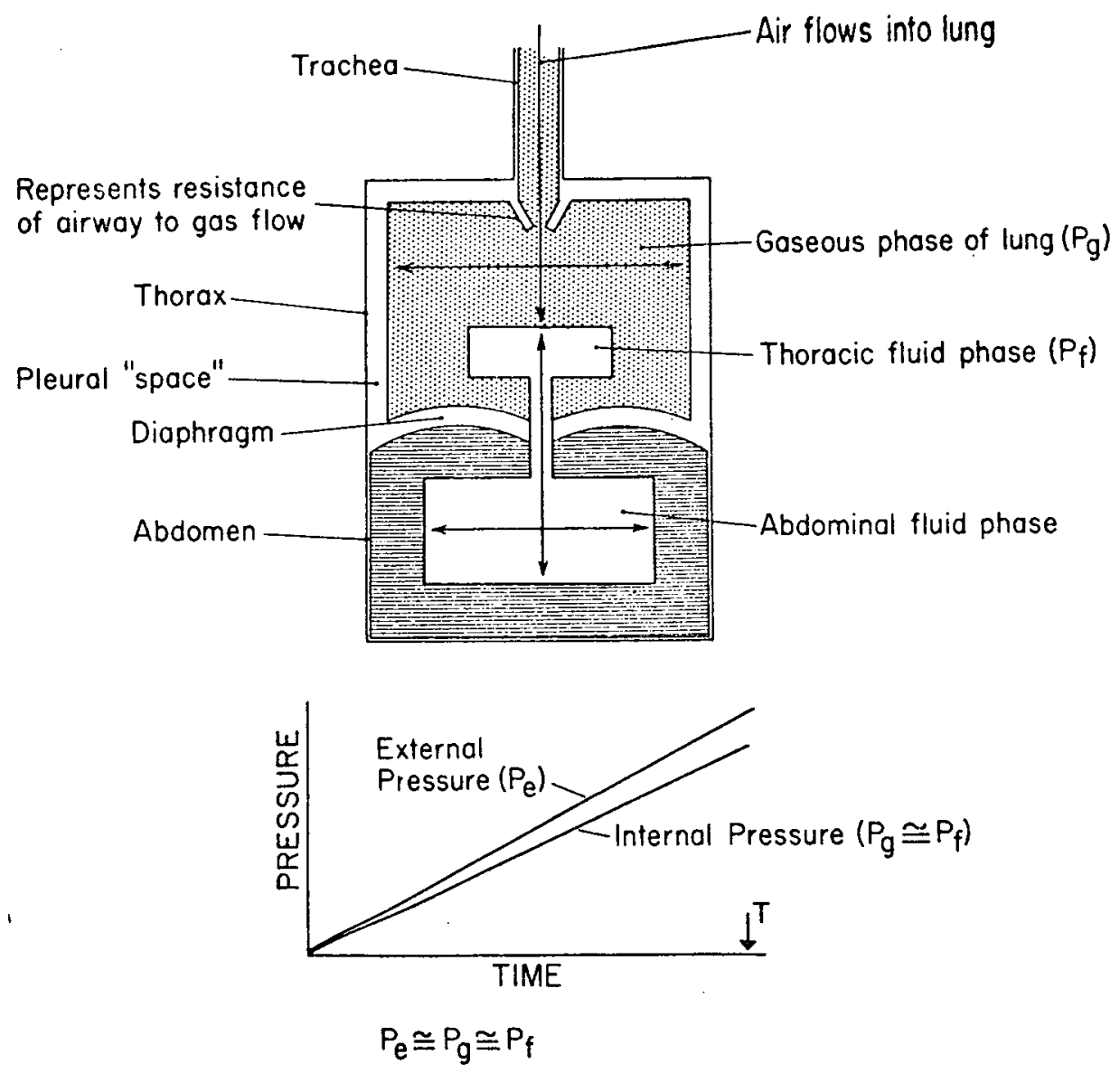

Figure 17. --Diagram of model response to "very slowly" rising overpressures. From White and Richmond (References 21 and 22). 


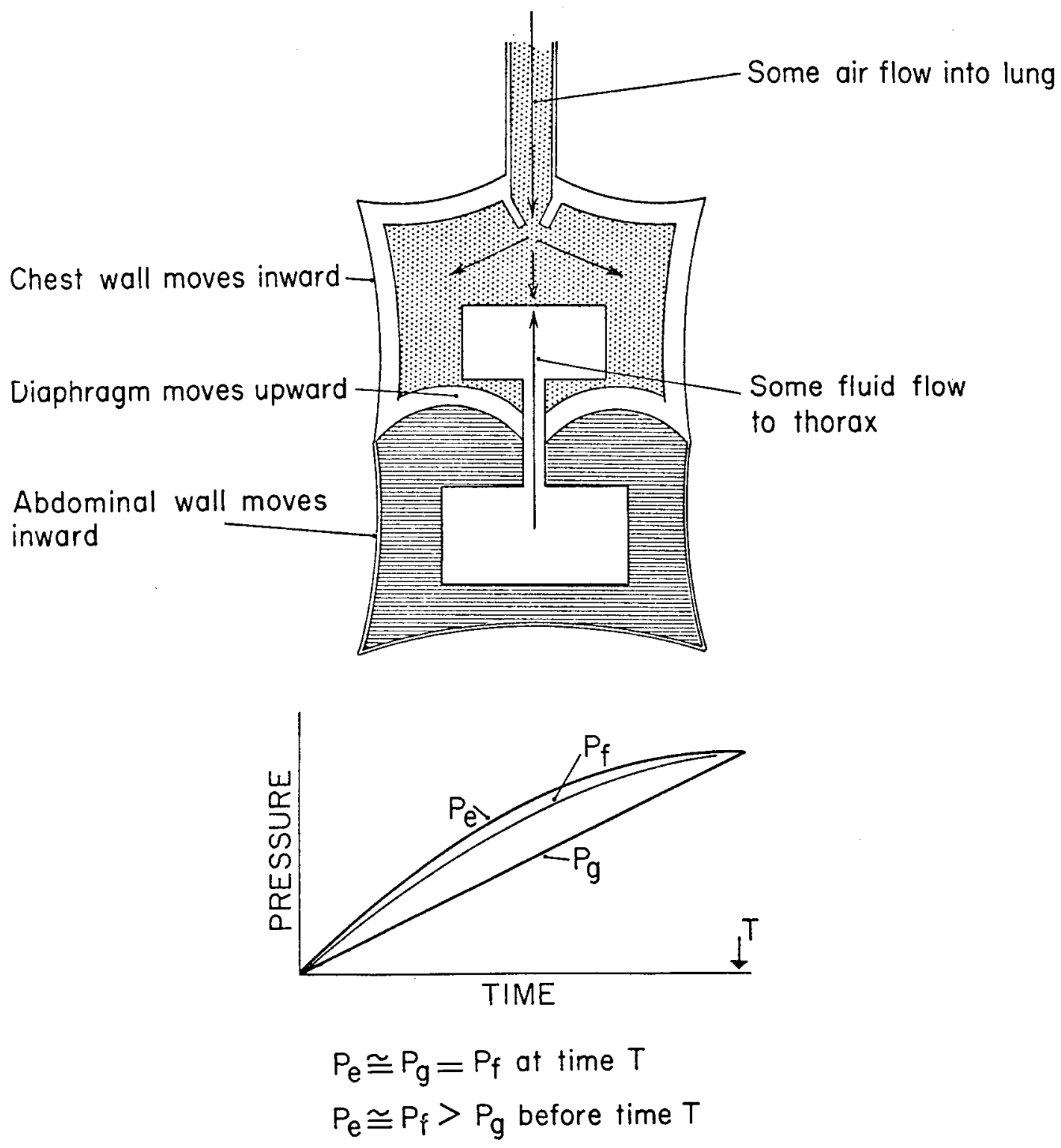

Figure 18. --Diagram of model response to "slowly" rising overpressures to which "protective" response is effective. From White and Richmond (References 21 and 22). 


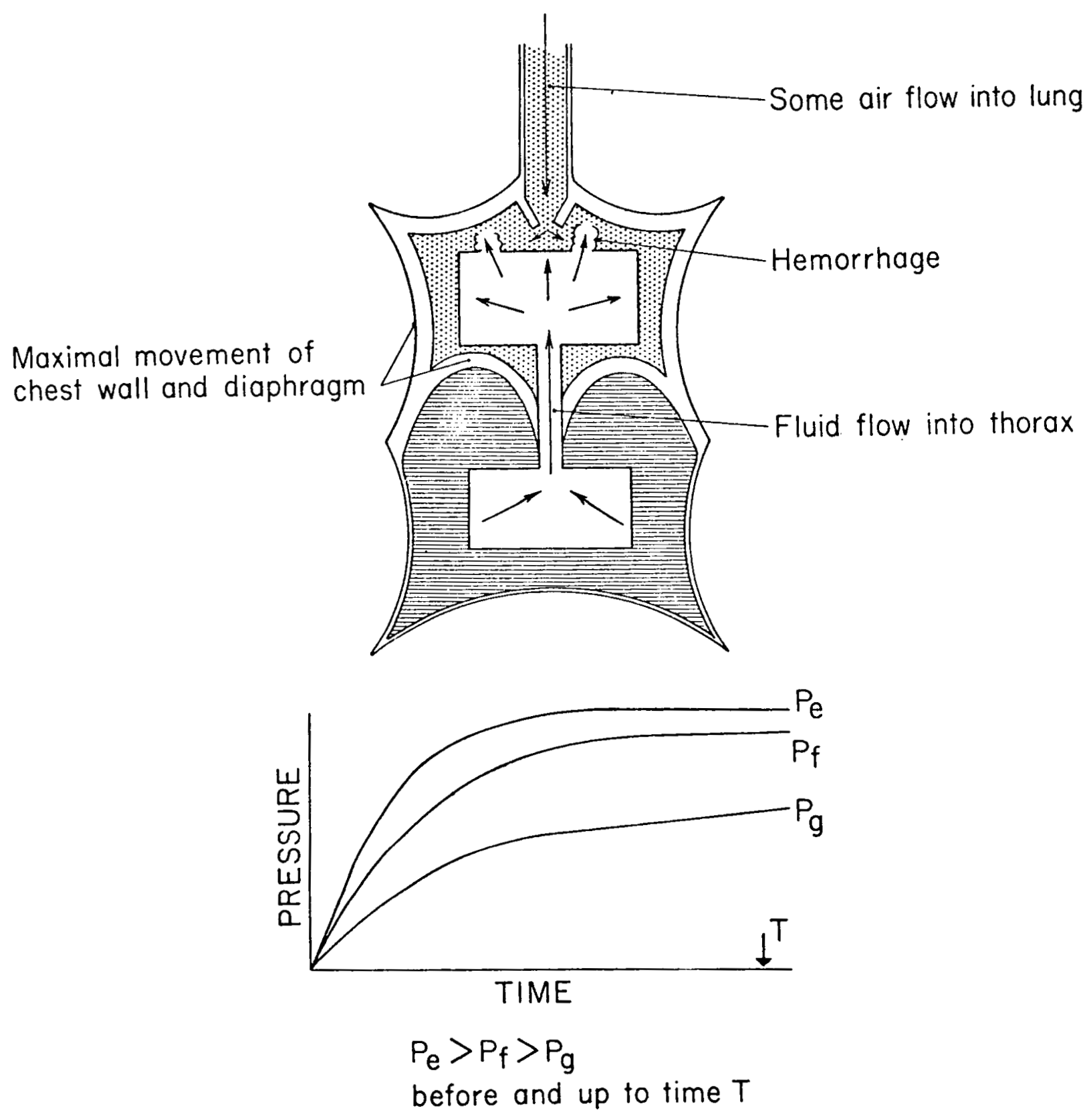

Figure 19. --Diagram of model response to "moderately rapid-rising" overpressures to which "protective" response is inadequate. From White and Richmond (References 21 and 22). 


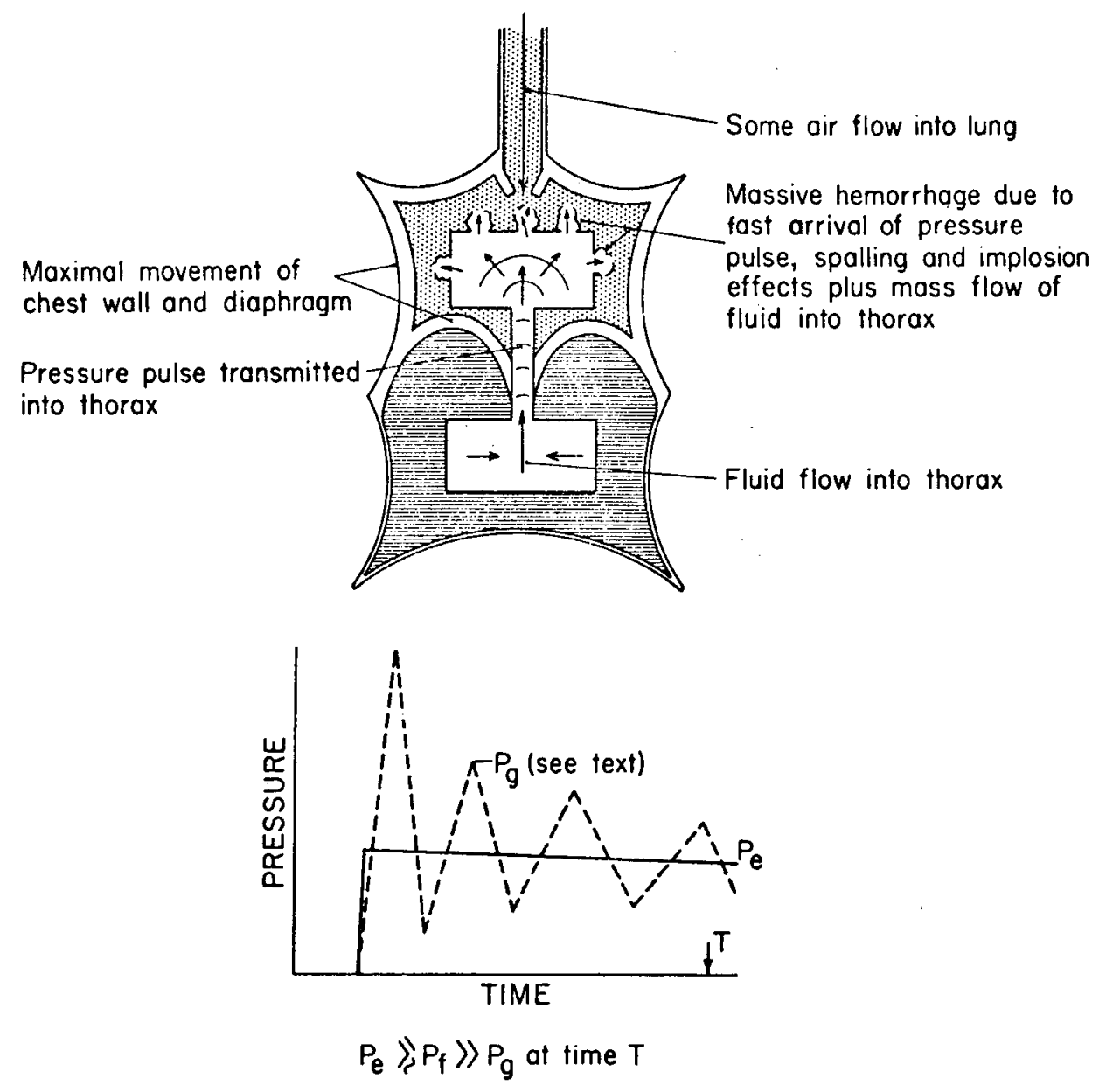

Figure 20.--Diagram of model response to "fast-rising" overpressures of "long" duration. The dotted line represents possible oscillations in the pressure of the gaseous phase of the lung. Modified from White and Richmond (References 21 and 22). 


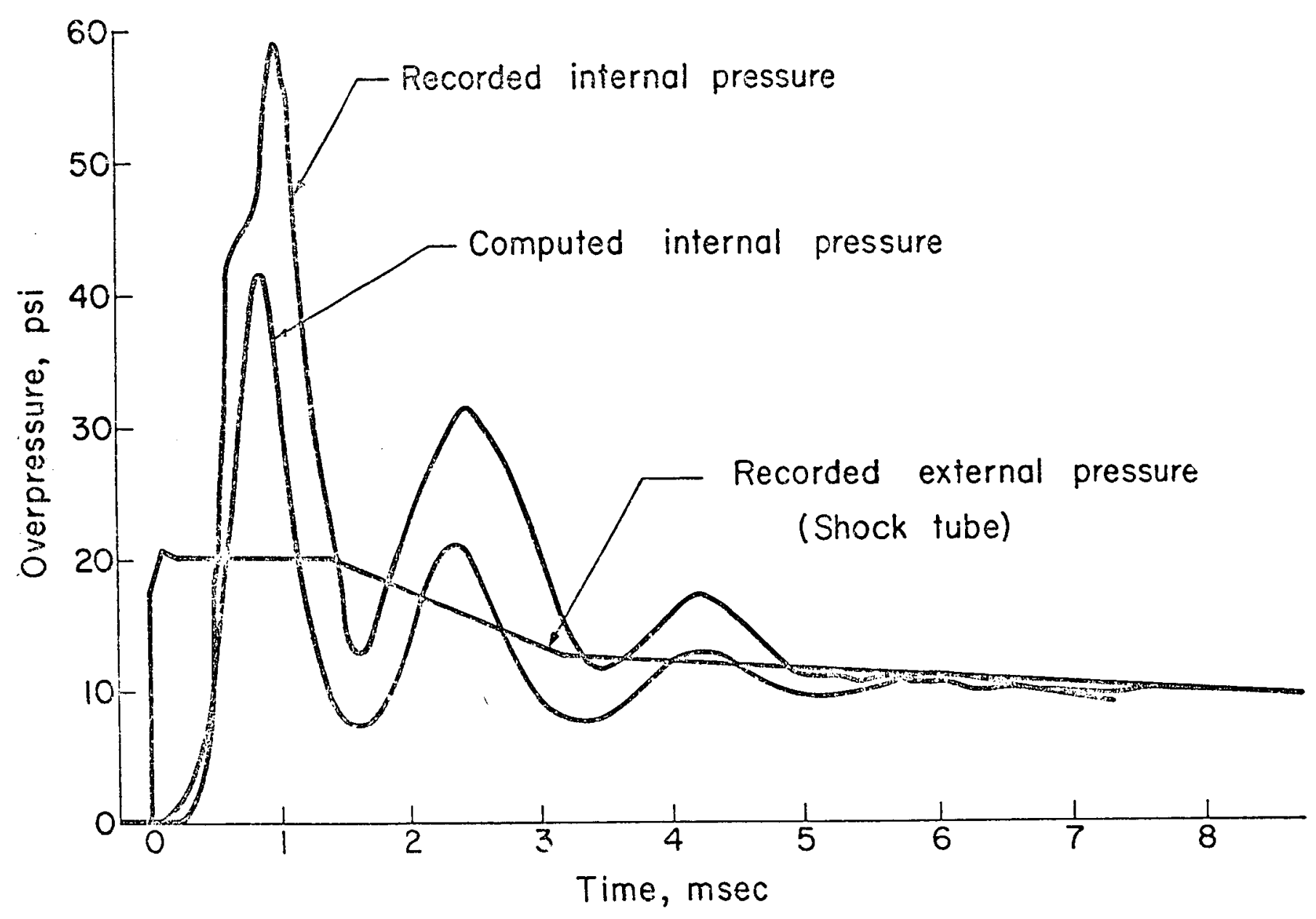

Figure 21. --Comparison of computed and recorded internal pressure-time curves for a rabbit exposed in a shock tube to a $20-$ p. s.i., "long-duration" pressure pulse: The internal transducer was located in the esophagus near the level of the heart. After White et al. (Reference 83). 


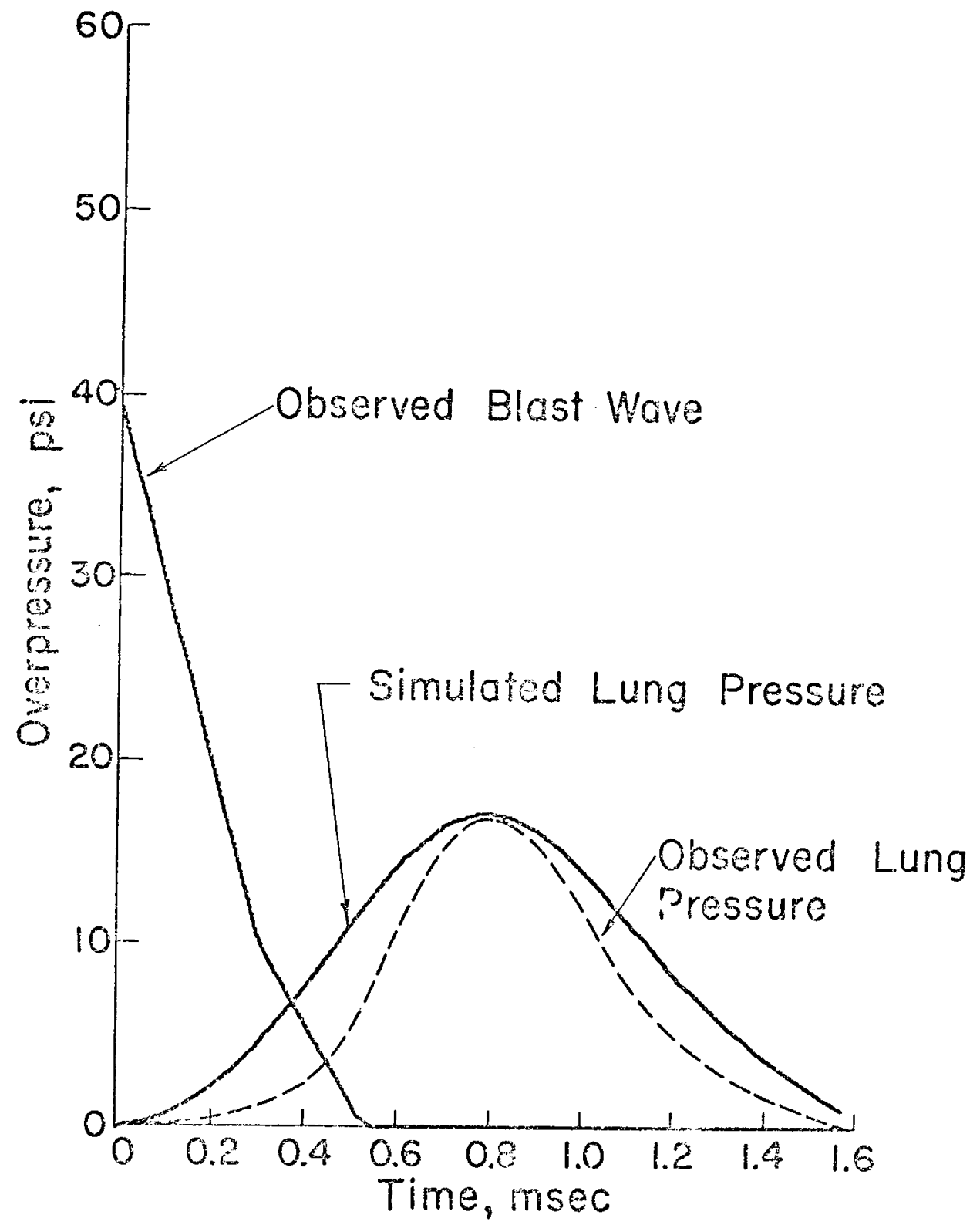

Figure 22, - - The intrathoracic pressure-time response elicited in a rabbit by a "short-duration" blast wave. Observed data from Clemedson and Jönsson (Reference 86). Simulated lung-pressure curve after Holladay and Bowen (Reference $82)$. 
A. Alternating Accelerative and Decelerative Loading of the Thoracic Wall and Diaphragm

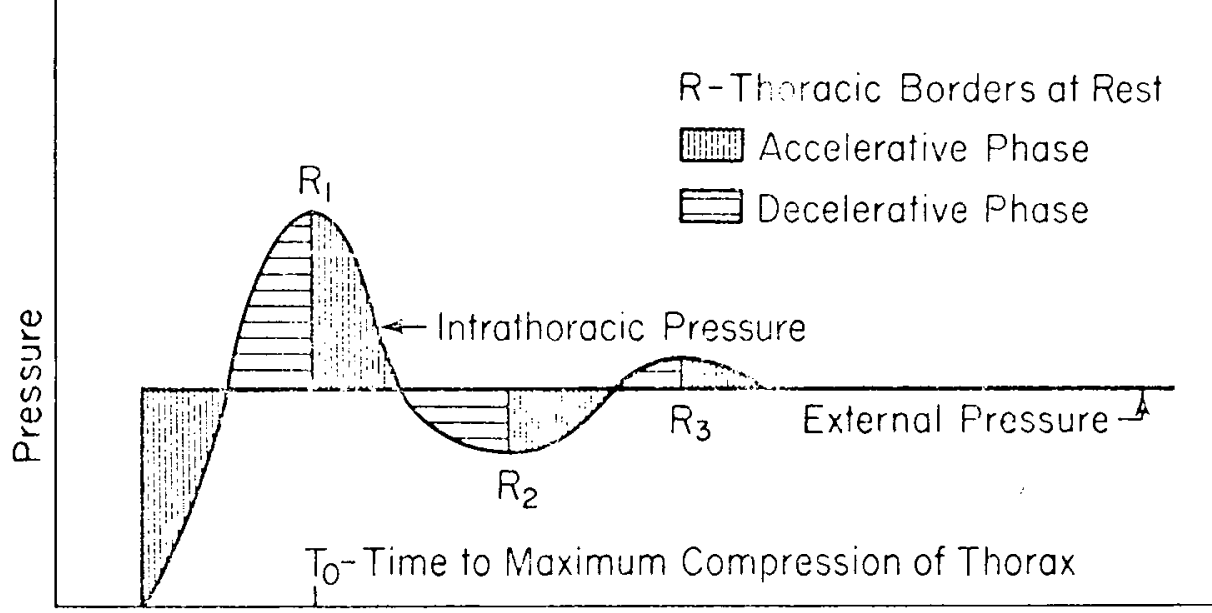

Time

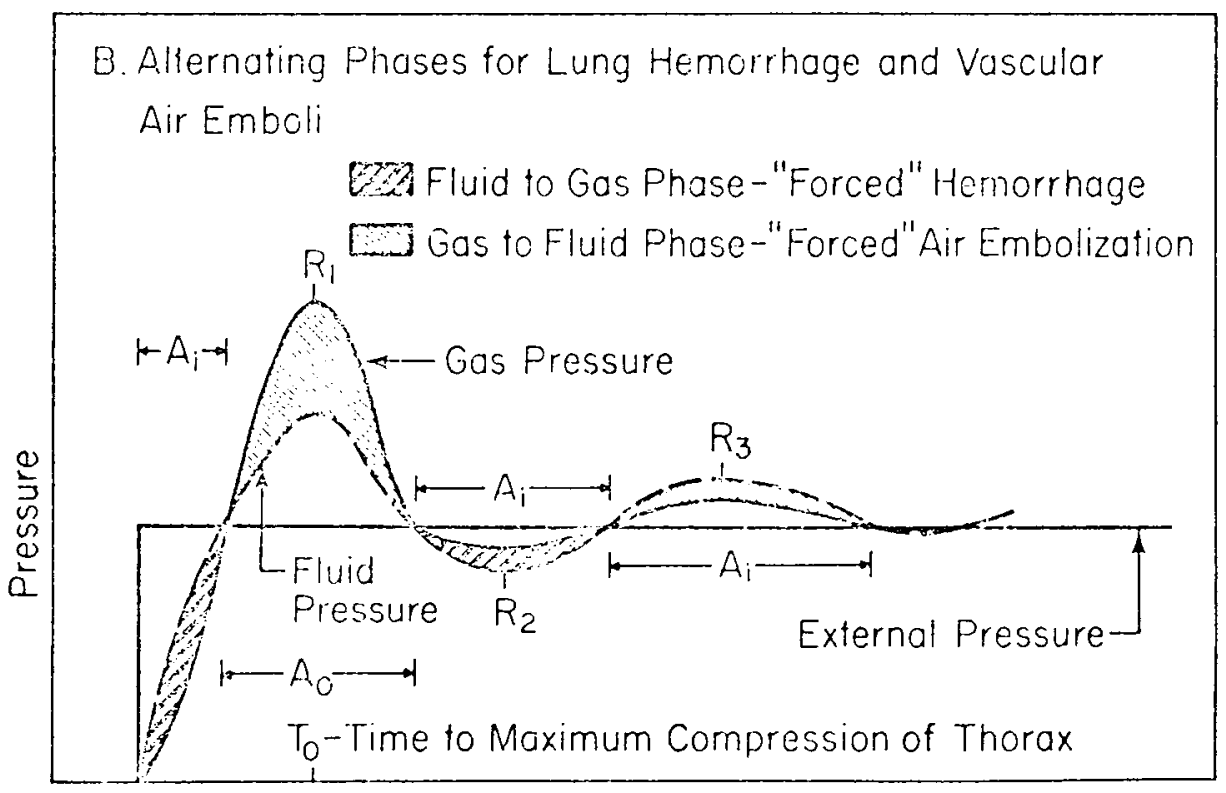

Time

Figure 23. --Pressure-time relationships between external pressure and the internal gas and fluid pressures. 


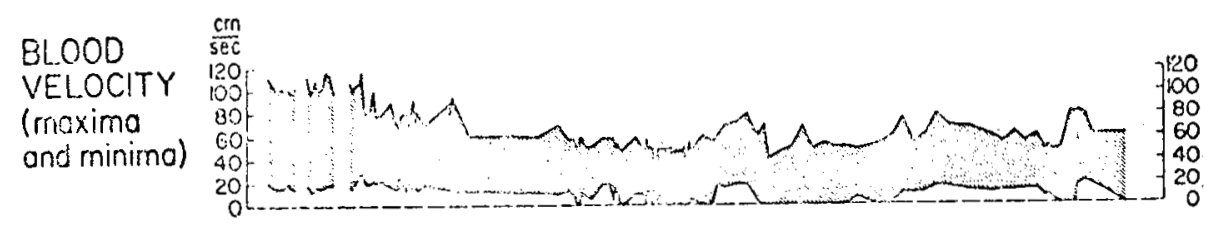

EMBOLUS

DETECTOR (deflections per ${ }^{0}$ ) 5 sec interval)

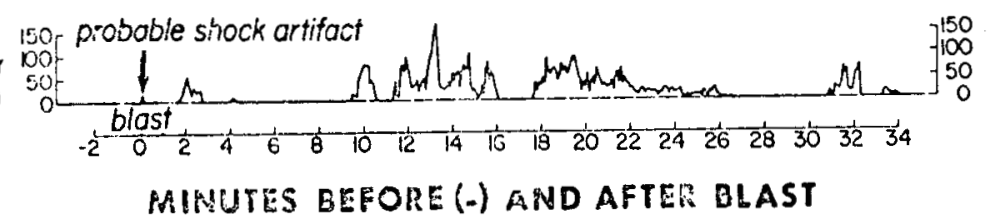

a. $\frac{\mathrm{cm}}{\mathrm{SeC}}$ BLOOD VELOCITY

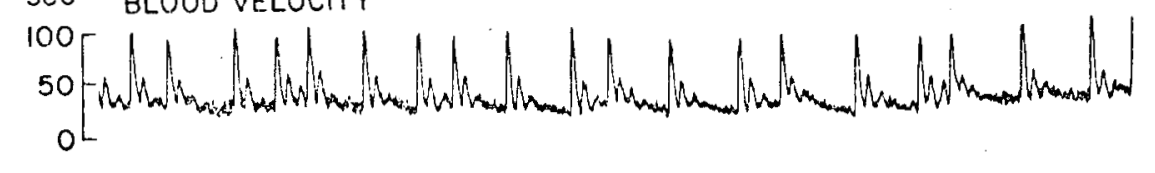

EMBOLUS DETECTOR

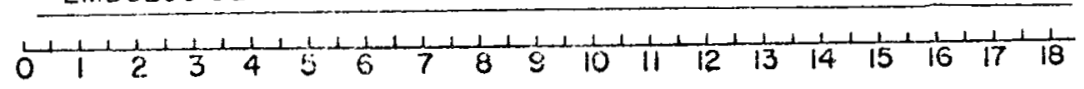

b.

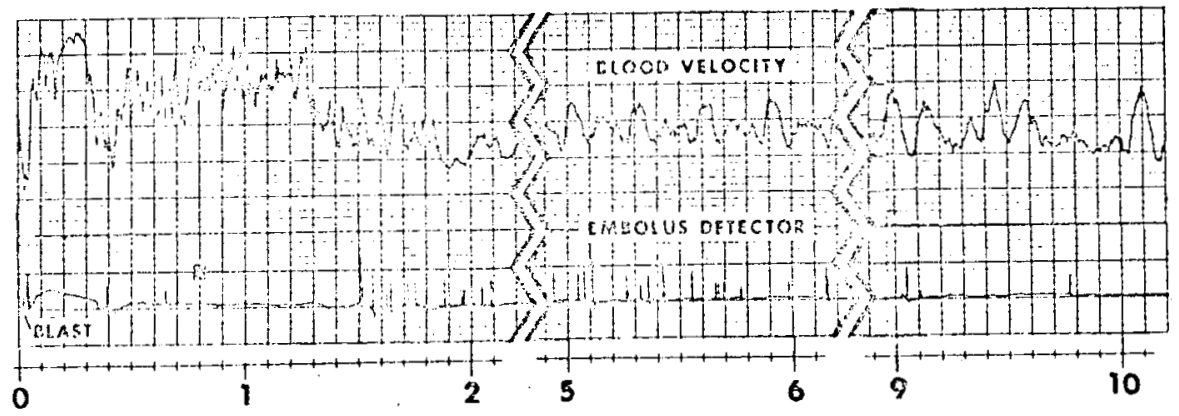

c. ${ }^{100}[$ BLOOD VELOCITY

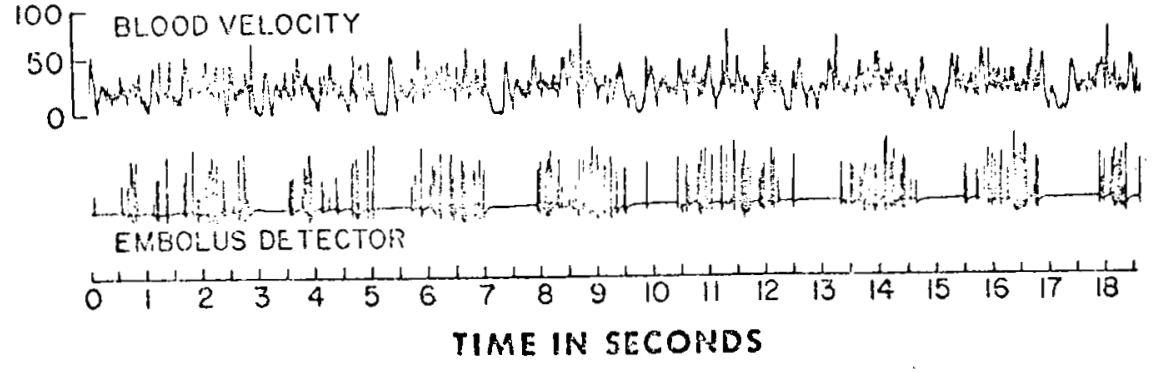

Figure 24. --Blood-velocity and embolus-detector traces:

a. Before blast; b. Immediately after blast;

c. Twelve minutes after blast. After Nevison

et al. (Reference 91) and Mason et al.

(Reference 92). 


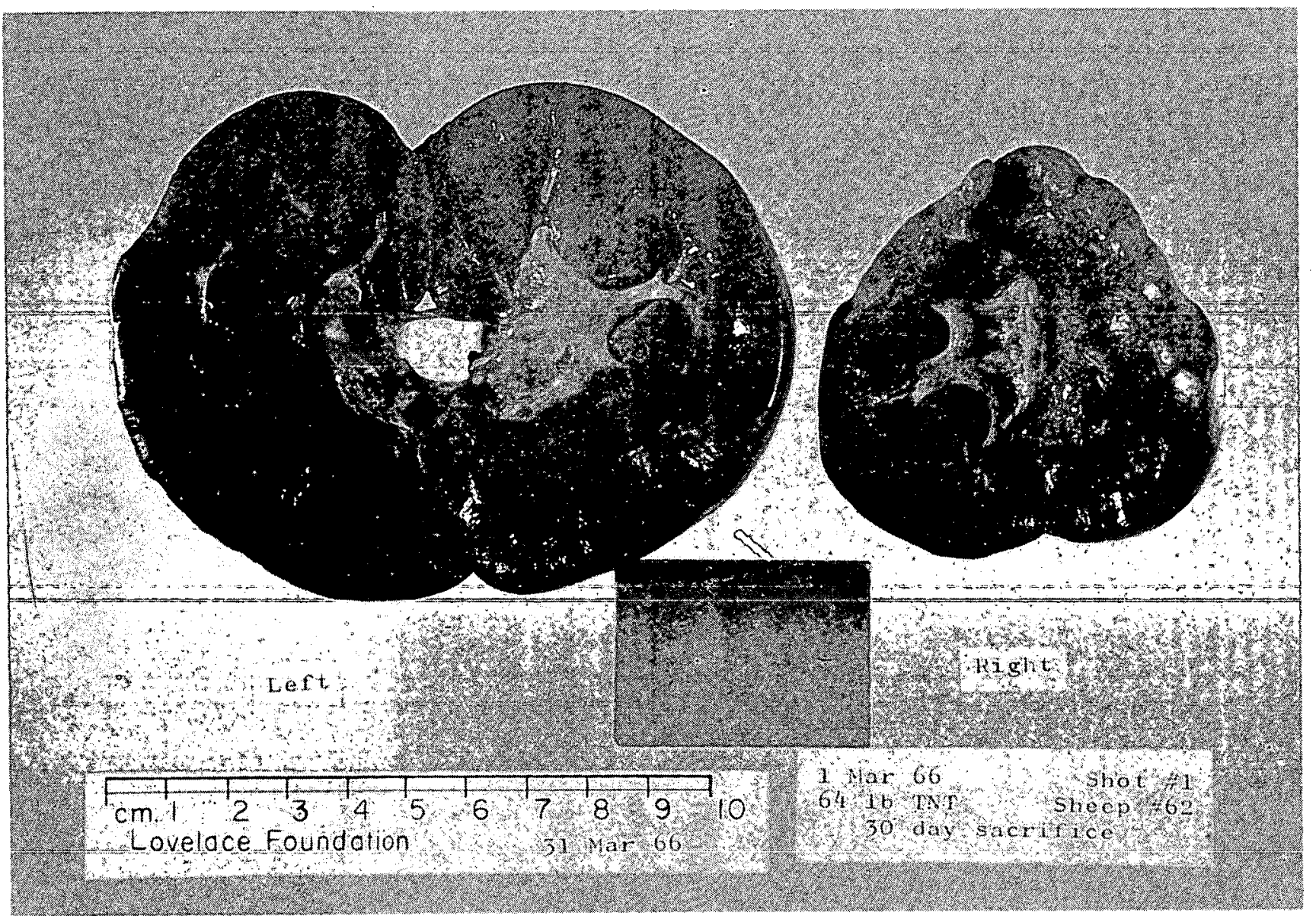

Figure 25.--Infarction sequelae in the kidneys of a sheep sacrificed 30 days after exposure to an $\mathrm{HE}$-produced overpressure of 166 p.s.i. and 3.0-msec. duration (near $\mathrm{LD}_{50}$ ). Note the marked difference in the size of the organs. After Jones and Richmond (Reference 93). 


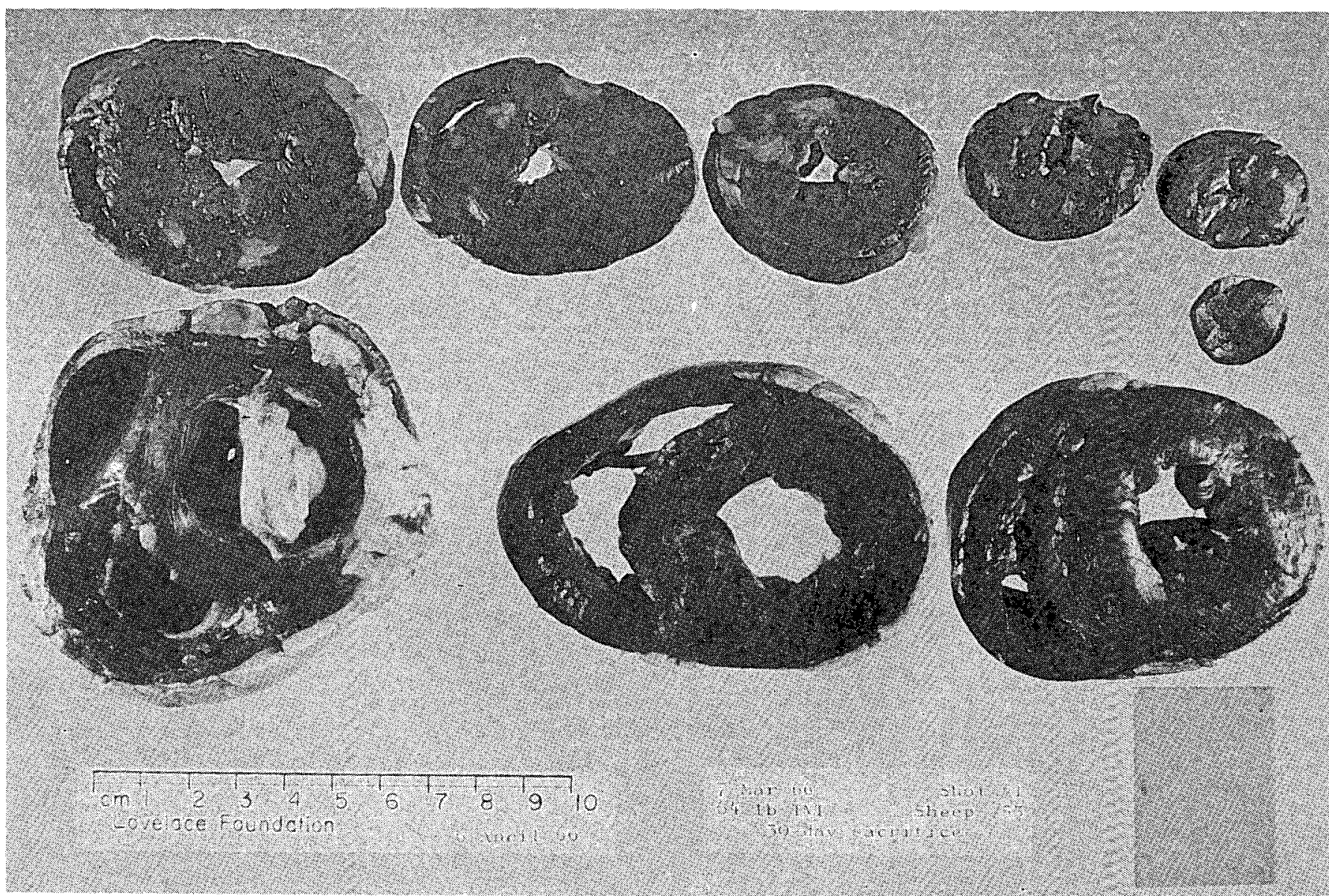

Figure 26. --Infarction sequelae in the heart of a sheep sacrificed 30 days after exposure to an HE-produced overpressure of $164 \mathrm{p}$. s.i. and $3.3-\mathrm{msec}$. duration (near LD50). Note the multiple scars in the myocardial walls. After Jones and Richmond (Reference 93). 


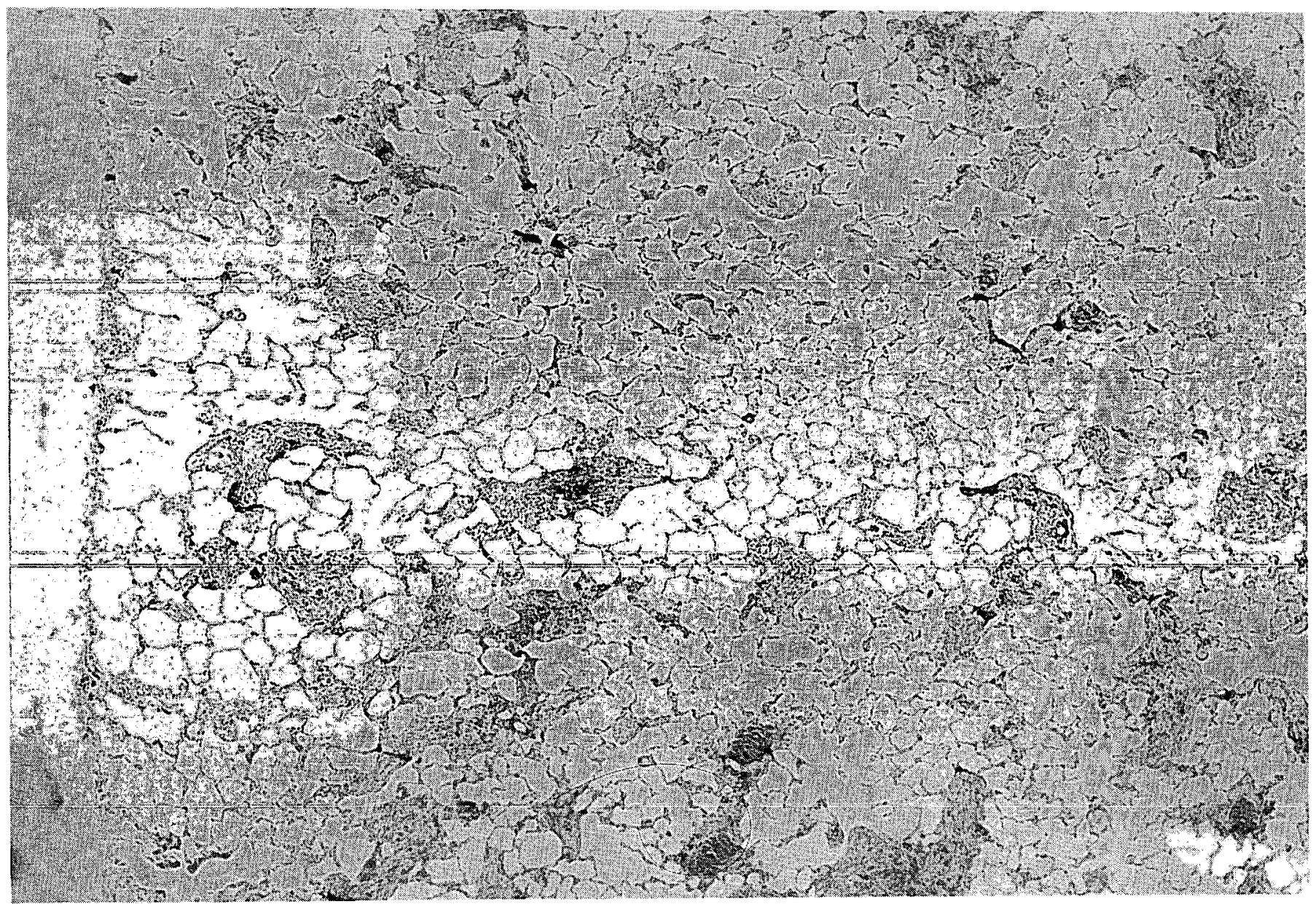

Figure 27. --Scattered small scars in the lung of a dog surviving severe blast injury and sacrificed 31 days post exposure. Hematoxylin and eosin (x28). After Jones and Richmond (Reference 32), Chiffelle et al. (Reference 33), and Chiffelle (Reference 90). 

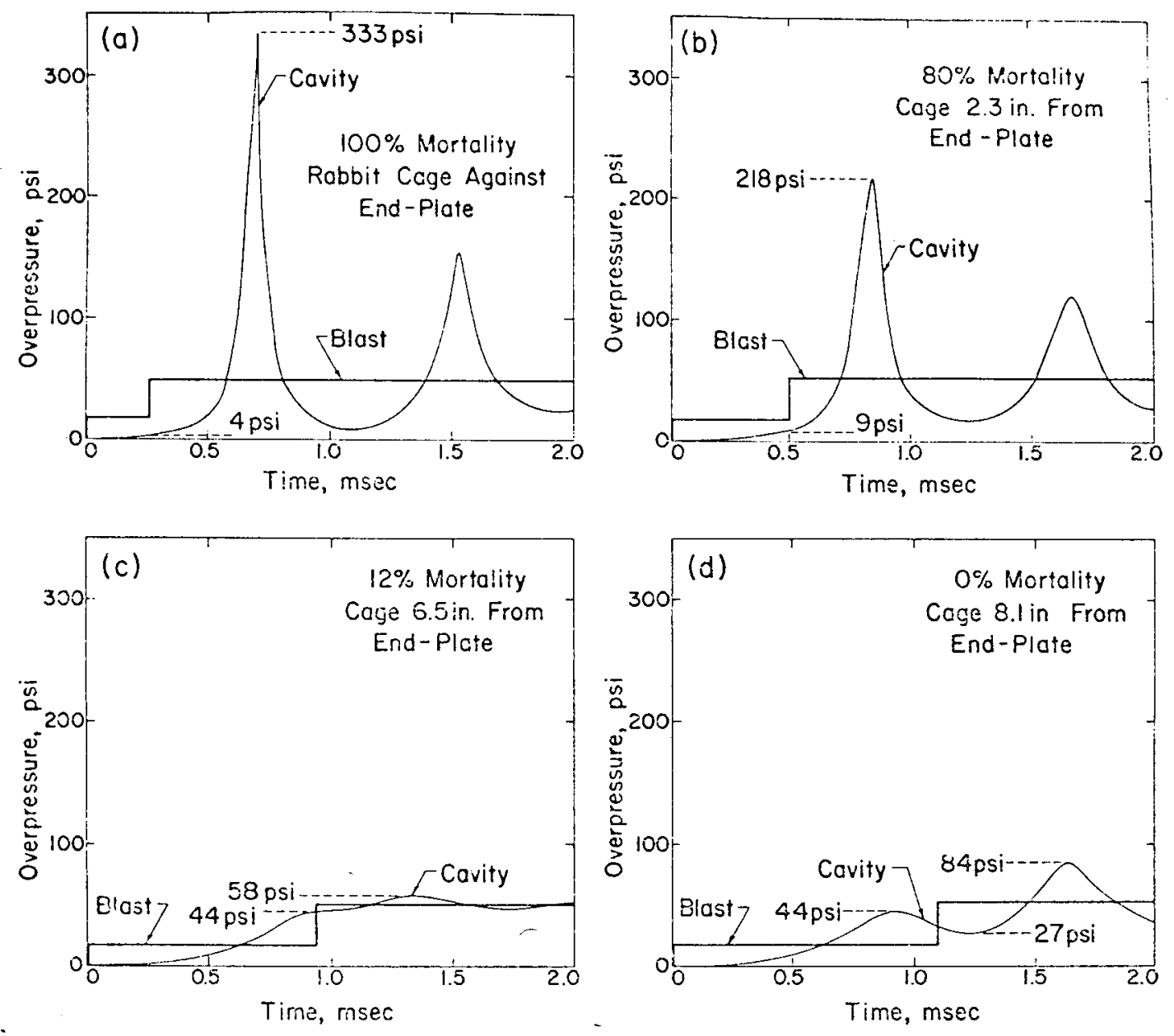

Figure 28.--Computed intrathoracic overpressure versus time for $1.7-\mathrm{kg}$. rabbits exposed at various distances from the end plate of a shock tube. The incident and reflected shocks were 17.2 and 52.1 p.s.i., respectively. Mortality data from Richmond et al. (Reference 72). After Bowen et al. (Reference 77). 
$L=4-1 / 4^{\prime \prime}$

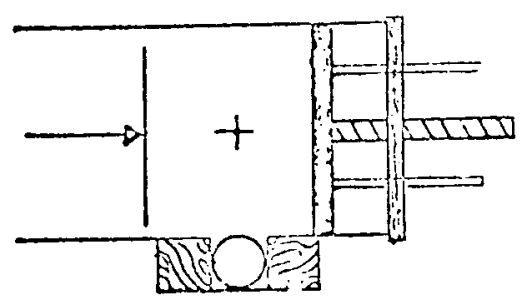

$L=7^{\prime \prime}$
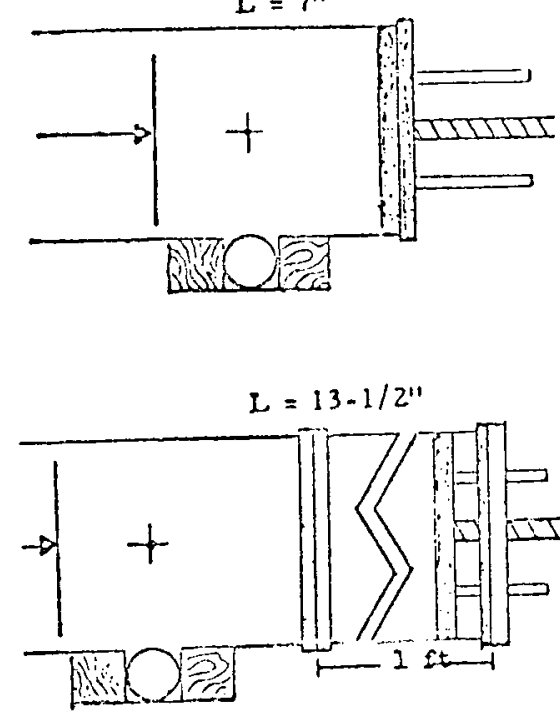

$L=20-7 / 8^{\prime}$

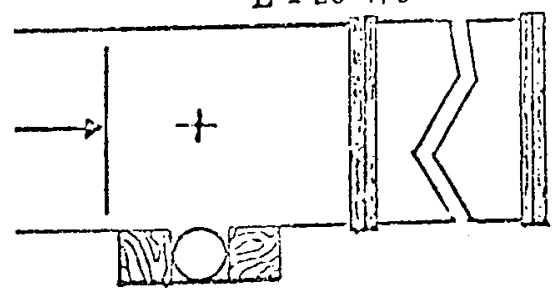

+ pressure gage
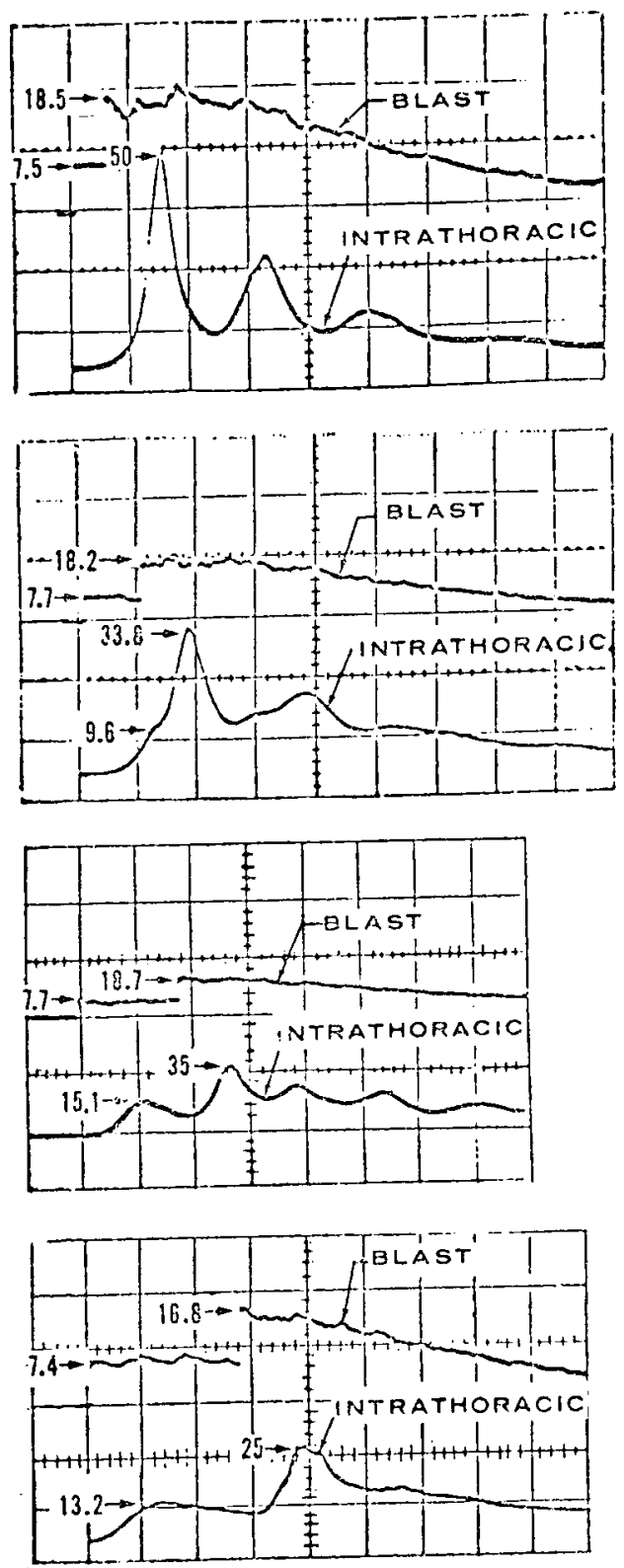

TIME IN MILLISECONDS

Figure 29. --Incident and reflected blast-pressure pulses and intrathoracic pressure-time responses recorded in guinea pigs with an intraesophageal transducer. Data, courtesy of Mitchell and Gaylord, obtained under the direction of Jones and Richmond (Reference 93 ); results also used in a recent study by Fletcher (Reference 59 ). 


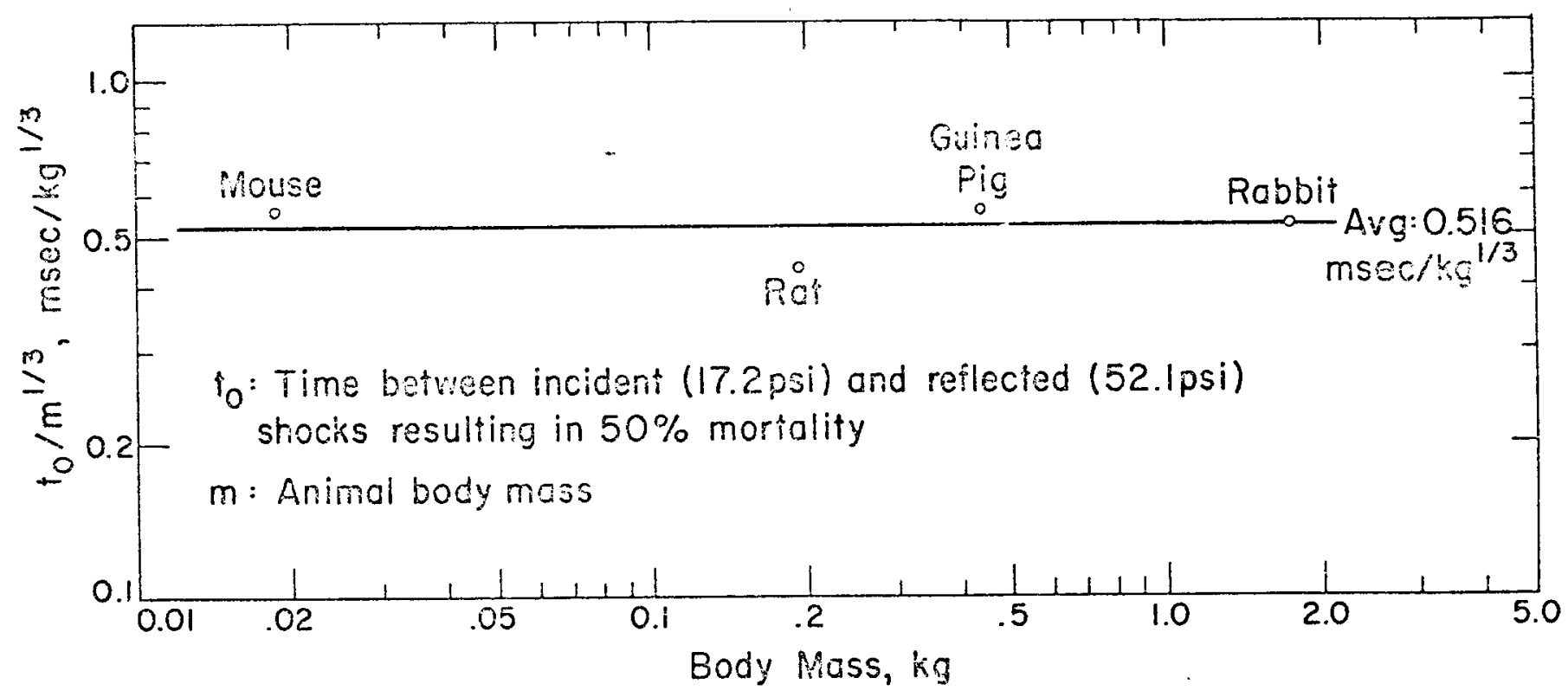

Figure 30.--A test of body-mass scaling for similar animals. The plotted data show that the 4 species of animals have approximately the same sensitivity to time separations of the incident and reflected shocks which are proportional to the cube root of body mass. Data from Richmond et al. (Reference 72). After Bowen et al. (Reference 77). 


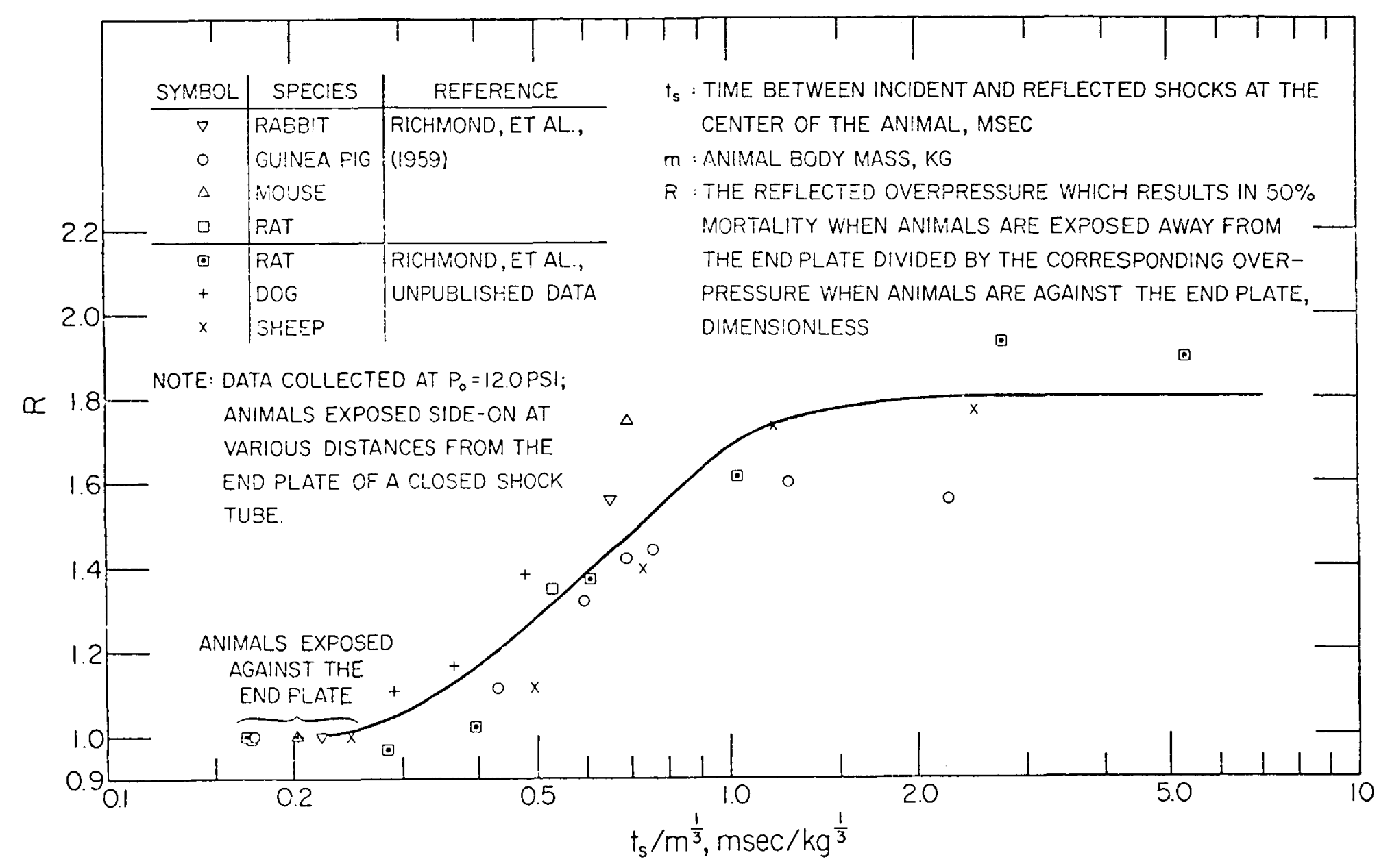

Figure 31.--Increase in tolerance when the time to maximum pressure is delayed by separating the incident and reflected pressure pulses for "fast-rising," "long-duration" waves. Data from Richmond et al. (References 72 and 88). After Fletcher (Reference 59). 


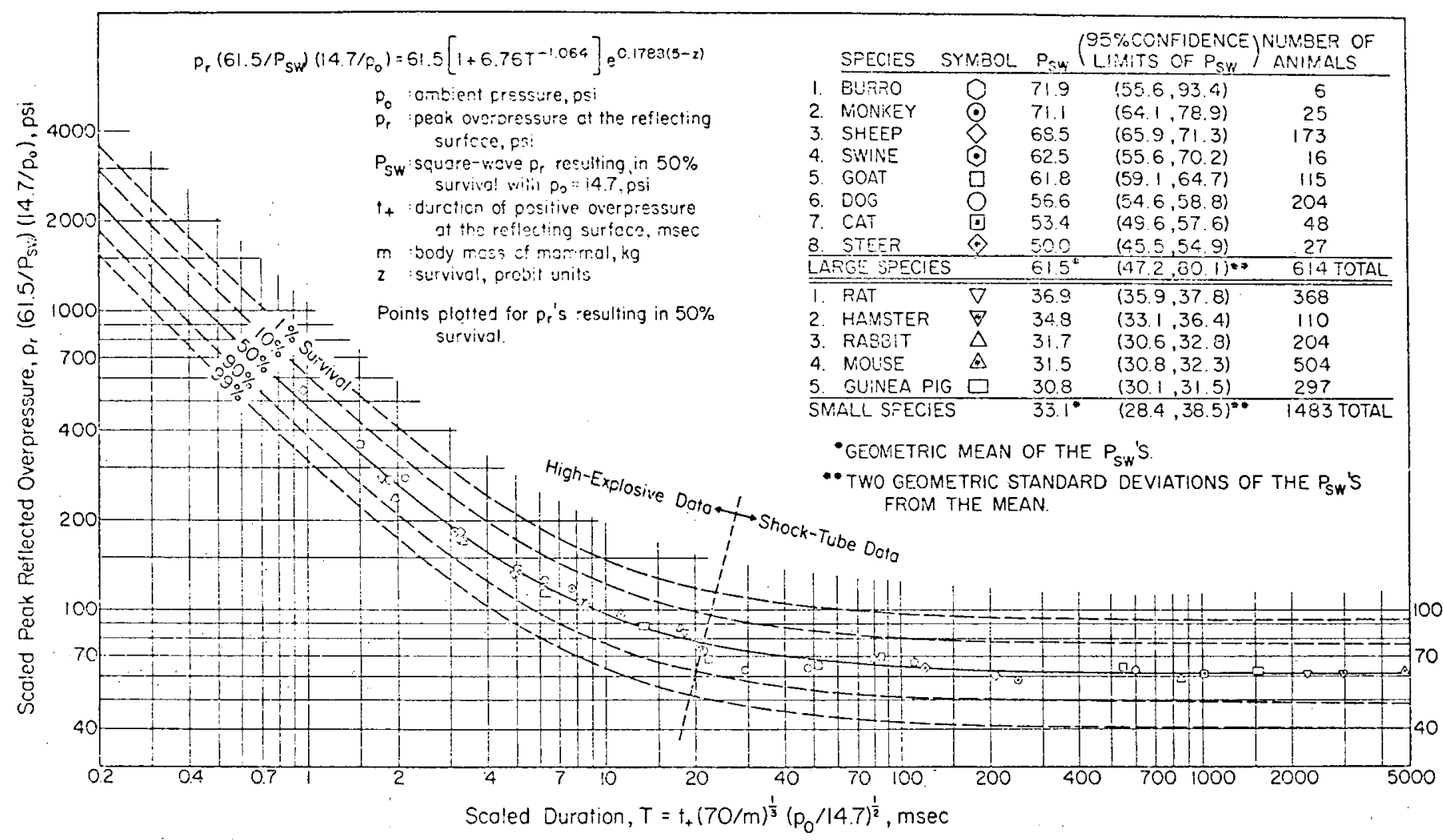

Figure 32. --Survival curves (24-hour), applicable to "sharp-rising" blast waves, derived from the analysis of data for 12 mammalian species (excluding guinea pigs). See text for explanation of plotted points. From Bowen et al. (Reference 94). 


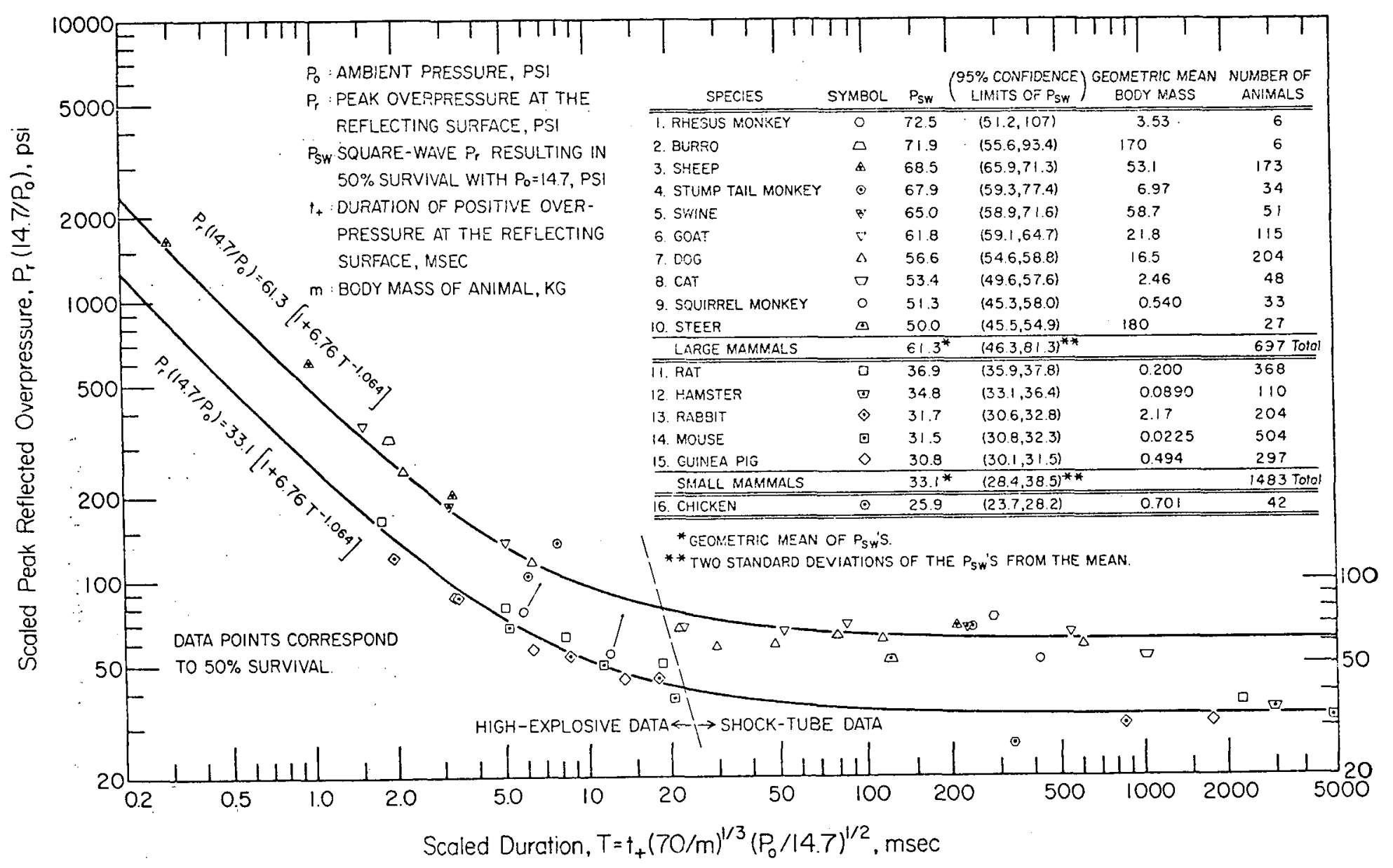

Figure 33.--Scaled peak reflected overpressures and scaled durations for "sharp-rising" blast waves which will result in 50-percent mortality. The curves, computed for a hypothetical average large and small mammal, were derived from data mostly tabulated by Bowen et al. (Reference 94). After Fletcher (Reference 59). 


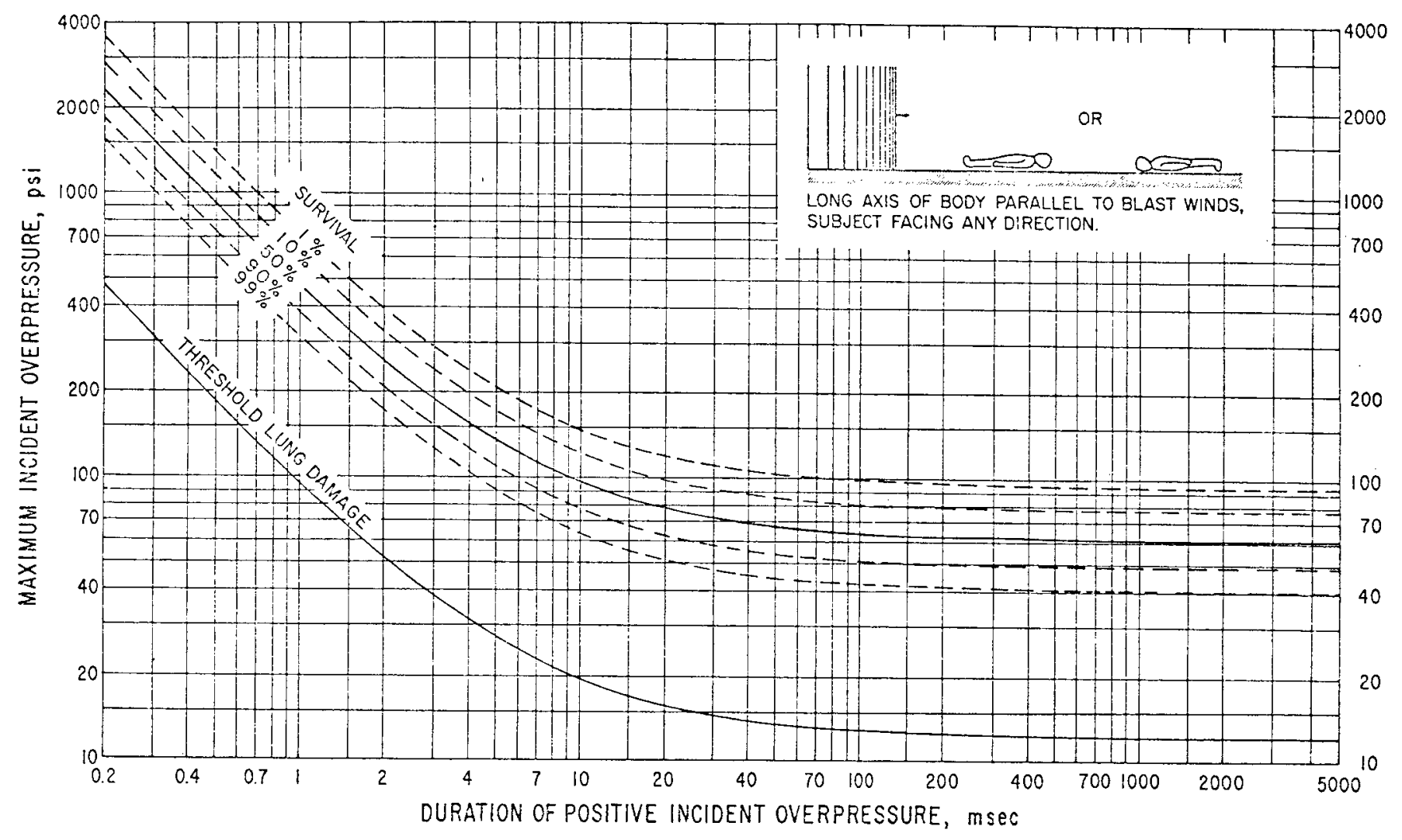

Figure 34. --Survival curves predicted for 70-kg. man applicable to free-stream situations where the long axis of the body is parallel to the direction of propagation of the shocked blast wave. After Bowen et al. (Reference 94). 


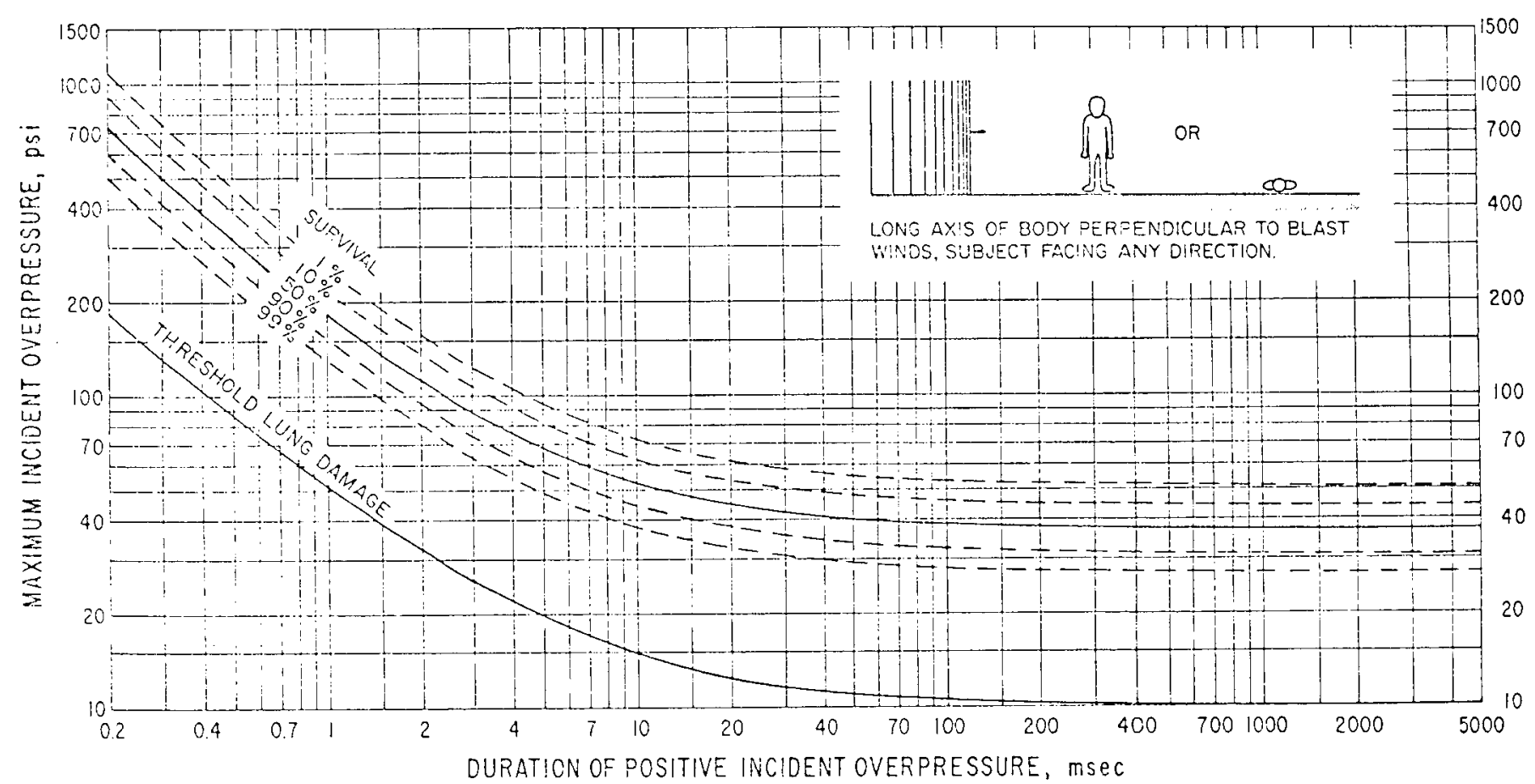

Figure 35.--Survival curves predicted for 70-kg. man applicable to free-stream situations where the long axis of the body is perpendicular to the direction of propagation of the shocked blast wave. After Bowen et al. (Reference 94). 


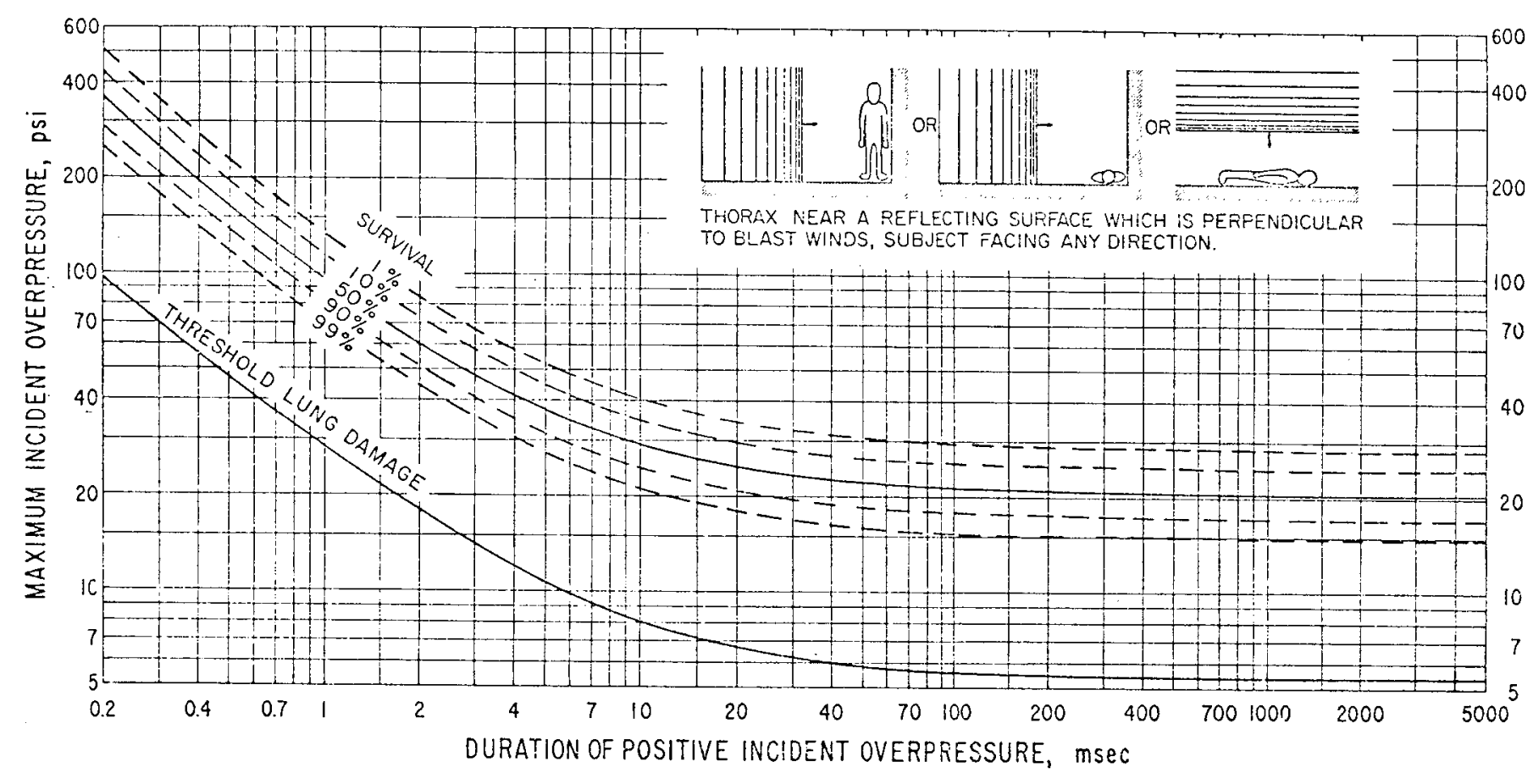

Figure 36. --Survival curves predicted for $70-\mathrm{kg}$. man applicable to blast situations where the thorax is $\mathrm{n}$ ear a surface against which a shocked blast wave reflects at normal incidence. After Bowen et al. (Reference 94). 

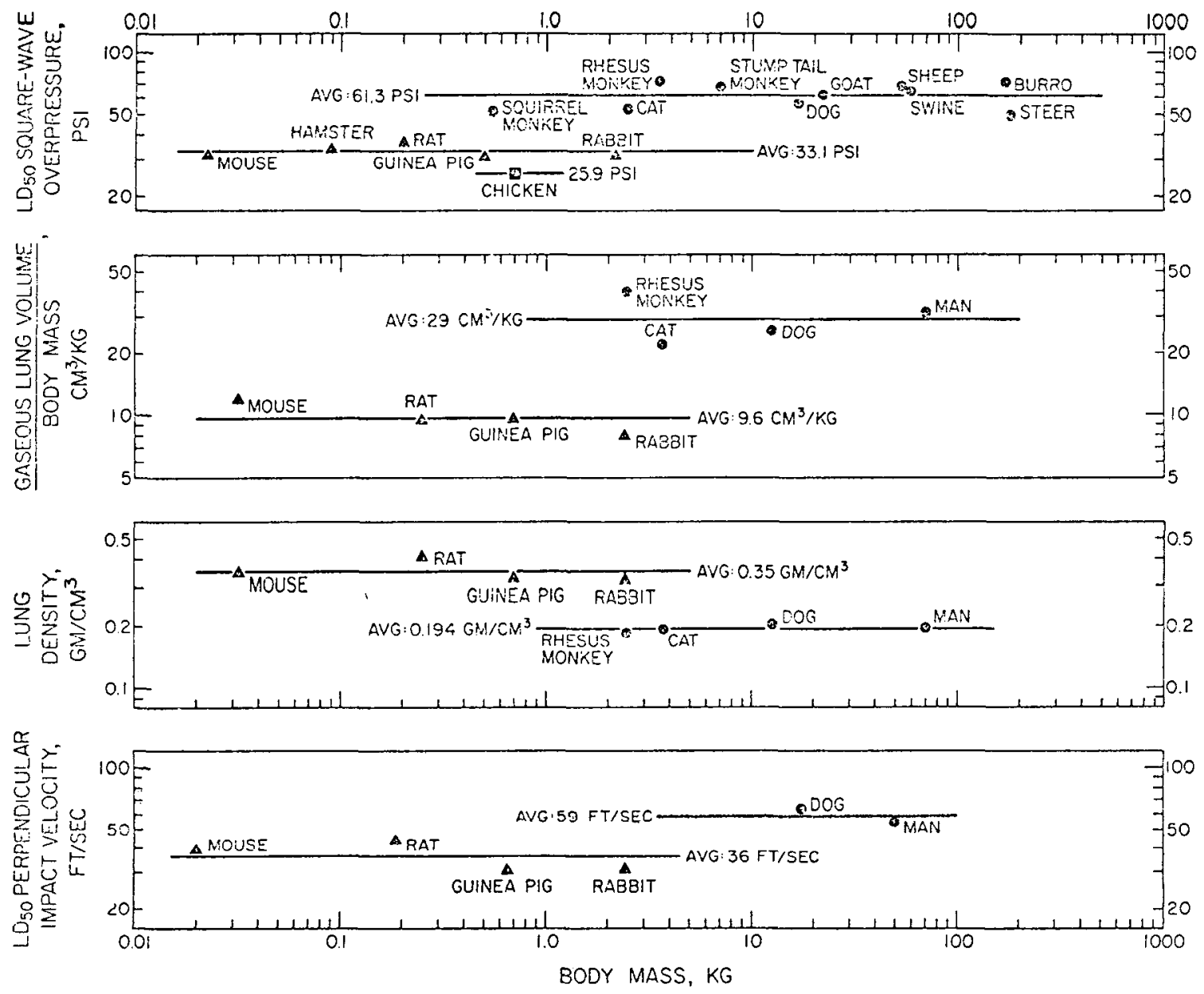

Figure 37. --Animal body mass versus the "square-Wave" overpressure for 50-percent survival at sea-level, the average gaseous lung volume divided by body mass, the average lung density, and the 50-percent lethal velocity for perpendicular impact with a nonyielding surface. Note that in each instance the mammals segregate into two groups and that the average values for the various parameters are given for the more- and less-tolerant groups. Pressure data from Fletcher (Reference 59), lung data from Crosfill and Widdicombe (Reference 63), impact data from Jones et al.(Reference 97). After Fletcher (Reference 59). 
53 Human Free-Fall Cases from Lewis et. al. , 1965

(Impact with concrete)

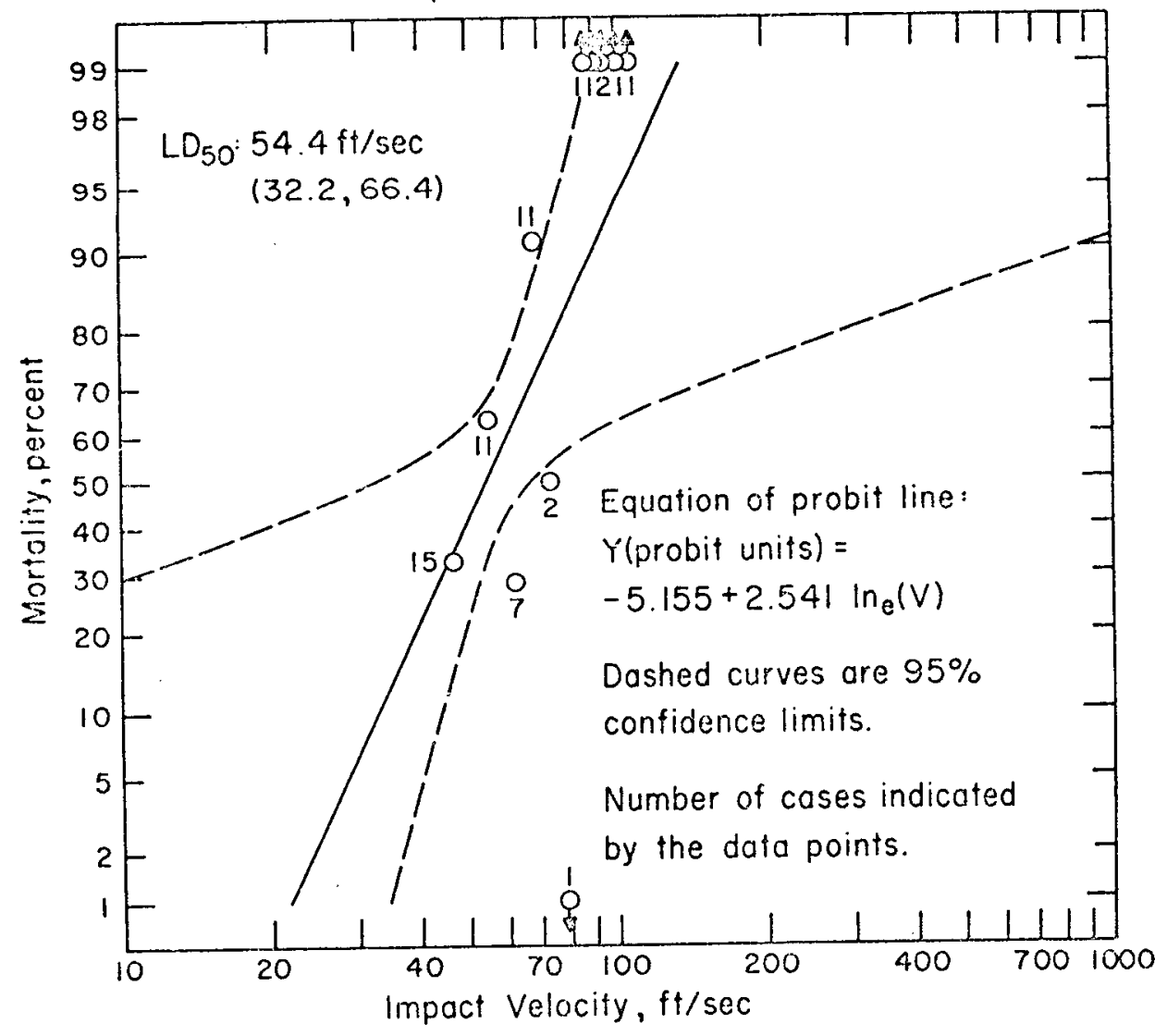

Figure 38. --Impact velocity versus mortality for man. Data from Lewis et al. (Reference 98). After Jones et al. (Reference 97). 


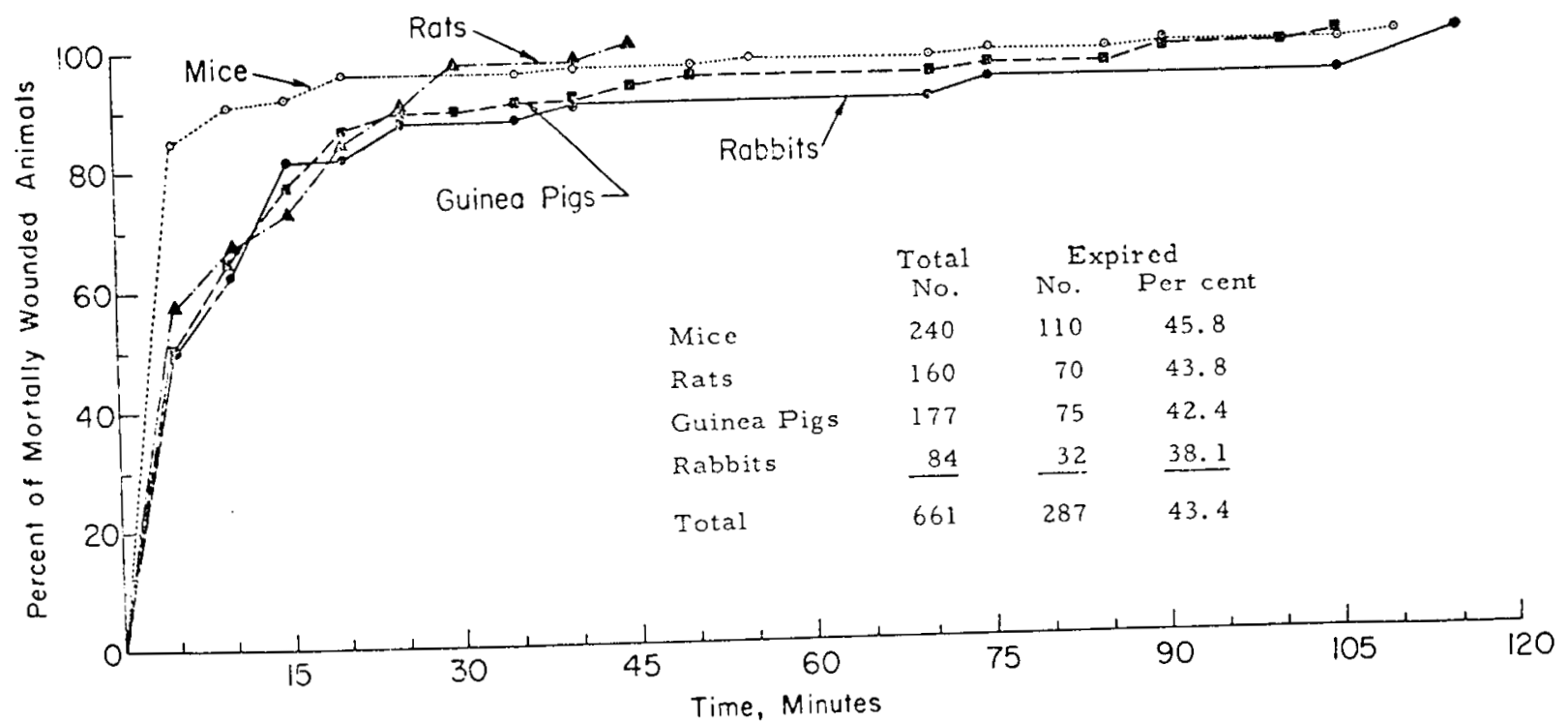

Figure 39. --Accumulative percent of mortally wounded animals dying over the 2-hour period following exposure to "sharp-rising" overpressures of 3-to 4-msec. duration. Data from Richmond et al. (Reference 99). After White et al. (Reference 4). 


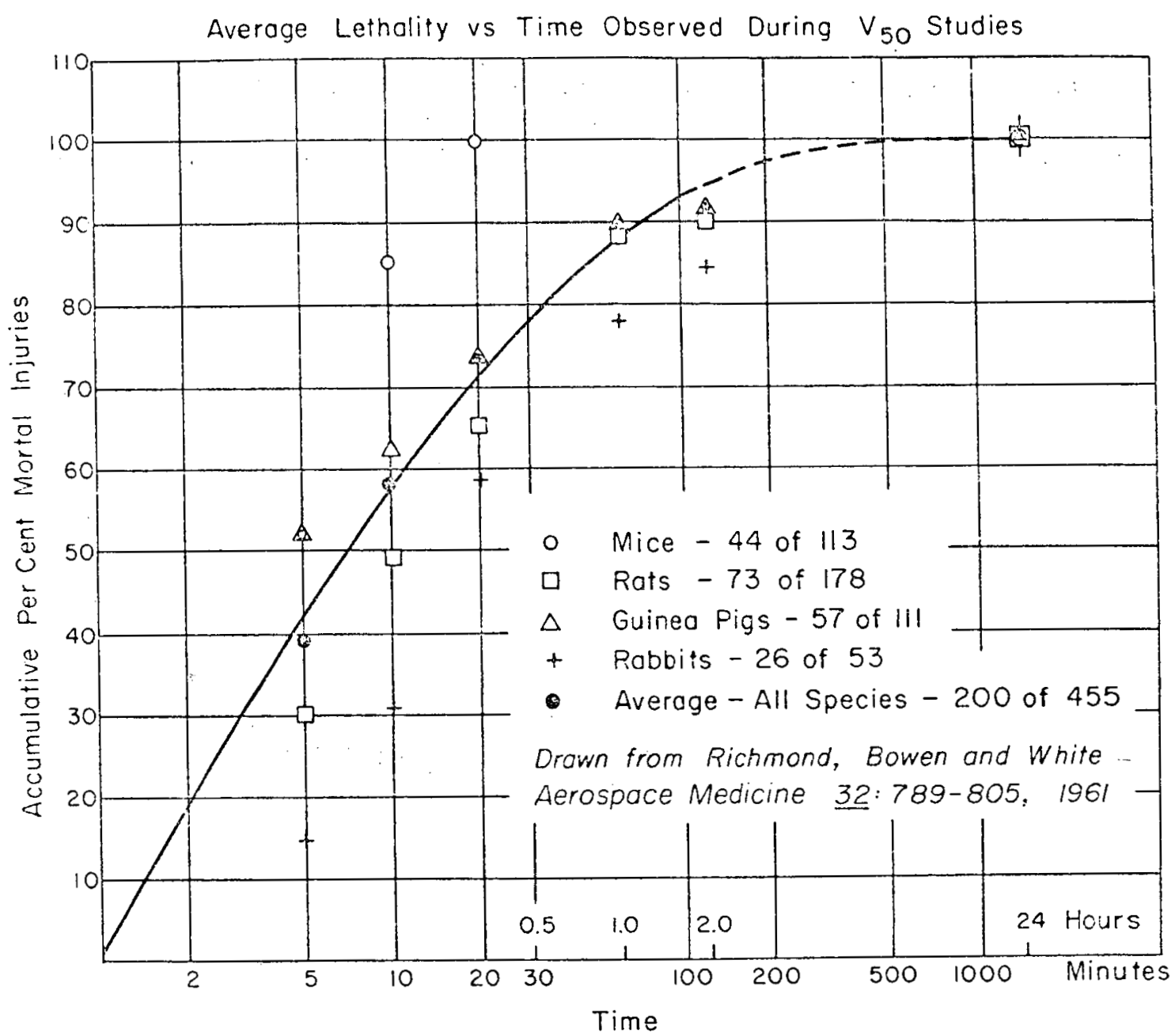

Figure 40. --Accumulative percent of mortally wounded animals dying over the 24-hour period following whole-body impact. Data from Richmond et al. (Reference 20). After White et al. (Reference 4). 


\section{Guinea Pig Mortality Over a 30-day Period}

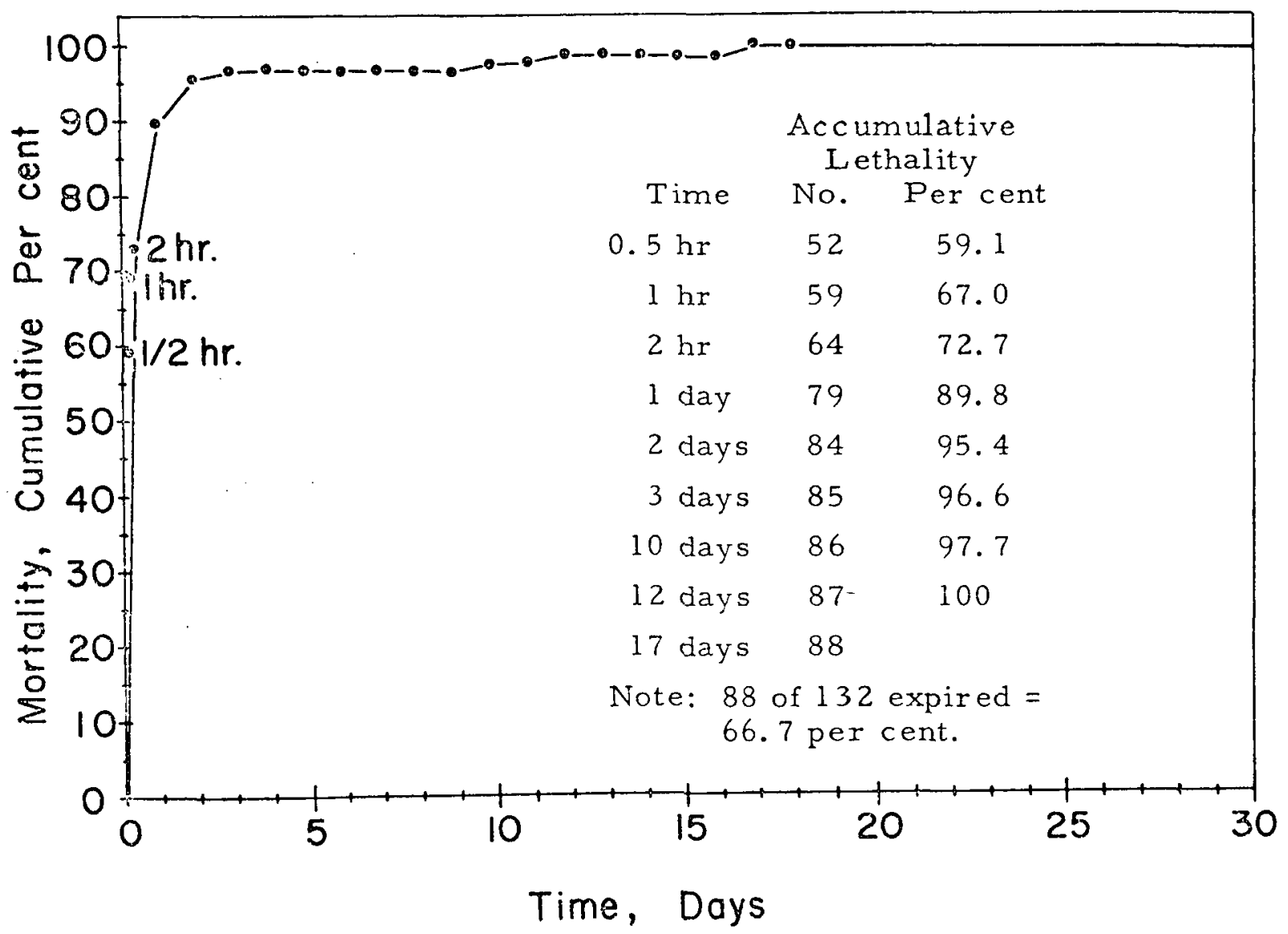

Figure 41.--Guinea-pig mortality over the 30-day period following exposure to "fast-rising, " "long-duration" shock-tubeproduced blast waves. After White et al. (Reference $4)$. 


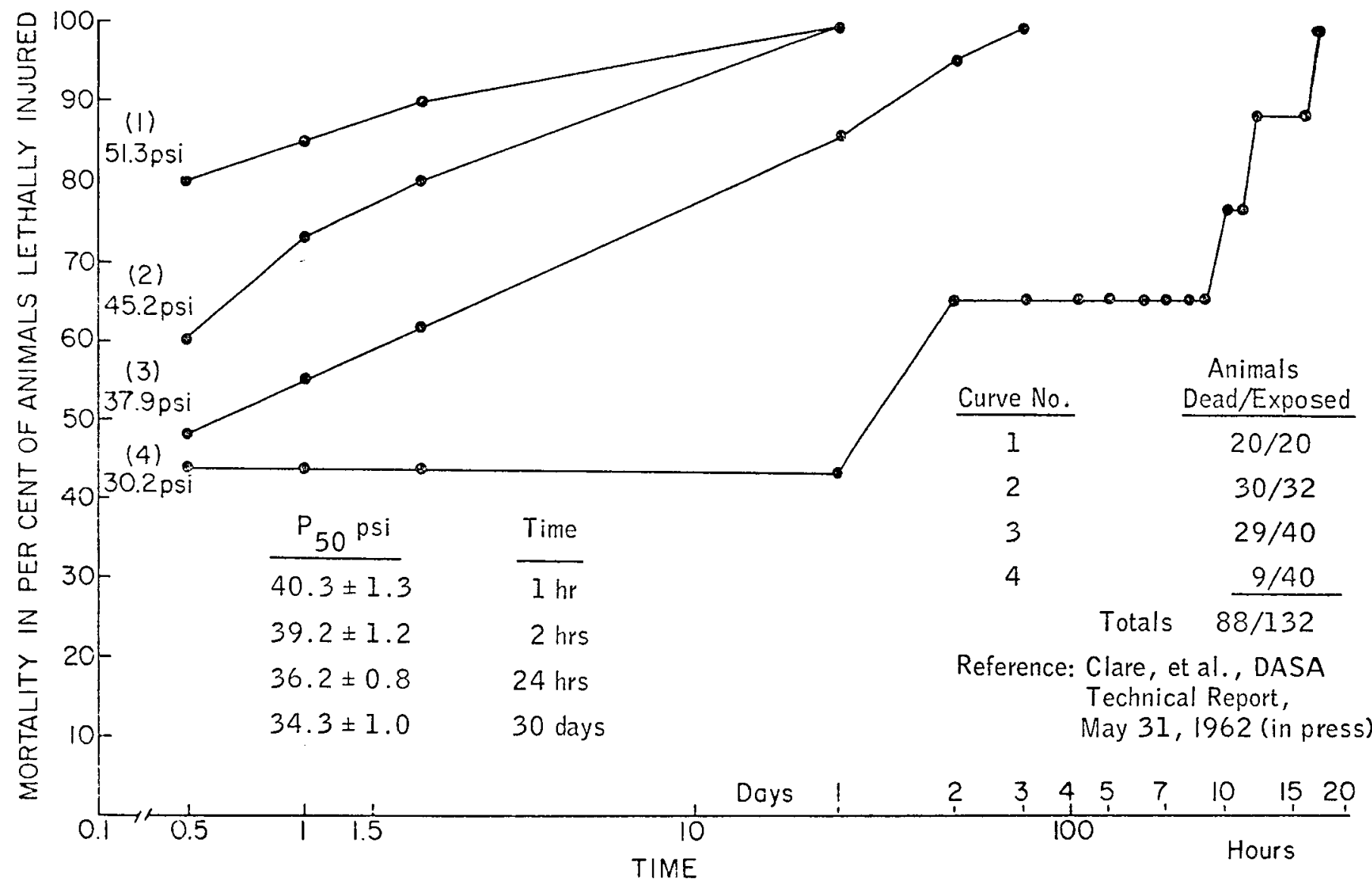

Figure 42. --Lethality-time data for guinea pigs exposed to "long-duration," "fast-rising" overpressures of the indicated magnitudes. After White et al. (Reference 4). 
Nortality as Related to Time for Animals Dying from Blast

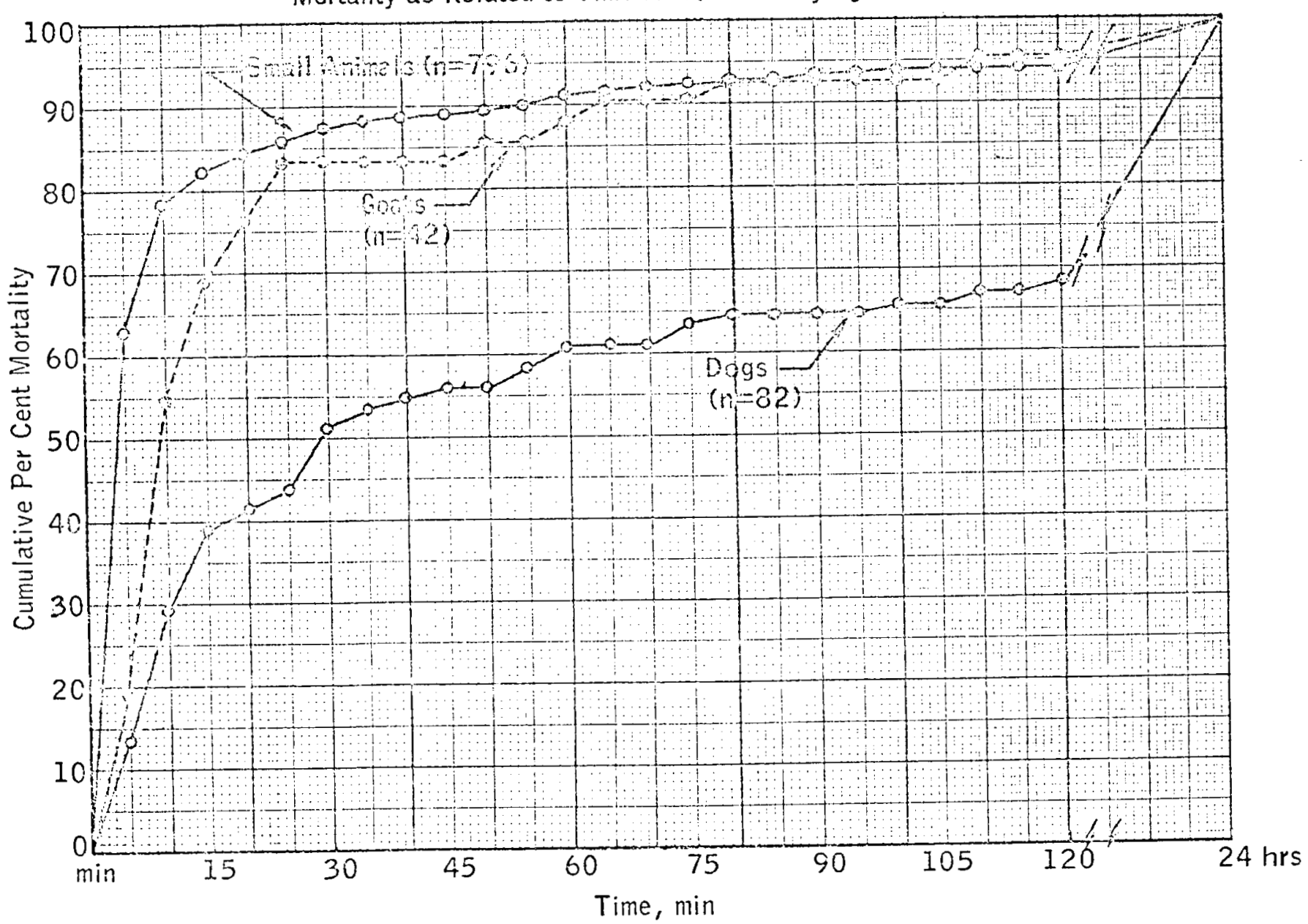

Figure 43. --Lethality-time curves for small animals (mice, rats, guinea pigs, and rabbits), goats, and dogs exposed to "fast-rising" overpressures of various durations. After Richmond and White (Reference 95). 
Exposed ogainst and vorious distances from plate closing end of a shock tube to $6-8 \mathrm{sec}$ duration overpressure rising rapidly in single

or double steps.

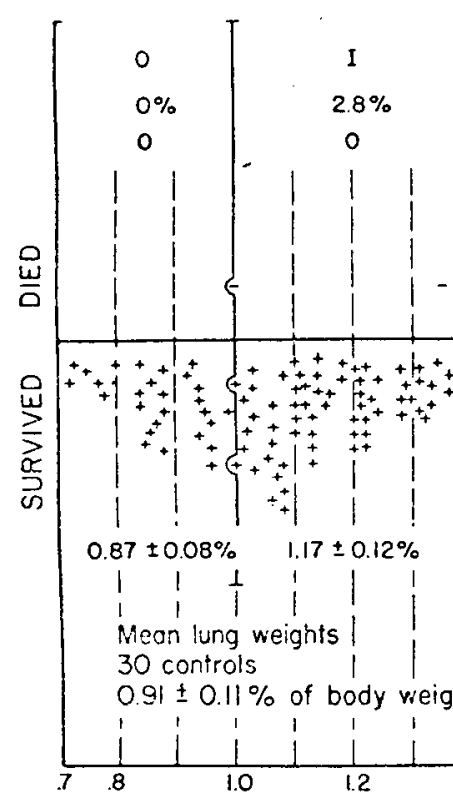

Total number of animals -556

+ Surviving animals - no coronary air emboli found at necropsy

- Died - coronary air emboli not seen at necropsy

- Died-coronary air emboli visualized at necropsy 


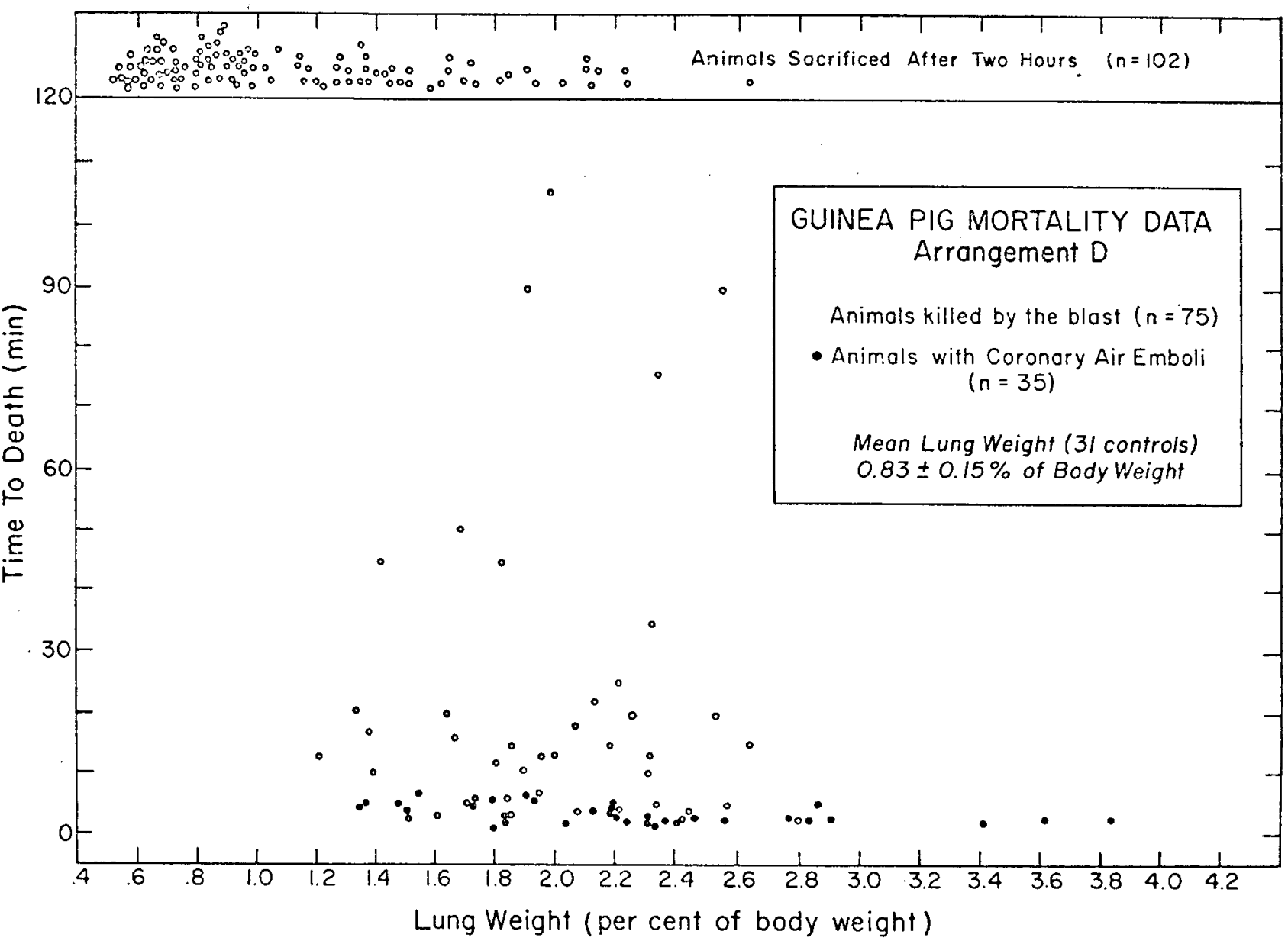

Figure 45. --The time relation between lung weight and the incidence of coronary air emboli in surviving and nonsurviving guinea pigs exposed to "fast-rising," "long-duration" blast waves. The mean body weight of the animals was less than that in Figure 44, which may account for the difference in the mean lung weights of the control animals in the two figures. After Richmond and White (Reference 95). 


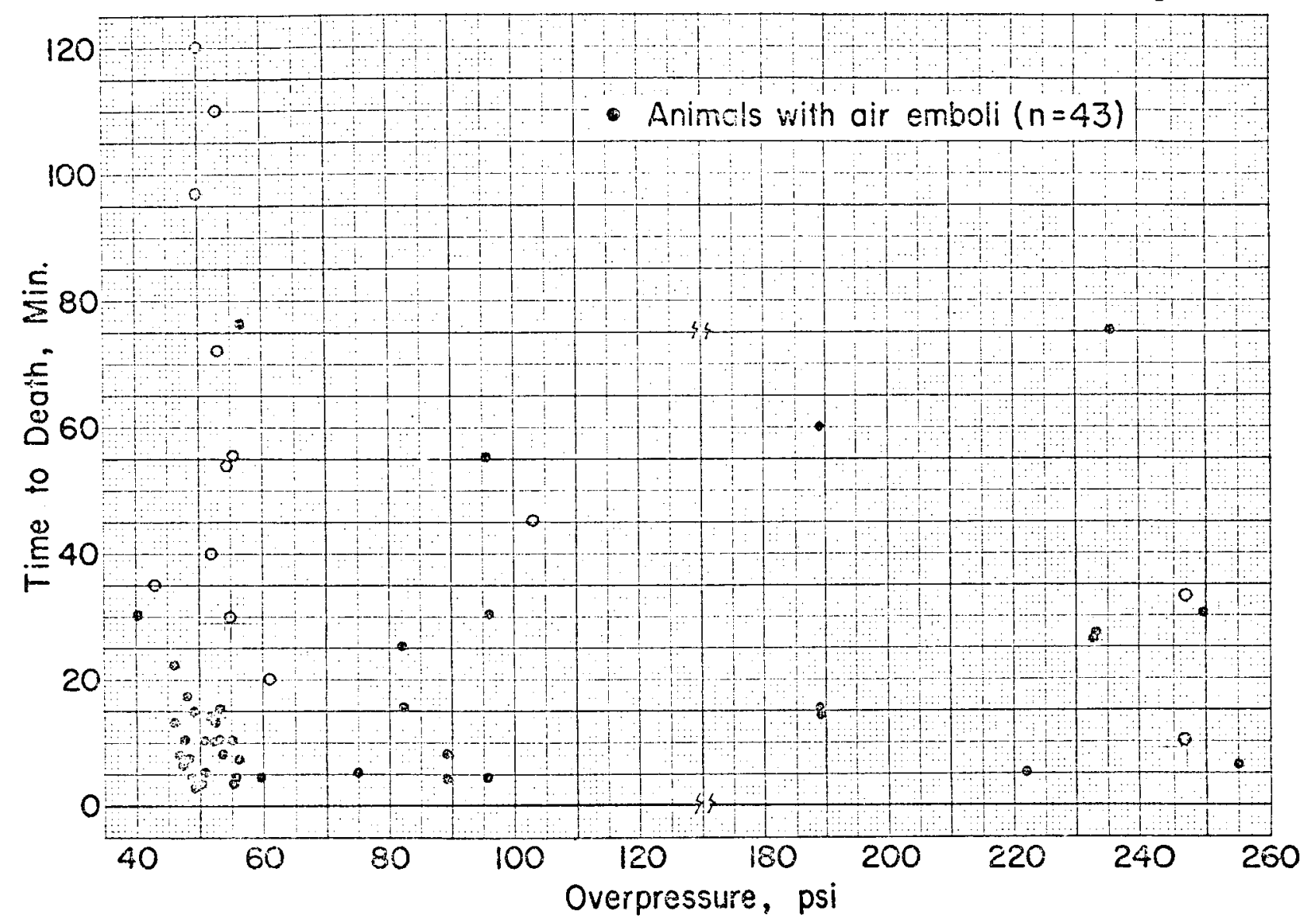

Figure 46. --Time of death and the incidence of air embolism in 56 dogs mortally injured by exposure to "fast-rising, "long-" and "short-duration" overpressures of the magnitudes shown. After Richmond and White (Reference 95). 


\section{SHEEPS' KIDNEYS}
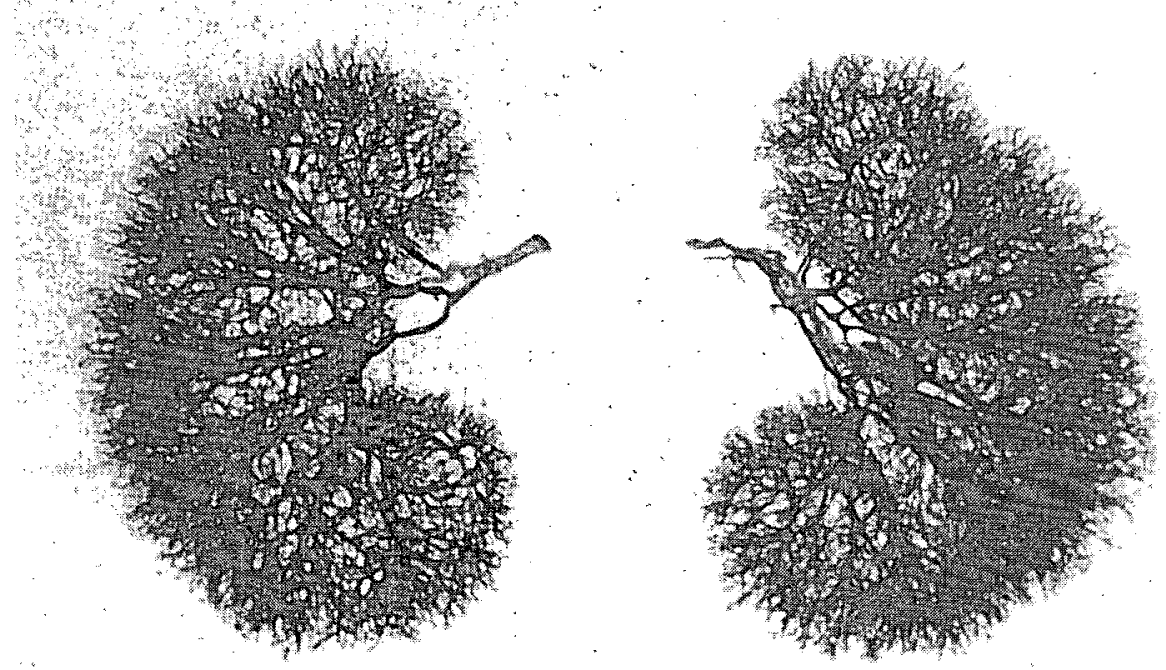

NORMAL

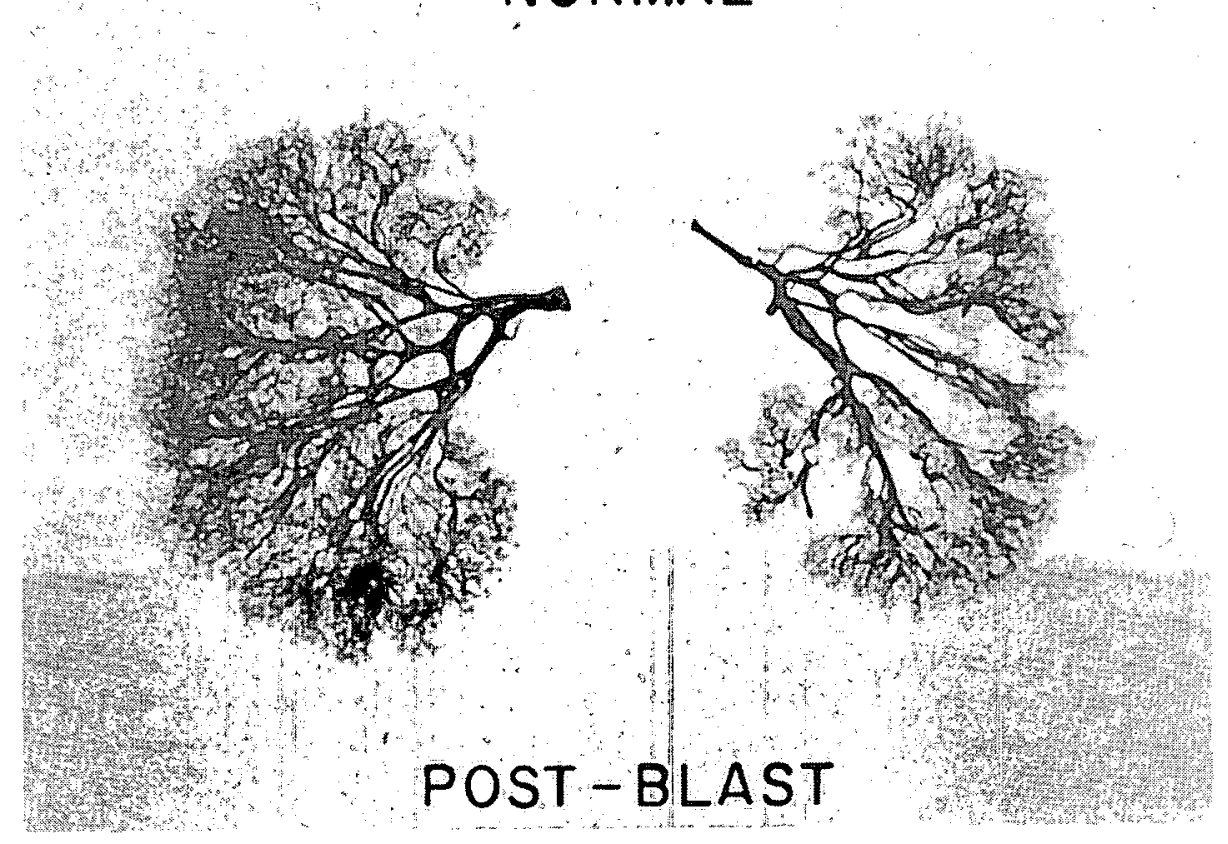

Figure 47. --Plastic injection casts of the renal circulation in a control sheep and in a sheep sacrificed 30 days after a single exposure to blast overpressure in a shock tube. Courtesy of F. G. Hirsch (Reference 105). 


\section{REFERENCES}

1. Glasstone, S. (Editor) The Effects of Nuclear Weapons, Revised Edition, U.S. Government Printing Office, Washington, D.C., April 1962 .

2. Zuckerman, S. "The Problem of Blast Injuries." Proc. Roy. Soc. Med., 34: $171-188,1941$.

3. White, C. S., Chiffelle, T. L., Richmond, D. R., Lockyear, W. H., Bowen, I. G., Goldizen, V. C., Merideth, H. W., Kilgore, D. E., Longwell, B. B., Parker, J. T., Sherping, F., and Cribb, M. E. "Biological Effects of Pressure Phenomena Occurring Inside Protective Shelters Following Nuclear Detonation." USAEC Civil Effects Test Group Report, WT-1179, Office of Technical Services, Department of Commerce, Washington, D.C., October 28, 1957.

4. White, C. S., Bowen, I. G., and Richmond, D. R. "A Comparative Analysis of Some of the Immediate Environmental Effects at Hiroshima and Nagasaki." Health Phys., 10: 89-150, 1964. Subsequently published as USAEC Civil Effects Test Operations Report, CEX-63.7, Office of Technical Services, Department of Commerce, Washington, D. C., August 1964 .

5. White, C. S., Bowen, I. G., and Richmond, D. R. "Biological Tolerance to Air Blast and Related Biomedical Criteria." USAEC Civil Effects Test Operations Report, CEX-65.4, Office of Technical Services, Department of Commerce, Washington, D.C., October 18, 1965. Subsequently published by the Clearinghouse for Federal Scientific and Technical Information, U.S. Department of Commerce, National Bureau of Standards, Springfield, Virginia, October 18, 1965.

6. White, C. S. "The Scope of Blast and Shock Biology and Problem Areas in Relating Physical and Biological Parameters." Technical Progress Report, DASA-1856, Defense Atomic Support Agency, Department of Defense, Washington, D.C., November 1966. Subsequently published in Ann. N. Y. Acad. Sci., 152: 89-102; 1968.

7. Chiffelle, T. L., Sherping, F., Goldizen, V. C., and White, C. S. "A Study of the Tissue Response to Sterile Deposits of Particulate Material." USAEC Technical Report, AECU-3574, Office of Technical Services, Department of Commerce, Washington, D.C., October 1957.

8. Bowen, I. G., Strehler, A. F., and Wetherbe, M. B. "Distribution and Density of Missiles from Nuclear Explosions." USAEC Civil Effects Test Group Report, WT-1217, Office of Technical Services, Department of Commerce, Washington, D. C., March 1956. 
9. Beyer, J. C. (Editor) Wound Ballistics, Office of the Surgeon General, Department of the Army, U.S. Government Printing Office, Washington, D. C. , 1962 .

10. Goldizen, V. C., Richmond, D. R., Chiffelle, T. L., Bowen, I. G., and White, C. S. "Missile Studies with a Biological Target." USAEC Civil Effects Test Group Report, WT-1470, Office of Technical Services, Department of Commerce, Washington, D.C., January 23, 1961.

11. Bowen, I. G., Franklin, M. E., Fletcher, E. R., and Albright, R. W. "Secondary Missiles Generated by Nuclear-Produced Blast Waves." USAEC Civil Effects Test Group Report, WT-1468, Office of Technical Services, Department of Commerce, Washington, D.C., October 28, 1963.

12. Bowen, I. G., Strehler, A. F., and Wetherbe, M. B. "Distribution and Density of Missiles from Nuclear Explosions." USAEC Civil Effects Test Group Report, WT-1168, Office of Technical Services, Department of Commerce, Washington, D.C., December 14, 1956.

13. Clemedson, C. J., Hellström, G., and Lindgren, S. "The Relative Tolerance of the Head, Thorax and Abdomen to Blunt Trauma." Ann. N. Y. Acad. Sci. , 152: 187-198, 1968.

14. Fletcher, E. R., Richmond, D. R., Bowen, I. G., and White, C. S. "An Estimation of the Personnel Hazards from a Multi-Ton Blast in a Coniferous Forest." Technical Progress Report, DASA-2020, Defense Atomic Support Agency, Department of Defense, Washington, D.C., November 1967.

15. Blocker, V. and Blocker, T. G. "The Texas City Disaster--A Survey of 3000 Casualties." Amer. J. Surg., 78: 756-771, 1949.

16. Bowen, I. G., Albright, R. W., Fletcher, E. R., and White, C. S. "A Model Designed to Predict the Motion of Objects Translated by Classical Blast Waves." USAEC Civil Effects Test Operations Report, CEX-58. 9, Office of Technical Services, Department of Commerce, Washington, D. C. , June 29, 1961.

17. Taborelli, R. V., Bowen, I. G., and Fletcher, E. R. "Tertiary Effects of Blast--Displacement." USAEC Civil Effects Test Group Report, WT1469, Office of Technical Services, Department of Commerce, Washington, D. C. , May 22, 1959. 


\section{REFERENCES (Continued)}

18. Fletcher, E. R. and Bowen, I. G. "Blast-Induced Translational Effects." Technical Progress Report, DASA-1859, Defense Atomic Support Agency, Department of Defense, Washington, D.C., November 1966. Subsequently published in Ann. N. Y. Acad. Sci., 152: 378-403, 1968.

19. Fletcher, E. R., Richmond, D. R., and Jones, R. K. "Blast Displacement of Prone Dummies." Operation Prairie Flat, Project Officers Report--Project LN 402, Technical Report on Contract No. DA-01-68C-0118, submitted to the Director, Defense Atomic Support Agency, Department of Defense, Washington, D.C., on July 2, 1970.

20. Richmond, D. R., Bowen, I. G., and White, C. S. "Tertiary Blast Effects: Effects of Impact on Mice, Rats, Guinea Pigs and Rabbits." Technical Progress Report, DASA-1245, Defense A tomic Support Agency, Department of Defense, Washington, D.C., February 28, 1961. Subsequently published in Aerospace Med., 32: 789-805, 1961.

21. White, C. S. and Richmond, D. R. "Blast Biology." USAEC Technical Report, TID-5764, Office of Technical Services, Department of Commerce, Washington, D. C., September 18, 1959.

22. White, C. S. and Richmond, D. R. "Blast Biology." Chap. 63 in Clinical Cardiopulmonary Physiology (B. L. Gordon and R. C. Kory, Editors), pp. 974-992, Grune and Stratton, Inc., New York, 1960.

23. Clemedson, C. J. and Jönsson, A. "Dynamic Response of Chest Wall and Lung Injuries in Rabbits Exposed to Air Shock Waves of Short Duration." Acta Physiol. Scand., 62 (Suppl. 233): 3-31, 1964.

24. Ashe, W. F., Jr. and Roberts, L. B. "Experimental Human Burns." War Med., 7: 82-83, 1945.

25. Wakeley, C. P. G. "War Burns and Their Treatment." Practitioner, 146: $27-37,1941$.

26. Fauley, G. B. and Ivy, A. C. "Prevention of Flash Burns by a Protective Glove Film." U.S. Naval Med. Bull., 43: 209-215, 1944.

27. Grieg, A. L. and Pearse, H. E. "Thermal Radiation Measurements (Parts I and II)." USAEC Civil Effects Test Group Preliminary Report, ITR-1502, Office of Technical Services, Department of Commerce, Washington, D.C., May 23, 1958. 


\section{REFERENCES (Continued)}

28. Davis, T. P., Miller, N. D., Ely, T. S., Basso, J. A., and Pearse, H. E. "The Scattering of Thermal Radiation into Open Underground Shelters." USAEC Civil Effects Test Operations Report, CEX-58.2, Office of Technical Services, Department of Commerce, Washington, D.C., May 1959.

29. White, C. S. "Biological Effects of Blast." Technical Progress Report, DASA -1271, Defense Atomic Support Agency, Department of Defense, Washington, D.C., December 1961.

30. White, C. S. "Tentative Biological Criteria for Assessing Potential Hazards from Nuclear Explosions." Technical Progress Report, DASA-1462, Defense Atomic Support Agency, Department of Defense, Washington, D.C., December 1963.

31. White, C. S. "The Nature of the Problems Involved in Estimating the Immediate Casualties from Nuclear Explosions." Lovelace Foundation Technical Report, LF-1242-1, Lovelace Foundation for Medical Education and Research, Albuquerque, New Mexico, November 1968. To appear soon (revised) as a USAEC Civil Effects Test Operations report.

32. Jones, R. K. and Richmond, D. R. "The Physical and Biological Aspects of Blast Injury." In Proceedings of a Workshop on Mass Burns, March 13-14, 1968, pp. 215-240, National Academy of Sciences, Washington, D.C., 1969 .

33. Chiffelle, T. L., Jones, R. K., Richmond, D. R., and Damon, E. G. "The Biologic and Pathologic Effects of Blast Injury." In Accident Pathology (K. M. Brinkhous, Editor), pp. 90-106 (Proceedings of an International Conference on Accident Pathology, June 6-8, 1968, Washington, D.C.).

34. White, C. S. "Rationale of Treatment of Primary Blast Injury to the Lung." Technical Progress Report on DASA Contract DA-49-146-XZ372, The Technical Cooperation Programme (TTCP), Minutes of the Second Meeting, Subgroup N, Panel N-5, Nuclear Effects on Personnel, Appendix M, pp. 1-32, School of Aviation Medicine, Brooks Air Force Base, Texas, May 27-29, 1968. (Unclassified paper in a classified report)

35. Jones, R. K. "Recommendations for Treatment of Human Direct (Primary) Blast Injury." To appear in the Therapy Regimes Working Group Proceedings of the Third Meeting of Panel N-5, Subgroup $\mathrm{N}_{\text {, The }}$ Technical Cooperation Programme (TTCP), April 16-18, 1969, Ministry of Defence, Whitehall, London (in the press). 


\section{REFERENCES (Continued)}

36. Hooker, D. R. "Physiological Effects of Air Concussion." Amer. J. Physiol., 67: 219-274, 1924.

37. Tunbridge, R. E. and Wilson, J. V. "The Pathological and Clinical Findings in Blast Injury." Quart. J. Med., 12: 169-184, 1943.

38. Corey, E. L. "Medical Aspects of Blast." U.S. Nav. Med. Bull., 46: $623-652,1946$.

39. Desaga, H. "Blast Injuries." Chap. 14-D in German Aviation Medicine, World War II, Vol. 2, pp. 1274-1293, U.S. Government Printing Office, Washington, D.C., 1950.

40. Benzinger, Theodor. "Physiological Effects of Blast in Air and Water." Chap. 14-B in German Aviation Medicine, World War II, Vol. 2, pp. 12251259, U.S. Government Printing Office, Washington, D. C., 1950.

41. Rössle, R. "Pathology of Blast Effects." Chap. 14-C in German Aviation Medicine, World War $\Pi$, Vol. 2, pp. 1260-1273, U.S. Government Printing Office, Washington, D.C. , 1950.

42. Schardin, H. "The Physical Principles of the Effects of a Detonation." Chap. 14-A in German Aviation Medicine, World War II, Vol. 2, pp. 1207-1224, U.S. Government Printing Office, Washington, D. C., 1950.

43. Clemedson, C. J. and Hultman, H. "Air Embolism and the Cause of Death in Blast Injury." Milit. Surg., 114: 424-437, 1954.

44. Clemedson, C. J. "Blast Injury." Physiol. Rev., 36: 336-354, 1956.

45. Rusanov, S., Drugov, Yu, Benzenezhrykh, and Barysknikou, K. "Combined Combat Injuries." JPRS: 5048, Office of Technical Services, Department of Commerce, Washington, D. C., July 14, 1960.

46. Weyer, E. M. (Editor) "Prevention of and Protection Against Accidental Explosions of Munitions, Fuels and Other Hazardous Mixtures." Part II: Personnel Sensitivity (pp. 89-198), Ann. N. Y. Acad. Sci., 152: 1-913, 1968.

47. Roth, E. M. "Pressure." In Compendium of Human Responses to the Aerospace Environment, Vol. III, Sect. 12, pp. 12-1 to 12-53 ("Overpressure." Pp. 12-34 to 12-41), NASA CR-1205 (III), National Aeronautic and Space Administration, Washington, D. C., November 1968. 


\section{REFERENCES (Continued)}

48. Roth, E. M. and Terchner, U. G. "Acceleration." In Compendium of Human Responses to the Aerospace Environment, Vol. II, Sect. 7, pp. 7-1 to 7-288 ("Impact." Pp. 7-190 to 7-221), NASA CR-1205 (II), National Aeronautics and Space Administration, Washington, D.C., November 1968.

49. Bowen, I. G., Fletcher, E. R., Richmond, D. R., Hirsch, F. G., and White, C. S. "Biophysical Mechanisms and Scaling Procedures Applicable to Assessing Responses of the Thorax Energized by Air-Blast Overpressures or by Nonpenetrating Missiles." Technical Progress Report, DASA-1857, Defense Atomic Support Agency, Department of Defense, Washington, D.C. , November 1966. Subsequently published in Ann. N. Y. Acad. Sci. , 152: 122-146, 1968.

50. Hirsch, F. G. "Effects of Overpressure on the Ear--A Review." Technical Progress Report, DASA -1858, Defense Atomic Support Agency, Department of Defense, Washington, D.C., November 1966. Subsequently published in Ann. N. Y. Acad. Sci., 152: 147-162, 1968.

51. Hirsch, A. E. "The Tolerance of Man to Impact." Ann. N. Y. Acad. Sci., 152: 168-171, 1968.

52. Richmond, D. R., Damon, E. G., Fletcher, E. R., Bowen, I. G., and White, C. S. "The Relationship Between Selected Blast Wave Parameters and the Response of Mammals Exposed to Air Blast." Technical Progress Report, DASA-1860, Defense Atomic Support Agency, Department of Defense, Washington, D.C., November 1966. Subsequently published in Ann. N. Y. Acad. Sci., 152: 103-121, 1968.

53. Sperrazza, J. and Kokinakis, W. "Ballistic Limits of Tissue and Clothing." Ann. N. Y. Acad. Sci., 152: 172-186, 1968.

54. von Gierke, H. "Response of the Body to Mechanical Forces--An Overview." Ann. N. Y. Acad. Sci., 152: 172-186, 1968.

55. von Gierke, H. "Biodynamic Response of the Human Body." Appl. Mech. Rev., 17: 951-958, 1964.

56. Fisher, R. B., Krohn, P. L., and Zuckerman, S. "The Relationship Between Body Size and the Lethal Effects of Blast." Ministry of Home Security Report R. C. 284, Oxford University, Oxford, England, December 10, 1941. 
57. Fisher, R. B., Krohn, P. L., and Zuckerman, S. "The Relationship Between Body Size and the Lethal Effects of Blast." Ministry of Home Security Report B. P. C. 146/W. S. 11, Oxford University, Oxford, England, November 23, 1941.

58. Clemedson, C. J. "An Experimental Study on Air Blast Injuries." Acta Physiol. Scand., 18 (Suppl. 61): 1-200, 1949.

59. Fletcher, E. R. "A Model to Simulate Thoracic Responses to Air Blast and to Impact." To appear in the Proceedings of the Symposium on Biodynamic Models and Their Applications, October 26-28, 1970, Dayton, Ohio, National Academy of Sciences, Washington, D.C. (in the press).

60. Richmond, D. R., Clare, V. R., Goldizen, V. C., Pratt, D. E., Sanchez, R. T., and White, C. S. "Biological Effects of Overpressure. II. A Shock Tube Utilized to Produce Sharp-Rising Overpressures of 400 Milliseconds Duration and Its Employment in Biomedical Experiments." Technical Progress Report, DASA-1246, Defense Atomic Support Agency, Department of Defense, Washington, D.C., April 7, 1961. Subsequently published in Aerospace Med. , 32: 997-1008, 1961.

61. Richmond, D. R., Gaylord, C. S., Damon, E. G., and Taborelli, R. V. "DASA-AEC-Lovelace Foundation Blast-Simulation Facility." Technical Progress Report, DASA-1853, Defense Atomic Support Agency, Department of Defense, Washington, D.C., August 1966.

62. Richmond, D. R. "DASA-AEC-Lovelace Foundation Blast-Simulation Facility." Published in Blast and Shock Simulation Facilities in the United Kingdom, Canada and the United States, DASA Data Center Special Report 27, Santa Barbara, Calif., April 1965.

63. Crosfill, M. L. and Widdicombe, J. G. "Physical Characteristics of the Chest and Lungs and the Work of Breathing in Different Mammalian Species." J. Physiol., 158: 1-14, 1961.

64. Damon, E. G. "The Effects of Ambient Pressure on the Biological Response of Mice to Air Blast." A dissertation submitted in partial fulfillment of the requirements for the degree of Doctor of Philosophy in Biology, The University of New Mexico, Albuquerque, New Mexico, 1965.

65. Damon, E. G., Richmond, D. R., and White, C. S. "The Effects of Ambient Pressure on the Tolerance of Mice to Air Blast." Technical Progress Report, DASA-1483, Defense Atomic Support Agency, Department of Defense, Washington, D.C., March 1964. Subsequently published in Aerospace Med., 37: 341-347, 1966. 


\section{REFERENCES (Continued)}

66. Damon, E. G., Gaylord, C. S., Hicks, W., Yelverton, J. T., Richmond, D. R., and White, C. S. "The Effects of Ambient Pressure on Tolerance of Mammals to Air Blast." Technical Progress Report, DASA-1852, Defense Atomic Support Agency, Department of Defense, Washington, D. C. , August 1966.

67. Damon, E. G., Gaylord, C. S., Yelverton, J. T., Richmond, D. R., Bowen, I. G., Jones, R. K., and White, C. S. "Effects of Ambient Pressure on Tolerance of Mammals to Air Blast." Aerospace Med., 39: 1039-1047, 1968.

68. White, C. S. and Richmond, D. R. "Shock-Tube and Free-Field Scaling." In Minutes of the Fifth Meeting, Panel N-1 (Biomedical), Sub-Group N, Tripartite Technical Cooperation Programme (TTCP), U.S. Naval Radiological Defense Laboratory, San Francisco, Calif., and Lovelace Foundation, Albuquerque, N. Mex., May 10-14, 1965, pp. N-1 to N-36.

69. Richmond, D. R., Damon, E. G., Bowen, I. G., Fletcher, E. R., and White, C. S. "Air-Blast Studies with Eight Species of Mammals." Technical Progress Report, DASA-1854, Defense Atomic Support Agency, Department of Defense, Washington, D.C., August 1966.

70. Richmond, D. R., Clare, V. R., and White, C. S. "The Tolerance of Guinea Pigs to Air Blast When Mounted in Shallow, Deep, and Deep-withOffset Chambers on a Shock Tube." Technical Progress Report, DASA1334, Defense Atomic Support Agency, Department of Defense, Washington, D.C., October 27, 1962.

71. Clare, V. R., Richmond, D. R., Goldizen, V. C., Fischer, C. C., Pratt, D. R., Gaylord, C. S., and White, C. S. "The Effects of Shock Tube Generated, Step-Rising Overpressures on Guinea Pigs Located in Shallow Chambers Oriented Side-On and End-On to the Incident Shock." Technical Progress Report, DASA-1312, Defense Atomic Support Agency, Department of Defense, Washington, D.C., May 31, 1962.

72. Richmond, D. R., Taborelli, R. V., Sherping, F., Wetherbe, M. B., Sanchez, R. T., Goldizen, V. C., and White, C. S. "Shock Tube Studies of the Effects of Sharp-Rising, Long-Duration Overpressures on Biological Systems." USAEC Technical Report, TID-6056, Office of Technical Services, Department of Commerce, Washington, D. C., March 10, 1959.

73. Richmond, D. R., Wetherbe, M. B., Taborelli, R. V., Chiffelle, T. L., and White, C. S. "The Biologic Response to Overpressure. I. Effects on Dogs of Five- to Ten-Second Duration Overpressures Having Various Times of Pressure Rise." J. Aviat. Med. , 28: 447-460, 1957. 
74. Richmond, D. R., Pratt, D. E., and White, C. S. "Orbital 'Blowout' Fractures in Dogs Produced by Air Blast." Technical Progress Report, DASA-1316, Defense Atomic Support Agency, Department of Defense, Washington, D.C., April 10, 1962.

75. Wünsche, O. "Die biologische Wirkung hoher stossfreier Druckbelastung. I. Mitteilung." Bericht 2/64, Deutsche-Französisches Forschungsinstitut, Saint-Louis, March 5, 1964.

76. Clemedson, C. J. and Kolder, H. "Druckänderungen im Thorax während cines Luftstobes (Blast)." Pflugers Archiv., 268: 597-603, 1959.

77. Bowen, I. G., Holladay, A., Fletcher, E. R., Richmond, D. R., and White, C. S. "A Fluid-Mechanical Model of the Thoraco-Abdominal System with Applications to Blast Biology." Technical Progress Report, DASA-1675, Defense Atomic Support Agency, Department of Defense, Washington, D.C., June 14, 1965.

78. Zuckerman, S. "Experimental Study of Blast Injuries to the Lungs." Lancet, 2: 219-224, 1940.

79. Penny, W. G. and Beckley, W. G. Ministry of Home Security Report R. C. 376, 1943 (unpublished).

80. Penny, W. G. and Pike, H. H. M. "Shock Waves and the Propagation of Finite Pulses in Fluids." Rep. Progr. Phys. (London), 13: 46-82, 1950.

81. Clemedson, C. J., "Some Blast Studies with Application to Explosive Decompression." J. Interplanetary Soc., 17: 279-285, 1959-60.

82. Holladay, A. E. and Bowen, I. G. "A Mathematical Model of the Lung for Studies of Mechanical Stress." In Proceedings of the San Diego Symposium for Biomedical Engineering, April 21-23, 1963, pp. 39-50, 8484 La Jolla Shores Drive, La Jolla, Calif.

83. White, C. S., Richmond, D. R., Bowen, I. G., Chiffelle, T. L., and Taborelli, R. V. "The Biological Effects of Blast from Bombs--Summary for Period 1960-62." Progress Report on Contract DA-49-146-XZ-055 submitted to the Defense Atomic Support Agency, Department of Defense, Washington, D.C. (July 1962), Lovelace Foundation, Albuquerque, New Mexico, July 1, 1962.

84. Clemedson, C. J. and Jönsson, A. Personal Communication, April 1969 . 


\section{REFERENCES (Continued)}

85. Clemedson, C. J. and Pettersson, H. "Propagation of a High Explosive Air Shock Wave Through Different Parts of an Animal Body." Amer. J. Physiol. , 184: 119-126, 1956.

86. Clemedson, C. J. and Jönsson, A. "Transmission of Elastic Disturbances Caused by Air Shock Waves in a Living Body." J. Appl. Physiol., 16: $426-430,1961$.

87. Clemedson, C. J., Frankenberg, L., Jönsson, A., Pettersson, H., and Sundqvist, A. B. "Dynamic Response of Thorax and Abdomen of Rabbits in Partial and Whole-Body Blast Exposure." Amer. J. Physiol., 216: 615-620, 1969.

88. Richmond, D. R. and Colleagues. Unpublished Data, DASA Blast and Shock Biology Project, Lovelace Foundation for Medical Education and Research, Albuquerque, New Mexico, 1965-1971.

89. Clemedson, C. J. "Correlation Between Respiratory Phase and Extent of Lung Damage in Air Blast Injury." J. Appl. Physiol., 7: 38-42, 1954 .

90. Chiffelle, T. L. "Pathology of Direct Air-Blast Injury." Technical Progress Report, DASA-1778, Defense A tom ic Support Agency, Department of Defense, Washington, D.C., April 1966.

91. Nevison, T. O., Mason, W. V., and Dickinson, A. R. "Measurement of Blood Velocity and Detection of Emboli by an Ultrasonic Doppler Technique." In Proceedings of the 11th Annual Symposium on Experimental Mechanics, February 11-12, 1971, pp. 63-68, University of New Mexico Press, Albuquerque, New Mexico.

92. Mason, W. V., Damon, E. G., Dickinson, A. R., and Nevison, T. O. "Arterial Gas Emboli After Blast Injury." Proc. Soc. Exp. Biol. Med., 136: 1253-1255, 1971 .

93. Jones, R. K. and Richmond, D. R. Unpublished Data, DASA Blast and Shock Biology Project, Lovelace Foundation for Medical Education and Research, Albuquerque, New Mexico, 1971.

94. Bowen, I. G., Fletcher, E. R., and Richmond, D. R. "Estimate of Man's Tolerance to the Direct Effects of Air Blast." Technical Progress Report, DASA-2113, Defense Atomic Support Agency, Department of Defense, Washington, D.C., October 1968. 


\section{REFERENCES (Continued)}

95. Richmond, D. R. and White, C. S. "A Tentative Estimation of Man's Tolerance to Overpressures from Air Blast." In Proceedings of the Symposium on Effectiveness Analysis Techniques for Non-Nuclear WarHeads Against Surface Targets, October 30-31, 1962, Vol. 1, pp. L to L-34, U.S. Naval Weapons Laboratory, Dahlgren, Virginia. Subsequently published as Technical Progress Report, DASA-1335, Defense Atomic Support Agency, Department of Defense, Washington, D.C., November 7, 1962.

96. Richmond, D. R., Fletcher, E. R., and Jones, R. K. "Blast Protection Afforded by Foxholes and Bunkers." Progress Report on DASA Contract No. DA-49-146-XZ-372, submitted March 15, 1971, Lovelace Foundation for Medical Education and Research, Albuquerque, New Mexico, March 1971. (To be presented at the Event Dial Pack Symposium, Ottawa, Canada, March 30-April 1, 1971.)

97. Jones, R. K., Richmond, D. R., and Fletcher, E. R. "A Reappraisal of Man's Tolerance to Indirect (Tertiary) Blast Injury." In the Minutes of the Eleventh Meeting of Panel N-2 (Blast, Shock and Thermal), Subgroup $\mathrm{N}$, The Technical Cooperation Programme (TTCP), April 21-24, 1969, Part II: Technical Papers and Discussions, pp. 41-56, Atomic Weapons Research Establishment (AWRE), Foulness, England, Ministry of Defense, London, S.W.l, October 1969.

98. Lewis, W. S., Lee, A. B., Jr., and Grantham, S. A. 'Jumpers' Syndrome--The Trauma of High, Free-Fall as Seen at Harlem Hospital." J. Trauma, 5: 812-818, 1965.

99. Richmond, D. R., Goldizen, V. C., Clare, V. R., Pratt, D. R., Sherping, F., Sanchez, R. T., Fischer, C. C., and White, C. S. "Biologic Response to Overpressure. III. Mortality in Small Animals Exposed in a Shock Tube to Sharp-Rising Overpressures of 3- to 4-Msec. Duration." Technical Progress Report No. DASA-1242, Defense Atomic Support Agency, Department of Defense, Washington, D. C., June 15, 1961. Also in Aerospace Med., 33: 1-27, 1962.

100. Brown, F. W., III and Lee, R. H. "Injury from the Decompression Component of an Air-Blast Wave," (Letter to the Editors) Nature, 178: $490,1956$.

101. Levy, W. J. and Richmond, D. R. "Air Blast Effects on the Eye." resume of exhibit displayed at the American Academy of Ophthalmology and Otolaryngology, Chicago, Ill., October 1967. 


\section{REFERENCES (Continued)}

102. Campbell, D. R. "Ophthalmic Casualties Resulting from Air Raids." Brit. Med. J., 1: 966, 1941.

103. Blocker, T. G., Jr., Blocker, V., Graham, J. E., and Jacobson, H. "Follow-Up Medical Survey of the Texas City Disaster." Amer. J. Surg., 97: 604-623, 1969.

104. Ruskin, A., Beard, O. W., and Schaeffer, R. L. "Blast Hypertension-Elevated Arterial Pressures in the Texas City Disaster." Amer. J. Med. , 4.: 228-236, 1948 .

105. Hirsch, F. G. Unpublished Data, DASA Blast and Shock Biology Project, Lovelace Foundation for Medical Education and Research, Albuquerque, New Mexico, June 1971.

106. White, C. S., Richmond, D. R., and Bowen, I. G. "Biological Effects of Blast from Bombs--Semiannual Progress Report, January 1-June 30, 1963." Progress Report on Contract No. DA-49-146-XZ-055, Lovelace Foundation for Medical Education and Research, Albuquerque, New Mexico, August 30, 1963. 


\section{DISTRIBUTION}

\section{DEPARTMENT OF DEFENSE}

Director, Armed Forces Institute of Pathology, Walter Reed Army Medical Center, 14th Street and Alaska Avenue, Washington, D.C. 20012 (1 copy)

Director, Armed Forces Radiobiology Research Institute, Defense Nuclear Agency, National Naval Medical Center, Bethesda, Maryland 20014 (1 copy)

Assistant to the Secretary of Defense (Atomic Energy), Washington, D. C. 20301, ATTN: Document Control (1 copy)

Defense Documentation Center, Cameron Station, Alexandria, Virginia 22314, ATTN: TC (12 copies)

Director, Defense Nuclear Agency, Washington, D.C. 20305

ATTN: DDST (1 copy)

ATTN: APSI (Archives) (1 copy)

ATTN: APIL (Technical Library) (2 copies)

ATTN: STMD (10 copies)

Commander, Field Command, Defense Nuclear Agency, Kirtland AFB, New Mexico 87115, ATTN: Technical Library FCWS-SC (1 copy)

Commander, Test Command, Defense Nuclear Agency, Kirtland AFB, New Mexico 87115, ATTN: Document Control (1 copy)

Director, Weapons Systems Evaluation Group, ODDR\&E Office, Secretary of Defense, 400 Army-Navy Drive, Washington, D.C. 20305, ATTN: CAPT Donald E. McCoy, USN (1 copy)

\section{DEPARTMENT OF THE ARMY}

Commandant, Army Medical Field Service School, Brooke Army Medical Center, Fort Sam Houston, Texas 78234 (1 copy)

Chief, Army Nuclear Effects Laboratory, Edgewood Arsenal, Maryland 21010, ATTN: AMXRD-BNL, Technical Library (1 copy)

Chief, Army Research Office, Life Sciences Division, 3045 Columbia Pike, Arlington, Virginia 22210 (1 copy)

Director, Ballistic Research Laboratories, Aberdeen Proving Ground, Maryland 21005, ATTN: AMXBR-TB, Mr. Julius J. Meszaros (1 copy)

Chief of Research and Development, Department of the Army, Washington, D.C. 20310, ATTN: NCB Division, LTC C. R. Sykes (1 copy) 
Director of Civil Defense, Department of the Army, Washington, D.C. 20310, ATTN: RE, Asst. Dir. Research, Mr. Walmer E. Strope (1 copy)

Department of the Army, Harry Diamond Laboratories, Washington, D. C. 20438, ATTN: AMXDO-NP (1 copy)

Commanding General, Medical Research and Development Command, Washington, D.C. 20314, ATTN: NBC Sciences Division (1 copy)

Safeguard System Manager, Safeguard System Office, 1320 Wilson Blvd., Arlington, Virginia 22209, ATTN: Plans Division (1 copy)

The Surgeon General, Department of the Army, Washington, D. C. 20360 (1 copy)

Chief, U.S. Army Combat Developments Command, Medical Service Agency, Fort Sam Houston, Texas 78234 (1 copy)

Commanding Officer, U.S. Army Combat Developments Command, Nuclear Agency, Fort Bliss, Texas 79916, ATTN: CDINS-E (1 copy)

Chief, U.S. Army Combat Developments Command, Chemical-BiologicalRadiological Agency, Fort McClellan, Alabama 36205, ATTN: CBR (1 copy)

Director, Walter Reed Army Institute of Research, Walter Reed Army Medical Center, Washington, D.C. 20012, ATTN: Documents Library (1 copy)

\section{DEPARTMENT OF THE NAVY}

Chief, Bureau of Medicine and Surgery, Navy Department, Washington, D.C. 20390 (1 copy)

Chief of Naval Material, Navy Department, Washington, D.C. 20360, ATTN: Mat 0323, Mr. Irving Jaffe (1 copy)

Chief of Naval Operations, Navy Department, Washington, D.C. 20350, ATTN: OP-752D (1 copy)

Chief of Naval Research, Department of the Navy, Arlington, Virginia 22217 ATTN: Code 402, Mr. Aubrey W. Pryce, Dep. Dir. Research (1 copy) ATTN: Code 418, Dr. Thomas P. Quinn, Dir. Field Proj. Pro (1 copy)

Commanding Officer, Naval Aerospace Medical Institute, Naval Aerospace Medical Center, Pensacola, Florida 32512 (1 copy)

Commander, Naval Air Development Center, Johnsville, Warminster, Pennsylvania 18974, ATTN: Code MRPV, Dr. Gloria T. Chisum (1 copy) 
Commander, Naval Air Systems Command, Headquarters, Washington, D. C. 20360

ATTN: AIR 5381, Satellite Comm/Astro-Defense Branch (1 copy)

ATTN: AIR 350, Ordnance Administrator (1 copy)

Commanding Officer, Naval Medical Research Institute, National Naval Medical Center, Bethesda, Maryland 20014 (1 copy)

Commander, Naval Ordnance Laboratory, Silver Spring, Maryland 20910

ATTN: Code 210, Dr. Wayne W. Scanlon (1 copy)

ATTN: Code 213, Mr. William L. Derksen (1 copy)

ATTN: Code 121, Navy Nuclear Programs Office (1 copy)

ATTN: Code 121, Dr. O. M. Meredith (1 copy)

Director, Naval Research Laboratory, Washington, D.C. 20390, ATTN: Code 2027, Technical Library (1 copy)

Commander, Naval Ship Research and Development Center, Washington, D. C. 20034, ATTN: Code L42.3, Library (1 copy)

Commanding Officer, Naval Submarine Medical Center, Naval Submarine Base-New London Groton, Connecticut 06340 (1 copy)

Commanding Officer, Naval Weapons Evaluation Facility, Kirtland Air Force Base, Albuquerque, New Mexico 87117, ATTN: Document Control (1 copy)

Commander, Naval Weapons Laboratory, Dahlgren, Virginia 22448, ATTN:

Code TIEC (1 copy)

DEPARTMENT OF THE AIR FORCE

Commander, Aerospace Medical Division, AFSC, Brooks AFB, Texas 78235, ATTN: AMRB, LTC. William R. Godden, Chief, Radiobiol. Div. (1 copy)

AF Director of Nuclear Safety, Kirtland AFB, New Mexico 87117 (1 copy)

Commander, AF Special Weapons Center, AFSC, Kirtland AFB, New Mexico 87117, ATTN: SWTSX, Survivability/Vulnerability Branch (1 copy)

AF Weapons Laboratory, AFSC, Kirtland AFB, New Mexico 87117

ATTN: DOGL, Technical Library (1 copy)

ATTN: CPT J. E. Dieckhoner (1 copy)

Director, Air Force Office of Scientific Research, Office of Aerospace Research, 1400 Wilson Blvd., Arlington, Virginia 22209, ATTN: SRGC, MAJ Thomas P. Baker, .Jr. (1 copy) 
Headquarters, Air Force Systems Command, Andrews AFB, Washington, D.C. 20331, ATTN: SGI (1 copy)

Chief of Staff, U.S. Air Force, Washington, D.C. 20330

ATTN: PDPS (Sci. \& Tech. Div., Dir. of Dev. \& Acq.) (1 copy)

ATTN: RDQPN (S/V \& Nuclear Programs Division) (1 copy)

The Surgeon General, Department of the Air Force, James Forrestal Building, Washington, D.C. 20314 (1 copy)

USAF Medical Service School, Sheppard AFB, Texas 76311 ( 1 copy)

USAF Radiological Health Laboratory, AFLC, Wright-Patterson AFB, Ohio 45433 (1 copy)

USAF School of Aerospace Medicine, AFSC, Brooks AFB, Texas 78235

ATTN: RA, COL John E. Pickering, Chief, Radiobiol. Div. (1 copy)

ATTN: RAT (1 copy)

ATTN: RAW, Dr. Donald R. Anderson, Radiobiol Div. (1 copy)

ATTN: RAW, Mr. Donald J. Barnes (1 copy)

ATTN: EDAD (1 copy)

6570th Aerospace Medical Research Labs., AFSC Wright-Patterson AFB, Ohio 45433 ( 1 copy)

\section{ATOMIC ENERGY COMMISSION}

Assistant General Manager for Military Application, U.S. Atomic Energy Commission, Washington, D.C. 20545, ATTN: Document Control for R\&D Branch (1 copy)

Battelle Memorial Institute, Pacific Northwest Laboratory, Post Office Box 999, Richland, Washington 99352, ATTN: Dr. K. H. Larson (1 copy)

Brookhaven National Laboratory, Post Office Box 150, Upton, Long Island, New York 11973, ATTN: Research Library (1 copy)

Los Alamos Scientific Laboratory, Post Office Box 1663, Los Alamos, New Mexico 87544 (1 copy)

U.S. Atomic Energy Commission, Division of Tech. Info. Ext., Post Office Box 62, Oak Ridge, Tennessee 37830, ATTN: Document Control (250 copies)

U.S: Atomic Energy Commission, Washington, D.C. 20545

ATTN: Doc. Control (Bio. \& Med. Div.), H. D. Bruner (1 copy)

ATTN: Document Control for Bio. \& Med. Div. -L. J. Deal (25 copies)

ATTN: Document Control for Reports Section (1 copy) 


\section{ATOMIC ENERGY COMMISSION (Continued)}

U.S. Atomic Energy Commission, New York Operations Office, 376 Hudson Street, New York, New York 10014, ATTN: Document Control for Dr. J. H. Harley, Dir. HASL (1 copy)

Union Carbide Corporation, Oak Ridge National Laboratory, Post Office Box X, Oak Ridge, Tennessee 37830, ATTN: Document Control for J. Auxier. Health Phy. Dept (1 copy)

Union Carbide Corporation, Nuclear Division, Post Office Box Y, Oak Ridge, Tennessee 37830, ATTN: Doc Cont-Atomic/Mol. Proc. Info. Ctr-C. F. Barnett (1 copy)

University of California, Lawrence Livermore Laboratory, Technical Information Division, Post Office Box 808, Livermore, California 94550, ATTN:

Technical Library (1 copy)

\section{OTHER GOVERNMENT}

NASA Scientific and Technical Information Facility, Post Office Box 33, College Park, Maryland 20740, ATTN: Acquisitions and Input Branch (1 copy)

National Library of Medicine, Accessions Branch, 8600 Wisconsin Avenue, Bethesda, Maryland 20014 (1 copy)

\section{DEPARTMENT OF DEFENSE CONTRACTORS}

Cincinnati General Hospital, Radioisotope Laboratory, Cincinnati, Ohio 45229, ATTN: Dr. Eugene L. Saenger, Dir., Radioisotope Lab. (1 copy)

General Electric Company, Tempo-Center for Advanced Studies, 816 State Street, (P.O. Drawer QQ), Santa Barbara, California 93102, ATTN: DASA Information and Analysis Center (1 copy)

Lovelace Foundation for Medical Education and Research, 5200 Gibson Blvd., S. E., Albuquerque, New Mexico 87108

ATTN: Asst. Dir. of Research, Dr. Robert K. Jones (200 copies)

ATTN: President-Director, Dr. Clayton S. White (100 copies)

ATTN: Head Dept. Comp. Envir. Biol., Dr. Donald Richmond (1 copy)

ATTN: Associate Scientist, Dr. Edward G. Damon (1 copy)

ATTN: Associate Scientist, Dr. E. Royce Fletcher (1 copy)

South Carolina, Medical College of, Department of Surgery, 55 Doughty Street, Charleston, South Carolina 29403, ATTN: Dr. Max S. Rittenbury, Assoc. Prof. of Surgery ( 1 copy) 
Technology, Inc., Life Sciences Division, 8531 N. New Braunfels Avenue, San Antonio, Texas 78217 (1 copy)

Virginia Commonwealth University, Medical College of Virginia, Health Science Division, 1200 East Broad Street, Richmond, Virginia 23219, ATTN: Dept of Biophysics (1 copy)

New York State Veterinary College, Cornell University, Ithaca, New York 14850, ATTN: Dr. C. L. Comar, Prof/Head, Dept. of Physical Biology (1 copy) 
(Security classification of itle, body of abstract and indexing annotation must be entered when the overall report is classilled) 1. ORIGINATING ACTIVITY (COPPORAto author) 2A. REPORT SECURITY CLASSIFICATION

Lovelace Foundation for Medical Education and Research, Albuquerque, New Mexico

3. REPORT TITLE

The Biodynamics of Air Blast

4. DESCRIPTIVE NOTES (TYPO of roport and Incluaivo dates)

\section{B. AUTHOR(S) (First namo, middlo initial, last namo)}

Clayton S. White, Robert K. Jones, Edward G. Damon, E. Royce Fletcher, and Donald R. Richmond

\begin{tabular}{|c|c|c|}
\hline $\begin{array}{r}\text { 6. REPORT DATE } \\
\text { July } 1971\end{array}$ & $\begin{array}{l}\text { 7A. TOTAL NO. OF PAGES } \\
139\end{array}$ & $\begin{array}{r}\text { 7b. NO. OF REFS } \\
106\end{array}$ \\
\hline $\begin{array}{l}\text { 8a. CONTRACT OR GRANT NO. } \\
\text { DASA OI-70-C-0075 } \\
\text { b. PROJECT NO. NWER XAXM }\end{array}$ & 9a. ORIGINATOR'S REPORT & ER(S) \\
\hline $\begin{array}{l}\text { c. Task and Subtask } \mathrm{AO} 22 \\
\text { d. Work Unit } 02\end{array}$ & $\begin{array}{l}\text { 9b. OTHER REPORT NO(S) } \\
\text { (his roport) } \\
\text { DNA 27. }\end{array}$ & her numbers that may bo acolened \\
\hline
\end{tabular}

Approved for public release; distribution unlimited.

\begin{tabular}{|l|l}
\hline 1 . SUPPLEMEN TARY NOTES & 12. SPONSORING MILITARY ACTIVITY \\
& Director \\
& Defense Nuclear Agency \\
& Washington, D.C. 20305
\end{tabular}

\section{ABSTRACT}

After pointing out that accelerative and decelerative events are associated with the direct (pressure) and indirect (translational events including penetrating and nonpenetrating debris and whole-body impact) effects of exposure to blast-induced winds and pressure variations, some of the relevant biophysical parameters were selectively noted and discussed. These included the pressure-time relationship; species differences; ambient pressure effects; the significance of positional (orientational) and geometric (situational) factors as they influence the wave form, the pressure "dose" and the biologic response; and data bearing upon the etiology of blast injury. The consequences of pressure-induced violent implosion of the body wall and the significance of the associated variations in the internal gas and fluid pressures were described and emphasized as were alternating phases of "forced" hemorrhage and arterial air embolization, fibrin thrombi, coagulation anomalies and renal, cardiac, and pulmonary sequelae. Tentative biomedical criteria consistent with recent interspecies scaling and modeling studies for assessing primary blast hazards were presented. 


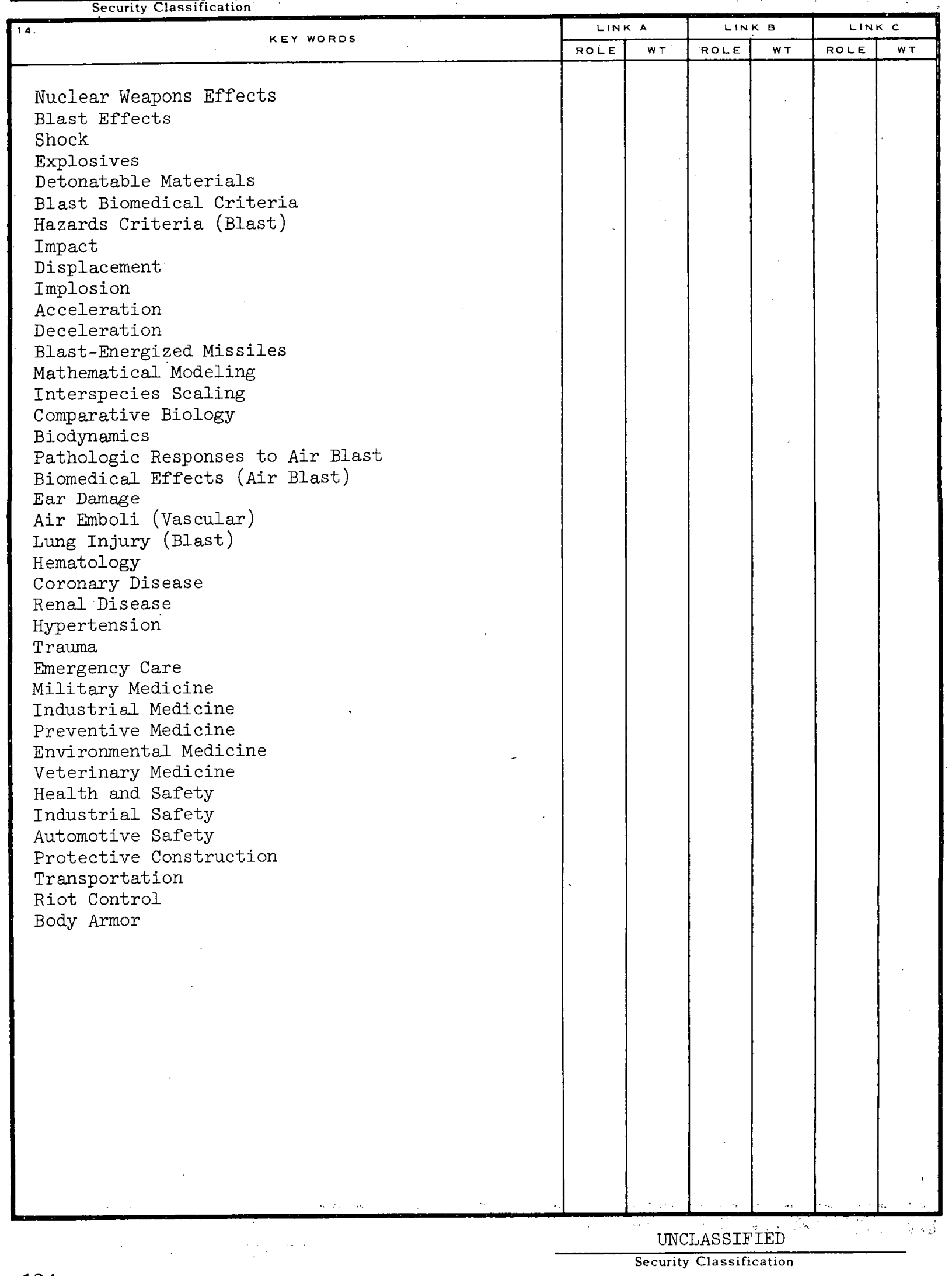

